Florida International University

FIU Digital Commons

$11-14-2019$

\title{
Student Affairs Professionals in Higher Education Institutions who Participate in Study Tours: A Qualitative Study
}

Michelle M. Castro

mimcast@fiu.edu

Follow this and additional works at: https://digitalcommons.fiu.edu/etd

Part of the Higher Education Commons

\section{Recommended Citation}

Castro, Michelle M., "Student Affairs Professionals in Higher Education Institutions who Participate in Study Tours: A Qualitative Study" (2019). FIU Electronic Theses and Dissertations. 4292.

https://digitalcommons.fiu.edu/etd/4292

This work is brought to you for free and open access by the University Graduate School at FIU Digital Commons. It has been accepted for inclusion in FIU Electronic Theses and Dissertations by an authorized administrator of FIU Digital Commons. For more information, please contact dcc@fiu.edu. 


\title{
FLORIDA INTERNATIONAL UNIVERSITY
}

\author{
Miami, Florida
}

STUDENT AFFAIRS PROFESSIONALS IN HIGHER EDUCATION

INSTITUTIONS WHO PARTICIPATE IN STUDY TOURS: A QUALITATIVE

$$
\text { STUDY }
$$

A dissertation submitted in partial fulfillment of

the requirements for the degree of

DOCTOR OF PHILOSOPHY

in

HIGHER EDUCATION

by

Michelle M. Castro 
To: Dean Michael R. Heithaus

College of Arts, Sciences, and Education

This dissertation, written by Michelle M. Castro, and entitled Student Affairs Professionals in Higher Education Institutions Who Participate in Study Tours: A Qualitative Study, having been approved in respect to style and intellectual content, is referred to you for judgment.

We have read this dissertation and recommend that it be approved.

Norma Goonen

$\begin{array}{r}\hline \text { Rebekah Schulze } \\ \hline \text { Hilary Landorf } \\ \hline \text { Benjamin Baez, Major Professor }\end{array}$

Date of Defense: November 14, 2019

The dissertation of Michelle M. Castro is approved.

Dean Michael R. Heithaus
College of Arts, Science and Education

Florida International University, 2019 
(C) Copyright 2019 by Michelle M. Castro

All rights reserved. 


\section{DEDICATION}

Nevertheless, she persisted

Thank you to all of those who believed in me when I did not believe in myself. 


\section{ACKNOWLEDGMENTS}

Thank you to my committee who helped me make this dissertation happen and believed I could do it. My many thanks to you all: Dr. Benjamin Baez, Dr. Norma Goonen, Dr. Hilary Landorf, and Dr. Rebekah Schulze. Thank you for asking the tough questions during my proposal defense and making me think critically. Thank you Dr. Benjamin Baez for meeting with me and giving me the extra encouragement to get it done. Thank you Dr. Hilary Landorf for taking the time to work with me on edits, and ensuring that this dissertation was what it needed to be!

To my mini cohort members Sabrena O'Keefe, Nashira Williams, and Bronwen Bares-Pelaz for sharing their knowledge and being supportive every step of the way through course work and through writing this dissertation. Truly grateful to have this mini cohort! All these women were my reason to finish, because we were on this wild ride with course work together. Thank you for letting me stop and ask you questions and always sharing helpful information!

To my Campus Life Colleagues and many Student Affairs Colleagues, thank you for your support and listening to me discuss the process or the topic I was working on. I am grateful for our many projects and other programs that kept me sane during the process, meaning I was not thinking about writing but knew I should be writing. Thank you Matilde Gramling for listening to me and letting me process my feelings about the process and giving me encouragement, and guess what you are next. Sofia Trelles, Damaris Valdes and Bridgette Cram to being my cheerleaders at the end! 
To my constant cheerleaders Jose Toscano and John Parmenter, thank you for reminding me to take a step back and breath and reminding me to get back to work. The endless pep talks worked. Also, for putting things into perspective and that I can get this paper written. Also, Jose Toscano thank for allowing me to take my trips which ended up being the reason I did this study. And now that I am done. I am planning my next adventure.

To Christina (Wicki) Witowicki, this journey would not have been the same without you. You were my constant cheerleader and your support was invaluable. We moved at different paces but you were always there via text when I needed you. I am grateful for our many years of friendship and I can't wait to be able to hang out with you again and hopefully we plan a grand adventure together again!

To the Wolf Pack who supported me even when we were not talking about the dissertation process. Having you all be my social outlet was what I needed during the moments of, I don't think I can write any more. Thank you to Bobby Borgmann, Claudia Gonzalez, Valeria Espina, Bill Buchanan, and Phillip Lloyd Hamilton for being my support system through it all. Thank you to Dania Pearson-Adams, Maegan Azpiazu and Breny Garcia for believing in me even when I did not! and always being just a text, phone call, or an office visit away. Thanks for letting me cry on your shoulders and reminding me that you care about me.

Thank you to all those who have earned a doctoral degree, especially all the women who have come before me. All these women are a source of inspiration, desire to get this degree, and just amazing folks I admire. 
To my parents, who are my rock! Thank you for being there and believing in me. I appreciate their understanding of my crazy schedule and my moments of despair were just my moments of frustration and fear that I would not be able to get it all done. Thank you for instilling my love of travel and learning and encouraging me to be the person I am. 


\title{
ABSTRACT OF THE DISSERTATION
}

\section{STUDENT AFFAIRS PROFESSIONALS IN HIGHER EDUCATION INSITUTIONS WHO PARTICIPATE IN STUDY TOURS: A QUALITATIVE STUDY}

\author{
by \\ Michelle M. Castro \\ Florida International University, 2019 \\ Miami, Florida

\section{Professor Benjamin Baez, Major Professor}

As colleges and universities are internationalizing their curriculum, there is a growing need for student affairs professionals to also become aware of and be familiar with internationalization and to become players in the global society. The present study focused on 12 participants who are currently student affairs professionals. The research focused on gaining an understanding and awareness of the role that international study tour experiences have on the professional and personal development of student affairs professionals.

A qualitative research design was used for the study. Kolb's Experiential Learning theory was used as the conceptual framework to explain the participants' experiences during their international study tour. Four different four-year public institutions served as the international study tour host institutions of the participants for this study - Bowling Green State University, Central Michigan University, Florida State University, and Miami University. For this study 12 participants were interviewed via 
semi-structured interviews using online technology of gotomeeting.com. All interviews were transcribed and analyzed.

Findings indicated that the international study tour experiences are supported by Kolb's Experiential Learning theory as participants in the study expressed that the entire experience of a tour is active learning. The study supports existing literature that international study tours further the personal and professional development of those student affairs professionals who participate. The following themes emerged from this study: transformational experiences; global awareness; intercultural communication; career paths; and, self-growth. Another research finding is that student affairs professionals who participant in a study tour express an expanded self-confidence that helps them to articulate what they learned and experienced. Several participants expressed that, as a result of their study tour experience, they had a sense of personal growth in various aspects of their lives. Recommendations include increasing the number of student affairs professionals attending international study tours, encouraging student affairs professionals to share the information learned from their visits, and exhorting participants to implement programs and ideas they gathered from their tours. 


\section{TABLE OF CONTENTS}

CHAPTER

$\underline{\text { PAGE }}$

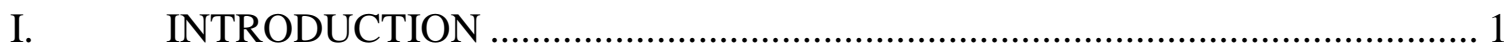

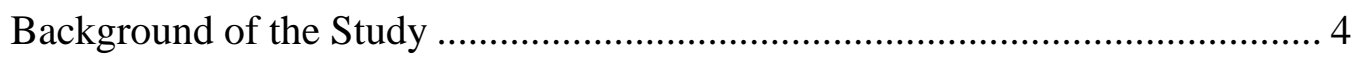

Statement of the Problem................................................................................ 5

Purpose Statement....................................................................................... 6

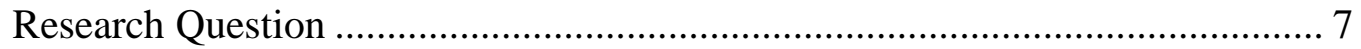

Definitions of Key Terms ......................................................................... 7

Kolb's Experiential Learning Theory ………………………………………...... 9

Summary of the Dissertation Chapters ........................................................... 10

II. LITERATURE REVIEW ……………………................................ 12

Review of the Literature .............................................................................. 12

Types of Participants in Study Abroad Programs.............................................. 16

Short-Term Study Abroad Programs .............................................................. 23

Outcomes of Study Tour Experiences ............................................................... 28

Kolb's Experiential Learning Theory ……………………................................ 37

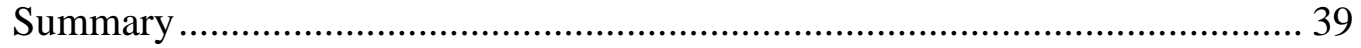

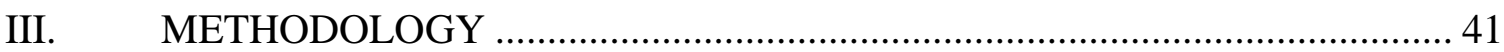

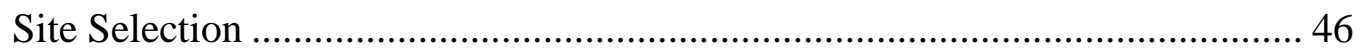

Study Participants ...................................................................................... 48

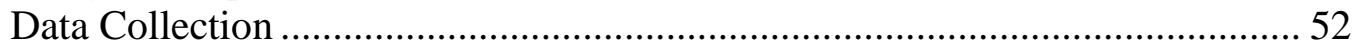

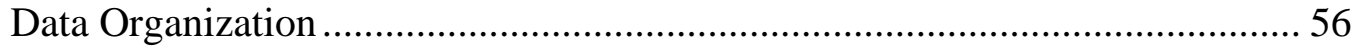

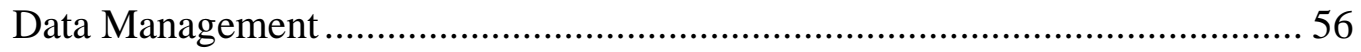

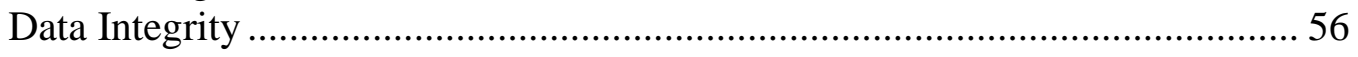

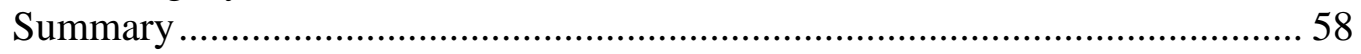

IV. PARTICIPANTS AND THEMATIC ANALYSIS …………………….........59

The International Study Tour Sites ............................................................... 59

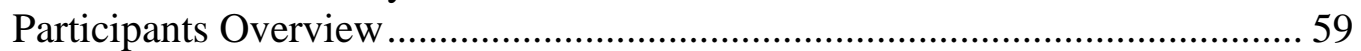

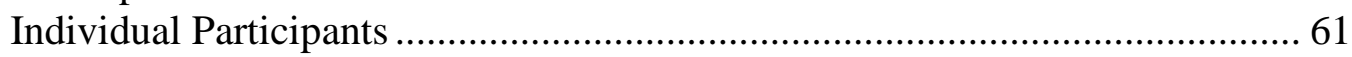

Why Did They Attend? ............................................................................... 114

What is Professional Development for Participants? ..................................... 117

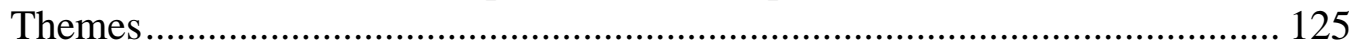

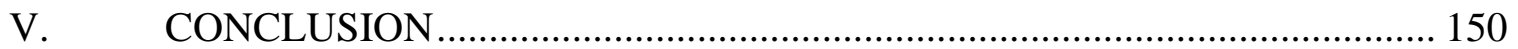

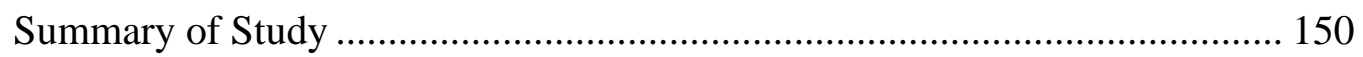

Review of the Study ................................................................................. 150

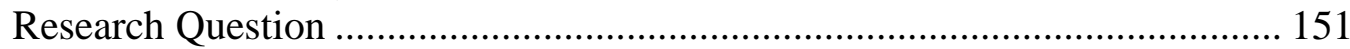

Revisiting Experiential Learning Theory ..................................................... 152

Perceptions of International Study Tours ...................................................... 156

Furthering Professional and Personal Development......................................... 157 


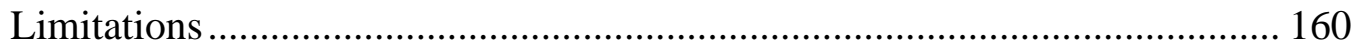

Recommendations for Future Research ..................................................... 163

Implications for Student Affairs Administrators .......................................... 167

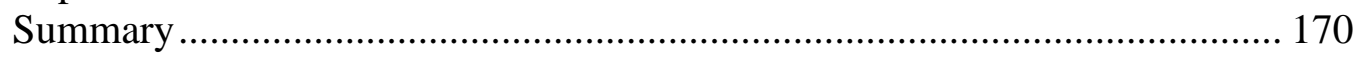

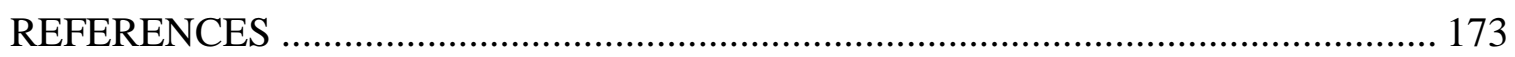

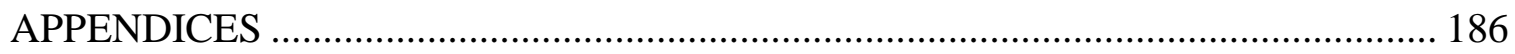

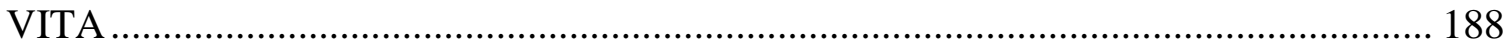




\section{CHAPTER I}

\section{INTRODUCTION}

As colleges and universities are internationalizing their curriculum, there is a growing need for student affairs professionals to become aware of and familiar with internationalization and to become players in the global society. The academic sector of higher education is moving towards the internationalization of the curriculum, yet the divisions of student affairs have been slower to react.

Student affairs professionals serve as mentors and are in a position to encourage students that they work with to see the world with a global perspective, yet student affairs professionals lack international experience themselves. As a means of achieving the internationalization of student affairs, short term international study tours as part of the study abroad programs are becoming increasingly important. Participation in a short-term international study tour presents an opportunity for student affairs professionals to experience the world of higher education and student affairs in a different way and through different lenses.

From the beginning of the $21^{\text {st }}$ century, there has been a push and a significant trend to internationalize higher education and in turn to internationalize the role and programs of Student Affairs. There have been several governmental initiatives to have more students from the United States study abroad. Stroud (2010) focuses on the importance of study abroad as referred to in the Simon Act, passed in 2009 as the Senator Paul Simon Study Abroad Foundation Act. The purpose of the legislation was to encourage the diversification of study abroad participants. This legislation showed the growing awareness of members of Congress and the Federal Government of the need for 
more U.S. students to experience the world. There were several governmental reports as well as educational reports promoting the internationalization of higher education with the use of study abroad measures (American Council on Education, 2017; NAFSA, “Senator Paul Simon Study Abroad Act," 2011; Commission on the Abraham Lincoln Study Abroad Fellowship, 2005). There is limited research on student experiences of short-term study abroad; however, there is a growing trend in the number of students participating in short-term programs.

The world and universities are becoming globalized and internationally aware and curricula need to adapt to a changing world politics. It is particularly important that university professionals, and student affairs professionals and administrators seek to understand the process and of internationalization on their college campus. Student affairs professionals are part of this internationalized world because of the work they do with students and other university colleagues, and it is becoming increasingly essential that they convey these changes and adaptations to their students. Internationalization is "the intentional process of integrating an international, intercultural or global dimension into the purpose, functions and delivery of post-secondary education” (Knight, 2003). Undergraduate students are being exposed to world views and graduate students in higher education programs are encouraged to explore the world, expanding their education experiences by attending study tours, (Rogers, Cawthon, \& O'Connell, 2016) enhancing their course work with international understanding components, and attending conferences. At the same time there is a need to expand professional development opportunities for student affairs professionals, encouraging them to be part of this internationalization process of integrating an international perspective into the curriculum 
and student experiences being developed on their college campus, particularly within their own departments in student affairs. Dalton (1999) states "there is much to learn from student affairs activities in colleges and universities in other countries" (p. 9). It is encouraging that in many cases the faculty and staff (Lindquist \& Bischof, 2006;

Sandgren, Ellig, Howde, Krejci, \& Rice, 1999) also become the students and they, as well as the students with them, may well develop and learn in the areas highlighted by the studies, including global awareness, intercultural communication, and expanded career paths, to name three of the possibilities.

The internationalization of student affairs has had student affairs professionals “engaged in international travel and involvement for many years but most often in individual and informal context" (Dalton \& Sullivan, 2008, p. 7). These professionals have interacted with international students but the collaborative opportunities with other international universities have been limited and, as described by Dalton and Sullivan, "international involvements were on the periphery of the profession and outside the mainstream of professional activities and responsibilities" (p. 7). Yet "international travel and exchange is an area in which student affairs professionals lag behind their academic colleagues" (p.11).

There is limited research pertaining to student affairs personnel who attend study tours or study abroad as professionals. Much of the focus of the research on study tours and study abroad has been on undergraduate students (Norris \& Gillespie, 2008;

Stebleton, Soria, \& Cherney, 2013; Younes \& Asay, 2003). What is recognized as the functional area and academic field of Study Abroad has been examined and investigated from the perspective only of the students who have had the opportunity to travel and 
participate in either full-term or short-term study abroad programs. Several research studies have focused on the development, growth, and progress of student participants with respect to career aspirations, professional development, and long-term benefits (Toncar, Reid, \& Anderson, 2006; Carlson, Burn, Useem \& Yachimowicz, 1990; Young, 2010; Orndorff, 1998).

\section{Background of the Study}

In many respects, internationalization is higher education's response to the ongoing process of globalization (Hill, 2016). Internationalization involves all aspects of a college/university campus which contribute to fulfill the mission and direction chosen by the institution. All members of the university community are part of the process to meet the institutions missions. Accordingly Student Affairs administrators must also be included and become active members in the greater university structure to advocate and develop an understanding of the internationalization efforts of the university.

Student Affairs is a division of a university or college made up of student affairs administrators who help to provide services, programs, and assist students to learn and grow outside of a formal classroom setting. Student affairs administrators are trained in student development theory and help to enrich the lives of students with whomthey interact. Another role of Student Affairs is to "prepare students for active participation in society" (Ciobanu, 2013, p.171). It is important to note that the role of student affairs is influenced by "the knowledge and beliefs of academic staff and administrative staff influence the manner and responsibility in which the student programs and services are delivered" (Ciobanu, 2013, p. 172). 
Student Affairs as a division has been evolving because of the ever-changing landscape of higher education but historically it has always had significant influence on students. "There are campus units whose historical role has included attempting to influence the social climate and students' interaction experience. These units are collectively termed 'student affairs"' (Franklin-Craft, 2010, p. 2). At some universities Student Affairs may be the largest division.

As a student affairs administrator and participant in international study tours, the researcher has been concerned by the general lack of discussion and direct advocacy towards the interantionaliztion of Student Affairs. Several of the researcher's colleagues serve as mentors, encouraging students to see the world and obtain a global perspective, yet as student affairs professionals, it appears that they lack international experiences themselves. In order for students develop the competencies to succeed in an increasingly

globalized world student affairs administrators must be part of the conversation regarding the process of internationalization of their university, develop an understanding of where student affairs fits into that process, and play an active role within their division in internationalization of their institution.

\section{Statement of the Problem}

There are currently few studies on the impact of study tours on student affairs personnel either professionally and personally. Christie and Ragans (1999) emphasized the expanded opportunities for student affairs professionals to grow from international service and exchange programs. Additionally, Kruger and Dungy (1999) highlighted the importance of international exchange for student affairs professionals, provided strategies to gain institutional support, and point out the value of exchange programs. Yet Student 
Affairs is not generally included within the greater internationalization of higher education development.

Student Affairs has a role in the internationalization process, in particular, "student learning experiences that encourage global citizenship, critical thinking, and an understanding of issues larger than the immediate self-play" (Manning, Kinzeie \& Schuh, 2006, p. 151). Areas of student affairs that encourage internationalization are "study abroad, short-term study tours, and on-campus internationalization certainly strive to meet these goals" (p. 151). Therefore, the need for a global perspective and mindset is important to increase the role of student affairs professionals in promoting opportunities to students and to peers to further their talents and abilities. The present study addressed the gap in the literature using a qualitative approach.

\section{Purpose Statement}

The purpose of the present study was to gain an understanding and insight into the role that international study tour experiences play in furthering the professional and personal development of student affairs professionals. The study will add to the literature available regarding study tours and is to be shared with stakeholders within student affairs administration to encourage the participation of staff on international travel, in particular, study tours, professional exchanges, and international conversations.

For the current study, the researcher inquired into whether the participation of student affairs professionals in an international study tour ranging from 7-28 days (Sachau, Brasher \& Fee, 2010, p. 653) can be helpful for the development and the internationalization of the field of student affairs. Through qualitative interviews, the researcher learned why student affairs professionals attend international study tours and 
how these experiences shaped their professional and personal development, and how these experiences might have influenced how they view their work as student affairs professionals.

\section{Research Question}

The research question that guided this study was:

In what ways do student affairs administrators involved in international study tours perceive their experiences as furthering their personal or professional development?

\section{Definitions of Key Terms}

Career Path. Creating a plan or interest in particular positions for future job opportunities.

Global Awareness. "knowledge of the interrelatedness of local, global, international, and intercultural issues, trends, and systems" (Florida International University (2011a).

Global Competency. "having an open mind while actively seeking to understand cultural norms and expectations of others, leveraging this gained knowledge to interact, communicate and work effectively outside one's environment" (Hunter, 2004, p. 130131).

Global Mindedness. "the capacity to examine local, global and intercultural issues, to understand and appreciate the perspectives and world views of others, to engage in open, appropriate and effective interactions with people from different cultures, and to act for collective well-being and sustainable development" (OCED, 2018). 
Global Perspective. "the ability to conduct a multi-perspective analysis of local, global, international, and intercultural problems" Florida International University (2011b).

Intercultural Communication. "the ability to behave effectively and appropriately in interacting across cultures" (Martin \& Nakayama, 2010, p. 47).

Internationalization. "the process of integrating an international, intercultural, or global dimension into the purpose, functions and delivery of post-secondary education" (Knight, 2003).

International Study Tours. A 2- to 3- week period of time (Ribeiro, 2004, p. 122) and "a 7 - to 28-day trip where participants travel from city to city and visit sites along the way" (Sachau, Brasher \& Fee, 2010, p. 653). Tour is led by a faculty member, from a higher education program and college credit may be earned.

Personal Development. Characteristics, personal preferences, and improvement of oneself enhancing skills, and abilities.

Self Growth. "a desire to become a better version of oneself every day. A timeless pursuit, self-growth refers to a life-long process to improve one's own performance through formal and informal approaches." (Jain, Apple, \& Ellis, 2015, p.41).

Student Affairs. Functional areas of academic advising, admissions, assessment, research, program evaluation; athletics; campus safety; career development; college or student unions; community service and service-learning programs; commuter services and off-campus housing; counseling and psychological services; dean of students' office; dining and food services; disability support services; enrollment management; financial aid; fundraising and fund development; graduate and professional services; Greek 
Affairs; health services; international student services; judicial affairs; lesbian, gay, bisexual, and transgender (LGBT) services; multicultural student services; orientation and new student programs; recreation and fitness programs; religious programs and services; registration services; residence life and housing; student activities; and women's centers. (Dungy, 2003).

\section{Kolb's Experiential Learning Theory}

For the research study, Kolb's Experiential Learning theory was used as the conceptual framework to understand and explain the participant's experiences in international study tours (Kolb, 1984). The researcher used the theory's four-step cycle of learning to explain the educational cycle of international study tours. Kolb's theory four cycle process combines experience, perception, cognition, and behavior with concrete experiences, reflective observation, abstract conceptualization, and active experimentation. The international study tour experience provides and supports that "in experiential learning theory, learning is considered to be a continuous process in which knowledge is created by transforming experience into existing cognitive frameworks, thus changing the way a person thinks and behaves" (Sewchuk, 2005, p. 2).

The international study tours that the participants embarked on were designed to support experiential learning. Traveling is a potential source of learning that is transformative in nature (Morgan, 2010). The international study tours were structured to accommodate the different learning styles of the participants. For example, classroom time (physical and virtual) provided pre-departure lessons, the institutional visits provided concrete experiences and periods of time were blocked out to encourage reflective observations and reflective journal entry time as well as time slots for group 
discussions. Also, during the tours, participants were able to apply what they were learning to their own professional positions and then able to implement lessons or ideas learned post trips as active experimentation.

\section{Summary of the Dissertation Chapters}

Chapter one addressed the need to conduct a study to understand why student affairs professionals choose to attend international study tours, the impact of these study tours, and the need to expand the research and literature available with regard to the professional growth and development of those who attend short-term study abroad programs, in particular, study tours. During the research and planning of this study, the specific research question was identified as the role and significance in professional and person development of student affairs professionals participating in international study

tours. Experiential learning theory was provided as the conceptual framework provided a lens in which to view the learning and growth experienced by the participants. The experiential learning theory is woven into the international study tour activities and educational programming that was direct and indirect to those who traveled.

The study contributes to the limited studies available regarding faculty-led shortterm study abroad trips and create a new area of research regarding student affairs professionals and their role and experiences within international study tours.

Chapter 2 provides a broad overview of the foundational literature which apprises this dissertation. It covers broad areas of literature: internationalization of higher education and student affairs, historical perspective, type of participants, short-term study abroad programs, and an overview of the theoretical framework used for this study. The type of participant literature and short-term study abroad program literature provide a 
context and perspective lens to place the specific participants of this research study and the need to add to the literature available. The theoretical framework provides the structure to explain this study which was informed by the literature. Chapter 3 presents an overview of the research design, the participants and the location sites, as well as the methods of data collection and the coding and analysis methods. Chapter 4 presents the findings of the interviews conducted and provides an analysis of the themes developed from the participant interviews. Chapter 5 offers conclusions from the data, provides further research, and implications for the field. 


\section{CHAPTER II}

\section{LITERATURE REVIEW}

The purpose of the present study was to gain an understanding and insight into the role that international study tour experiences help to further the professional and personal development of student affairs professionals. To facilitate this research focus, a review of related literature was conducted. This chapter discusses the literature related to research on international study tours, providing a brief historical perspective along with reasons to attend study abroad tours, competency outcomes, and the types of programs related to the present study. In addition, this chapter also reviews the literature which provides the basis and support for this study including professional development, internationalization of student affairs, and the impact of study abroad on those who participate. The literature highlighted the variety and mode of participants in study abroad programs and particularly international study tours. The research included examining the graduate student experience as well as faculty professional growth from participating in and leading international study tours.

\section{Review of the Literature}

Within the literature related to study abroad, there was an overwhelming focus on undergraduate students as participants (Hovey \& Weinberg, 2009; Norris \& Dwyer 2005), with such topics as the learning outcomes of students (Elola \& Oskoz, 2008;) and students' desire to study abroad (Carlson et al., 1990). There was limited literature regarding graduate students' experiences or desire to study abroad (Richardson, Imig, \& Flora, 2014), compared to the greater quantity of undergraduate research. There is a somewhat larger amount of literature regarding faculty members who led short-term 
study abroad programs (Mosely, 2009; Özturgut, 2007; Brubaker, 2006; Festervand \& Tillery 2001) and limited adult learner research regarding study abroad (Coryell 2011; Dirx, Spohr, Tepper \& Tons, 2010; Younes \& Asay 2003).

It is important to understand the limited type of literature that was available to set a framework for the current study. The impact of international study tours on student affairs professionals is significant. In particular, it is an opportunity to experience a new country and to interact with peers from different institutions who are also working to provide higher education to students. At the same time, there are professionals who attend these study tours as life-long learners and are impacted in a similar fashion as the undergraduates.

\section{Internationalization of Higher Education and Student Affairs}

The university system is changing to fit into the $21^{\text {st }}$ century and the demands of an increasingly interdependent world. There is research and current literature discussing the internationalization strategies that universities are implementing (de Wit \& Knight, 2002). In this research, Knight's (2015) definition of internationalization was used: "the process of integrating international, intercultural or global dimension into the purpose, functions and delivery of post-secondary education, in order to enhance the quality of education and research for all students and staff, and to make a meaningful contribution to society". Another definition that provides guidance and understanding to internationalization is

the conscious effort to integrate and infuse international, intercultural, and global dimensions into the ethos and outcomes of postsecondary education. To be fully 
successful, it must involve active and responsible engagement of the academic community in global networks and partnerships (NAFSA, 2008, p.1)

The benefits of internationalization of higher education are not only improving the university but also benefiting students by changing their perspectives (Bond, Qian \& Huang, 2003; Wiley 2001). There is literature supporting the need for internationalization to be prominent in all aspects of the universities, not just the curriculum (Jowi, 2009; Warner 2004) but research regarding the roles of student affairs administrators in internationalization of higher education is limited (Jons, 2012; Sullivan, 2011).

Universities are creating programs and internationalizing their core curriculums to focus on the ever-changing demands of the world, and the same will be expected from the Division of Student Affairs. Student Affairs is poised to create programming and resources that fit "internationalization with a competency perspective emphasizes the development of skills, knowledge, attitudes, and values that are important for one to compete in the global marketplace" (Knight, 1994, p. 7). Christie \& Ragans (1999) argue that "student affairs professionals must become more international themselves" (p. 80). These authors highlight a program created at Florida State University (FSU) in which both students and professional staff have benefited and have had the opportunity to travel abroad. From their experience with this program, the participants have stated it has "been rewarding both professionally and personally" (p. 85). These participants have exchanged information and "have influenced programs and delivery of service to students" (p. 85). 
Student Affairs has always had a significant influence on students. "There are campus units whose historical role has included attempting to influence the social climate and students' interactions experience. These units are collectively termed 'student affairs"” (Franklin-Craft, 2010, p. 2). At some universities, Student Affairs may be the largest division where professionals perform a variety of duties; the professionals within what is termed "student affairs" provide a multitude of services for students as well as provide support and development.

Not only do student affairs professionals and divisions need to keep pace with the changing world but so do graduate preparation programs aimed at developing future student affairs professionals. Schulz, Lee, Cantwell, McClellan, and Woodard (2007) investigated the "extent of internationalization among student affairs graduate preparation programs in the United States" (p. 610). The mixed-methods study of Schulz et al, (2007) indicated that there is "an uneven distribution of internationalization among student affairs graduate preparation programs and reveal multiple ways by which internationalization is being incorporated into curricula" (p. 621). The study emphasized that the international components within the curriculum tend to be "episodic and studentdriven rather than stable faculty-driven initiatives" (p. 630).

Callahan (2015) states "for the field of student affairs to truly internationalize as the definition describes [used in this study], all student affairs professionals must integrate the international dimension into their own work" (p. 188). Callahan used the NASPA definition 2008 of internationalization, "the conscious effort to integrate and infuse international, intercultural, and global dimensions into the ethos and outcomes of postsecondary education" (p. 1). Callahan (2015) did a historical review of the 
internationalization of student affairs within the United States from 1951-1996, providing an oral history of the process and evolution of student affairs. There is a need to add to the literature regarding the role of student affairs in the internationalization process, particularly investigations of the ways in which student affairs professionals are involved in the internationalization process.

\section{Types of Participants in Study Abroad Programs}

For the present study, the researcher focused on student affairs professionals and their experience on an international study tour. There is an overwhelming number of studies and research conducted on undergraduate students. The researcher found in doing this study that the student perspective is important to use as a guide for understanding what the professionals may be experiencing. There are also several studies in a variety of disciplines regarding faculty who led short-term study abroad programs that will be reviewed here (Mosely, 2009, Özturgut 2007; Brubaker, 2006; Festervand \& Tillery 2001). There is limited adult learner research regarding study abroad (Coryell 2011; Dirx, Spohr, Tepper \& Tons, 2010, Younes \& Asay 2003). The following sections describe the motivations of students, faculty, and adult learners to participate in study abroad programs.

\section{Students}

Students have various reasons for study abroad participation. For many students "international learning can be a cornerstone for an undergraduate education that prepares students to be engaged and informed citizens in an increasingly globalized world" (Hovey \& Weinberg, 2009, p, 35). Study abroad provides opportunities for "college students to add an international experience to their academic career" (Norris \& Dwyer, 
2005, p. 121) in addition to which these programs "offer a wide range of learning contexts, varying in length, academic content, and degree of immersion in the host culture" (Norris \& Dwyer, 2005, p. 121).

Nyaupane, Paris, and Teye (2010) found four motivational factors for students to participate in study abroad programs: "international travel, escape, social, and academic" (p. 263). For Wiers-Jenssen (2003), students' study abroad motivators were focused on academics, future-careers, and cross-cultural experience. Sánchez, Fornerino, and Zhang (2006) determined that U.S. students desire to study abroad as the following: "the search for pleasure/liberty positively influenced the intention to study abroad" (p. 47).

Motivational factors of the Gen Y are the focus of study abroad for Pope, Sánchez, Lehnert \& Schmid (2014). They found that, students are motivated to attend study abroad programs because of a desire for personal growth as well as "gender, parents' educational level, prior international experience, age, and house-hold income" (p. 97). For Clarke, Flaherty, Wright, and McMillen (2009) students value the experiences of study abroad particularly because of an anticipation of, independence, unique experiences, and cultural encounters.

For Forsey, Broomhall and Davis (2012), students in their study had priorities and interests pertaining to having fun, travel, and making friends as motivators for study abroad. In sum, the factors influencing students' motivation to attend a study abroad program are both academic and fulfillment of their own personal interests.

\section{Faculty}

Faculty and/or staff play an important role in the experience of the students who attend any type of study abroad program. Lee (2014) suggests that faculty members 
incorporate the experiences of the students into their course structure, in particular, "journal prompts" (p. 155) as well as part of "follow-up with students after they return from a study abroad program" (p. 155).

The Brubaker (2006) study emphasized the contributions of faculty-led programs within short-term study abroad. The study especially reinforced the concept that faculty can "systematically guide and direct students through culture learning activities and processing their experience" (p. 151). Besides helping students process their learning experience, faculty also should have the "opportunity to explore and reflect on their ideas of culture and culture learning, become knowledgeable and comfortable with experiential learning" (p. 153).

Özturgut (2007) proposes that faculty who go abroad "would greatly enhance their academic capabilities, and also send a positive and encouraging message to students with their instructors being role-models" (p. 45). In addition, Özturgut points out there is the advantage of universities being able to promote study abroad within the classes and the curriculum, with the personal accounts of faculty members incorporating their experiences into their discussions and course lectures, thereby encouraging and assisting the students.

Paus and Robinson (2008) emphasize the need for faculty support and encouragement of students to study abroad. The authors state that they "stress the role of the faculty in increasing study abroad participation" (p. 34) as well as "faculty encouragement of study abroad may well be the key to enticing significantly more students to study abroad, especially from groups which have been underrepresented in study abroad" (p. 34). The authors also describe ways in which universities may 
encourage faculty to advocate for the study abroad experience. One way in which faculty may be encouraged is "to facilitate short-term faculty visits abroad where the focus is on research and intellectual exchange and not exclusively on the program and department assessment" (p.46). Paus and Robinson (2008) believe that faculty who see the value in study abroad would and could be more encouraging to their students to research and attempt to attend a study abroad trip.

Moseley (2009) discusses how "study abroad opportunities may be leveraged in support of the research imperatives of junior faculty, as a mechanism for encouraging student-faculty research collaborations" (p. 231). Moseley also suggests that universities provide some sort of funding opportunities for faculty, as well as consider "involvement with study aboard programs as a positive contribution when reviewing a faculty members' tenure portfolio" (p. 237).

There have been several articles encouraging faculty to plan and execute study tours. Festervand and Tillery (2001) emphasize the need for faculty members to attend study abroad study tours as a means of professional development. Participating and planning a study tour is an opportunity for faculty members to be students and to fulfill their educational requirements as faculty. In particular, these authors describe a graduatelevel course for business students during which they can experience business corporations in Japan. Benefits of these trips include "academic validation, intellectual growth, acculturation, and cognitive repositioning" (p. 109). The emphasis is on the concept that with "the learning that occurs from on-site visits and presentations, students and faculty will experience cultural diversity as the macro- and micro-levels" (p. 110). Festervand and Tillery (2001) describe the experience of visiting companies and speaking 
with executives, as well as the experience of staying in hostels as part of the cultural exchange and growth which may occur from the visit.

Koernig (2007) emphasizes that the "faculty tour leader will gain exposure and experience in a different culture, and this knowledge can be used in the classroom to enhance teaching for any course with an international focus" (p. 217). Another positive aspect of study tours and study abroad courses stated in this study that "large amounts of time spent with students during the trip will result in a better professor-student relationship compared to a traditional course and can result in lifelong relationships" (p. 217).

Sandgren et al., (1999) interviewed faculty members who attend study tours and study abroad experiences to determine if they changed the way they taught their courses after their experience. The study highlighted that "participants repeatedly noted a greater feeling of confidence, authority or credibility when talking to students about the places they visited on the seminar" (p. 54). Participants reported that "no matter how much previous study they had done of the cultures they visited, nothing could compare with actually being there" (p. 54). These experiences "produce dramatic and enduring transformative change in participants and their teaching" (p. 55). The study concluded that not only do students learn and grow but so do faculty in restructuring their course and the topics which are highlighted.

Iammarino and O'Rourke's study focuses on faculty and students in the health profession, highlighting the benefits of traveling overseas as faculty as "an opportunity to visit another country" (1999, p. 167) as well as stating that "leading a travel/study group also enhances their own interests by helping broaden their personal and professional 
horizons" (p. 167). Another aspect encouraged by the authors is that traveling abroad "often stimulates new ways of looking at a health problem or health systems" (p. 167) as well as "assists in interpreting theory into practice" (p. 167). Another highlight for faculty promoted in this article is that "the successful travel/study course can be showcased across your campus via campus publications as well as other informal mechanisms" (p. 167).

Evans, Finch, Toncar and Reid (2008) from their quantitative study focusing on students' perceptions and preferences regarding short-term study tours highlight that "faculty can benefit enormously from short study tours" (p. 15) as well as emphasize that these tours "offer flexibility, in that they can take place between semesters, during spring break, or in the summer months" (p. 15). Their study focused on business majors and emerging international markets and is important as it indicates that there is a market for specialized studies focusing on the needs of specialized professional interests. They found that that universities can "develop study tours that, to some extent satisfy the needs and desire of these customers while still meeting specific educational objectives" (p. 16). The creation of study tours with particular educational components which can justify the opportunities for professionals in higher education to participate in study tours opens the possibilities for further exploration.

\section{Adult Learners}

Coryell (2011) examines the experiences of adult learners as study abroad participants, stating that the study abroad opportunities "present adult learners with a setting in which to learn about global diversity and the interrelationships of issues across the world's population today" (p. 4). The author explains that "adults may find that short- 
term programs fit better within their financial limitations and time constraints of work and family" (p. 4). In addition, the author shared important teaching strategies not only for adult learners but for all students, taking time for reflection and interactions which may occur inside and outside the classroom. Adult learners may be seen as another population that may be interested in attending study abroad programs, especially those which are defined as short-term.

Dirkz, Spohr, Tepper and Tons (2010) focused on adult learners participating in a short-term study abroad program. They had participants who stated that "the sensemaking process of their experience reflected a complex relationship between the academic goals they construe for the experience and their own career goals" (p. 126) as well as stating the experience "represented an enjoyable, meaningful experience" (p. 126).

Bodger (1998) emphasized that life-long learning can be achieved through travel. In particular, traveling for an educational purpose "provides an immediate and personal experience of an event, place, or issue that cannot be duplicated" (p. 28) but also travel is "the continuum of lifelong learning" (p. 29).

Another study that focuses on adult learners and their experiences is that of Younes and Asay 2003, which utilized the Jung theory of learning to analyze the study abroad results of introverted and extroverted learners. The study focused on "what they learned about themselves as group members and the impact that the travel experience had on expanding their world perspectives" (Younes \& Asay, 2003, p. 146). Once again, the impact of study abroad is significant on those who participate, regardless of their age. In 
particular, student affairs professionals work with and advise students and influence their lives.

Dapko's (2016) study focuses on adult learners and their learning by going on a self-directed learning experience of travel. Dapko (2016) phenomenological study addressed gaps in the literature about adult learners being life-long learners and their travel experiences. He highlighted that the participants in this study "pursued learning activities and experiences not to pass some sort of test or receive a grade from a teacher, but to gain a pride in achievement, development of character, and personal enrichment" (p. 106). Dapko's (2016) study found that international study tours increase adult learners' ability to gain personal enrichment.

\section{Short-Term Study Abroad Programs}

Donnelly-Smith (2009) found that short-term study abroad experiences -- those in which students are engaged for fewer than eight weeks -- are the most common type of undergraduate study abroad in the United States (p. 12). They also explained that "shortterm programs can range from weeklong programs conducted during spring break in conjunction with a single course, to three- to four-week programs conducted during January term or in the summer, to longer programs of up to eight weeks that can involve home stays, travel to multiple sites, and service or research experiences (p. 12). Shorter length study abroad programs such as short-term trips are important to student affairs professionals who may be able to travel for a short period of time for their own professional and personal development. There are possibilities of taking vacation time or time off to participate in these short-term opportunities. 
"Short-term study abroad is a good alternative to longer-term study abroad for some students, especially those that feel constrained by the requirements of their majors, such as science students" (Lewis \& Niesenbaum, 2005, p. 258). Short-term programs are relevant because universities are trying to support the needs of students while providing them the chance to go abroad and experience the world. Attendance in short-term programs becomes an alternative form of professional development and provides a learning experience to meet and share knowledge with other professionals.

Ritz (2011) discovered that "short-term faculty-led programs provide great opportunities to practice holistic education, develop significant learning experiences, and promote transformative learning" (p. 165). Ritz also states that short-term study abroad programs "provide educators with great opportunities to achieve holistic education because they allow educators to relate in-classroom learning with the outside world and position students in culturally diverse contexts" (p. 166). Ritz (2011) emphasized that a "short-term study abroad program reinforced the emotional and social connection between faculty members and participants and therefore allowed for open discussions to take place" (p. 176), from which one can draw the conclusion that students can gain significant experience from short-term programs. These faculty-led experiences are not limited to students. Student affairs professionals who participate in study tours are provided an opportunity to interact with a faculty member both inside and out of the classroom environment. They have the chance to question and apply what has been presented as a concept in theory as well as create those academic connections that are needed within the profession in an off-campus setting. 
Perry, Stoner, and Tarrant (2012) state "short-term study abroad could serve as a vehicle for fostering transformative learning environments where new experiences and perspectives may be developed" (p. 682). Anderson, Lawton, Rexeisen, and Hubbard (2006) provided "evidence that short-term, non-language-based study abroad programs can have a positive impact on intercultural sensitivity" (p. 467). Anderson et al., (2006) supports the fact that short-term study experiences can provide students with stimulating learning opportunities for them to grow developmentally. In particular, Anderson et al., (2006) focused on the improvement of intercultural sensitivity measured by quantitative surveys of participants. These studies reinforce the conclusion that regardless of the length of the study abroad experience, participants will learn and grow from their time abroad. This is significant to those student affairs professionals with limited travel time available. The learning experience from the tour participation justifies their time spent in this endeavor.

Chieffo and Griffiths (2004) state that short-term study abroad programs "even as short as one month, are worthwhile educational endeavors that have significant selfperceived impacts on students' intellectual and personal lives" (p. 174). These outcomes help to foster the need for students to participate and take time from their current academic schedules. Being able to participate in a shorter study abroad experience can provide growth.

The Goldoni (2013) study takes a qualitative ethnographic and case study approach to understanding the effects of study abroad on students. Goldoni effectively summarized the effects of study abroad on students as follows: it lets them "explore new spaces, challenge themselves and their preconceived ideas, observe other people's 
practices with curiosity, and suspend judgment for the sake of learning without being afraid to encounter differences in traditions and unfamiliar values and customs" (p. 373). Understanding that students will learn from these valuable trips will also influence their future experiences once back to their home campus.

The Bretag and Van der Veen (2015) study provided insight into understanding “students' motivations and objectives in participating in short-term study tours" (p. 3). Utilizing a qualitative approach, this study highlighted the students' motivation which "revolved around the allure of a challenge, the desire to complete coursework quickly, experience cultural immersion, expand their networks, develop their 'soft' skills and to set themselves apart from other graduates in the future" (p. 7).

In a qualitative case study by Lee (2014), the findings showed that "the participants understood the world differently" (p. 123) after their short-term study abroad experience and that "the students and arguably the faculty who attend short-term study abroad programs have important and rich stories to tell” (p. 170). The study also emphasized that "if more students were engaged in a short-term study abroad program, we would have deeper conversations in the classroom and larger community abroad" ( $\mathrm{p}$. 171).

One of the current educational concepts or goals is to "make every student a global citizen" (Picard, Bernardino, \& Ehigiator, 2009, p. 342). So much of the literature regarding study abroad is positive and encompasses the notion of developing global citizens. Davies and Pike (2009) emphasize that "the goal of developing global citizens must lie in the abilities and willingness to question the very structure and processes that afforded them the opportunity to participate in the study experience" (p. 74). As the 
authors state, the nature of study abroad should actually "guide students toward fulfilling their responsibilities in our global community (p. 363). Once again, it is anticipated that these students will be able to relate their experiences to the global market.

Short-term study abroad can be used as a method to introduce not only undergraduate but also graduate students to intercultural experiences. As universities continue to expand their study abroad programs, it is important to view short-term study abroad as "a way to not only introduce students to one or more cultures, but also, and perhaps more importantly, as an opportunity to develop cultural learning strategies that can prepare students for future intercultural experiences abroad and at home" (Clayton, 2016, p. 25). Clayton (2016) focused on graduate students and found that short-term study abroad provides "an educational opportunity for exploratory, fact-finding, developing the cohort's social capital and expanding their pristine worldview of international travel" (p. 127).

These short-term study abroad programs provide participants and especially student affairs professionals opportunities to gain and enhance their global mindset, explore new places, and learn from other participants. Each opportunity may provide growth, cultural sensitivity, understanding of themselves and others. The literature available is extensive regarding beneficial outcomes of the travel and provides the researcher with an important approach to comprehend the growth student affairs professionals may encounter while participating in study tours. These tours serve as professional development and provide moments of enlightenment in the development of a global perspective. 


\section{Outcomes of Study Tour Experiences}

The vast majority of the research regarding the outcomes of study abroad programs, regardless of their length, concerns students. Nevertheless, the value-added of study abroad programs lies in their outcomes, as described in the following sections.

\section{Professional Development}

Lindquist and Bischof (2006) focused their study on "participating librarians and representatives from sponsoring organizations" (p.19) who were surveyed during a study tour to Germany, analyzing their data utilizing both qualitative and quantitative methods. In their case study, while the authors specifically state that the librarians were not studied in regard to their professional development, they do emphasize that study tours are "critical to the continued growth and effectiveness of library professionals at all stages of their careers" (p. 20). In particular, the authors state that the main purpose of the tour "was to educate participants, on-the-spot, about developments in librarianship, culture, and publishing" (p. 27). An important aspect of Lindquist and Bischof (2006) study was that the "establishing of contacts with colleagues while in Germany was an important goal of the tour participants as well as for the organizers and sponsors" (p. 28). Notably, Lindquist and Bischof (2006) pointed out that the home institutions would also benefit from the time their participants spent on the tour through new professional contacts made, new information that they felt would aid in their job effectiveness, and the fact that "participants also contributed to the continuing education of all interested staff through reports and presentations about what they learned" (p. 37). In all, these participants "returned with new information to share, new contacts to develop, and a new outlook on their work, all of which rebounded to their employers' advantage" (p. 37). In other 
words, Lindquist and Bischof (2006) found that participants in study tours gained in their opportunities for professional development.

Professional development for social workers was the focus of the Dorsett and Clark study. In particular, they conducted a qualitative study using evaluations and reflections of the participants, focused on study tours to India. For the most part, the themes which emerged were "significant personal growth, enhanced professional confidence, and cultural sensitivity" (2015, p. 47). Also, the study tours "expose students to social arrangements that can be considered in contrast to their own experiences" (p. 48) as well as provide "opportunities to engage, reflect, and ask questions in an environment with a different level of intensity to other teaching environments" (p. 48).

The phenomenological qualitative study conducted by Orndorff (1998) found that "meaningful, and sometimes transformational learning, took place" (p. 111) by the participants in a short-term travel experience through Rotary International for professionals. Those who participated in the study reported they "became more aware of their self-worth as professionals, sensing that they were of value" (p. 104).

Professional development for teachers was the focus of the Young (2010) qualitative study which focused on a 30- day international study tour. Young states the impact of the international study tour on professional development was profound in many respects. In addition to providing learning opportunities that updated cognitive domain knowledge, the study tour also provided many affective learning opportunities that increased teachers' cultural awareness, understanding, and empathy (p. 130). 
The study emphasized that international study tours are in themselves a form of professional development and beneficial for teachers in diverse communities.

In terms of student affairs professional, professional development "activities should attend to the contextual issues that shape the nature of student affairs work" (Hirt \& Strayhorn, 2010, p. 380). Komives and Carpenter (2009) stressed "developing professionally must be viewed as a daily activity of learning and applying new perspective as a way of being" (p. 413). Also, a case is made that the student affairs offices and divisions should "support, expect, and promote continuing education in diverse forms, but even if the employer does not provide reasonable support to make that happen, individual professionals must ensure their own capacity building and renewal" (p. 413).

It is also important to understand professional development is to be "the careerlong process of professional improvement” (Carpenter \& Stimpson, 2007, p. 275). International tours fit into that definition well. "Student affairs professionals have a responsibility to continue learning; there are multiple methods in which to gain knowledge and skills" (Roberts, 2007, p. 575). Professional development is a learning process that must be developed as stated by Roberts (2007):

The ultimate responsibility lies in the hands of the practitioners, who must find the time to assess their own areas for growth and devote the appropriate time and resources to be competent in their current and future positions (p. 574). International study tours are those opportunities with experiential learning that provides a time to reflect and to apply what is learned to current and future positions. 


\section{Global Awareness}

Global awareness is defined by Florida International University as "knowledge of the interrelatedness of local, global, international, and intercultural issues, trends, and systems (2011). Study abroad provides students with experiences that will open their eyes to the world, preparing them to become global citizens. The impact of their experience is or will be far-reaching, affecting their lives, careers and vision of the world community for many years. In particular, "educators throughout the world have tried to help students understand our interconnectedness and to help weave a garment of global awareness and mutuality by building international bridges of understanding through the promotion of students abroad” (Lutterman-Aguilar \& Gingerich, 2002, p. 41).

"Education abroad has considerable potential in providing an environment that results in value-added to student global learning and development” (Braskamp, Braskamp, \& Merrill, 2009, p. 101-102). Again, study abroad reinforces the opportunities students have to become truly aware of the world economy and increase global awareness.

Research has shown that study abroad opportunities not only bring awareness to the students of the host cultures to which they have traveled but that in addition, study abroad experiences also provide students with their own cultural awareness. Studies show that "living in another country can bring insight to one's own culture" (Forsey et al., 2012, p. 133). Students have the opportunity to see culture on a wider scope, getting a bigger picture of similarities and differences, much like looking at the world through multiple lenses, in essence, the difference of watching movies in color rather than in black and white. 
Bertag and van der Veen (2015) emphasizes the use of a buddy from the host culture. These students "participated in classes, organized social events and assisted with local logistical issues" (p. 6). These buddies also "had a profound effect on students' understanding of the local culture, and their ability to gain insider cultural knowledge" (p. 6), and their contact with the buddy post-trip "can extend their opportunities for future intercultural learning benefits" (p. 7).

The students who participate in study abroad programs can engage in experiences and activities which "expose them to greater cultural immersion" (McKeown, 2009, p. 26) as well as that "the amount of time put forth in these endeavors could positively affect their development" (McKeown, 2009, p. 27). These are significant moments in a student's life and theoretically should have an impact on their future development.

Research has shown that "understanding how study abroad participants interpret their cross-cultural experiences can provide valuable information to anyone interested in fostering the development of students' identities and their understanding of difference" (Jessup-Anger, 2008, p. 360). Jessup-Anger (2008) focused on gender perception of students who participated in a 3-week study in Australia and New Zealand, providing assumptions which were then evaluated by participants. The author points out that "study abroad experiences offer a unique opportunity for students to reconsider the assumptions with which they have framed their understanding of the world in which they live" (Jessup-Anger, 2008, p. 372). In other words, this is an opportunity for students to see the world as it is instead of how they may have envisioned it in an idealized, "Hollywood" style world. 
The study by Elola and Oskoz (2008) focused on the intercultural awareness of students by using technology, especially through the use of blogs, while studying abroad. Elola and Oskoz highlighted important aspects of blogging such as "create new intercultural learning environments that foster cultural awareness" (2008, p. 472). The use of technology is a new trend in study abroad programs and research into this area is limited. While there has been some research in the use of technology, its use and impact in documenting cultural awareness and personal growth of the students have not yet been specifically analyzed.

Goldoni (2013) effectively summarizes what study abroad is to students as follows: it lets them "explore new spaces, challenge themselves and their preconceived ideas, observe other people's practices with curiosity, and suspend judgment for the sake of learning without being afraid to encounter differences in traditions and unfamiliar values and customs" (p. 373).

\section{Intercultural Communication}

Intercultural communication is "the ability to behave effectively and appropriately in interacting across cultures" (Martin \& Nakayama, 2010, p. 47). The study by Rundstrom (2005) focused on students and their growth and development in terms of intercultural communication while abroad. Their research found that "students who study abroad do in fact show a greater change in intercultural communication skills than students who stay on campus" (p. 369). The study specifically looked at "change skills, allowing us to see that study abroad does enhance students' intercultural communication skills even if they are already present" (p. 369). Rundstrom (2005) also highlights that students need to be exposed to other cultures, especially those in the host countries. 
Importantly enough, Clarke et al., (2009) also reinforce from their study that students who participated in study abroad "perceive themselves as being more proficient, approachable, and open to intercultural communication" (p. 177).

Root and Ngampornchai (2012) focused their qualitative study regarding “students' education abroad experiences with the purpose of identifying how components of intercultural competence are represented in descriptions of learning" (p. 517). Root and Ngampornchai (2012) provided "rich firsthand experience of culture" (p. 517) but it also highlights the fact that "more guidance and knowledge about intercultural communication will better help students to analyze their own experiences, which in turn will hopefully raise levels of intercultural competence" (p. 517).

Understanding the student experiences in the literature provides the direction for the researcher to add to the body of literature experiences of these student affairs professionals.

\section{Self-Growth}

Several studies concerning students' study abroad experience have found selfgrowth as an outcome. Some students identified their independence and growth as related to their travel/study experience, including having to live on their own and take care of their expenses. Understanding the outcomes of students on study tours is important because student affairs professionals who embark on tours are students and learners while on tours particularly if the tour is for academic credit. Forsey et al., (2012) report the reflections of students who have studied abroad that "some students thought they had become more confident, particularly when communicating with other people" (p. 134). 
The study by O'Reilly, Ryan, and Hickery (2010) focused on the psychological well-being of students in short-term study abroad programs. As study abroad programs help develop students, it is important to note the significance of their sense of well-being and their ability to adapt to their living situations. Their study discussed cross-cultural adjustment as a framework on which to understand the effects of being outside of their comfort zone in a completely new environment. In particular, the study focused on their adaptation to their new residential and learning surroundings. Even though their study focused on students in Ireland, the authors noted some important generalizations in the well-being of students. Franklin (2010) also had positive findings suggesting that "knowledge, skills, and self-awareness gained by studying abroad are professionally applicable in the form of intercultural competencies and personal growth" (p. 186).

\section{Career Paths}

Career paths are not limited to students; participants of international study tours may develop an interest in student affairs work in the international setting as internationalization of higher education and of student affairs occurs. Norris and Gillespie (2008) focused on global career choices of students who had studied abroad, looking at their career paths and goals as influenced by their study abroad experiences. The authors share that "the findings are a useful resource for professionals and faculty advising students on specific program elements to select when shaping their study abroad experience" (p. 394). In addition, Norris and Gillespie stress that there is a need for more research in this area.

Relyea, Cocchiara, and Studdard (2008) highlight the need for university personnel to promote the benefits of the international experience that students receive 
from their study abroad program, with special attention to its positive effects upon career aspirations and additional educational and employment opportunities. Relyea et al, state clearly that "students must be made aware of the value and impact that this cultural intelligence or ethno-capability can have on their career aspirations" (2008, p. 359). They openly advocate for study abroad programs.

Carlson et al., (1990), found that students "noted that career factors were significant to them in electing to study abroad" (p.16). The students also "viewed the upcoming experience abroad as almost essential to their career development" (p.16). Carlson et al.,1990) reinforces the observation that students look at study abroad as opportunities to prepare for their future career plans. These experiences prepare the students to possibly live abroad if their career choices provide them with that path in their future.

The Trooboff, Vande Berg, and Rayman (2007-2008) study focused on companies hiring participants of study abroad programs. Evidence shows that the students articulate their experiences and "human resource professionals and others responsible for hiring value all types of study abroad more than senior managers, and they are more likely to believe that study abroad enhances desired qualities and skills" (p. 29). The study also emphasized that collaboration takes place between study abroad and career services professionals in working with students regarding articulating their experiences. It is clear that "students who opt to study abroad are making a decision that can have a very positive impact on their employability" (p. 31). Findings from this study should prove helpful to student affairs professionals and study abroad educators in their efforts to promote the benefits of education abroad. It can also be the decisive line of 
reasoning for those students who are undecided about embarking on a study abroad program.

Toncar et al., (2006) focused on the perceptions and preferences of business students and their desire to study abroad. The findings of the study revealed that both business students and general study abroad participants "recognize the value of study abroad in broadening their horizons, giving them greater knowledge of the world, and demonstrating their initiative" (p. 75). Once again, it is important to articulate to the student the added value of the study abroad experience to both career and education accomplishments, especially to those students who may not be convinced that the experience may be worth the expense and a change of their educational plans.

Kehl and Morris (2008), as a result of their investigations, believe that the international experiences are qualities that employers may consider important. They recommend that students should plan for a semester-long experience.

All of these studies emphasize the positive impact study abroad may have on students in regard to career aspirations.

As student affairs professionals, to understand the impact of study tours and study abroad experiences on students, it is necessary to understand not only the type of work done by staff in supporting roles but also the possibility of professionals being students. The educational outcome of study tours has an impact on anyone of any age and these outcomes can also impact the professional development of student affairs administrators.

\section{Kolb's Experiential Learning Theory}

This research study has employed Kolb's Experiential Learning Theory as the conceptual framework. The theory provides an explanation to the educational cycle of a 
study tour and the "meaning-making" (Savicki \& Price, 2017, p. 64) of the trips for student affairs professionals who take part. Lutterman-Aguilar and Gingerick (2002) stated that "study abroad and experiential education are natural partners" (p. 46) because of the empowering nature of the theory and participants becoming responsible global citizens.

Kolb's theory has four specific learning styles and a four-step cycle of learning that includes opportunities for experiencing, reflecting, thinking, and acting based on an experience or opportunity. In this process, immediate and concrete experiences lead to observations and reflections, which then are converted into abstract ideas with possibilities of actions that can be tested, further leading to potentially new experiences. Knowledge is created through initial experiences, followed by reflections, thoughtful development, and eventually alterations of experiences. There are several studies that use Kolb's theory as a framework for the student/participant experience in study abroad and international study tours (Pond, 2017, DeMello, 2011; Weaver \& Tucker, 2010; Bergsteiner \& Avery, 2008; Montrose, 2002).

Kolb's experiential learning relates to study abroad, particularly study tours; this is because the "ultimate goal of experiential learning is learning by doing" (Pasquarelli, 2017, p. 40). Pond (2017) used Kolb's experiential learning theory to explain student learning, in particular in regard to reflection as well as the implications for instructional design for students to engage in reflection. As stated by Bergsteiner \& Avery (2008) "study tours touch all four modes of the model" (p. 29). Concrete experiences are the institutional visits, reflective observations are the journal entries and group discussions, abstract conceptualization are applying lessons learned to their own professional 
positions or institutions, and active experimentation is the actual implementation of their ideas or lessons learned. Bergsteiner and Avery in their study have emphasized that Kolb's experiential learning has "produced deep-level and long-lasting learning" (2008, p. 35). Kolb's experiential learning provides support and structure for this study. Participants "take responsibility for their own learning" and "determines intentional, measurable learning objectives" (Montrose, 2002, p. 2). This learning is "meant to be a continuing spiral, where the learning achieved from new knowledge gained is formulated into a prediction for the next concrete experience" (p. 6). The learning spaces on a study tour are not limited to the classroom but include the physical, institutional, cultural and social elements of the environment in which they are active.

\section{Summary}

Most important to the researcher, this literature review opened the need to focus on the faculty and staff who participate in study abroad programs and the impact of the "transformative learning environments where new experiences and perspectives may be developed" (Perry et al., 2012, p. 682) for their own areas of expertise or interest. The influence and impact they have had on this educational process, helping students reflect and process their educational experience abroad, should be fully investigated and appreciated, and this theme be given more consideration. Attention was given to the transformative and reflective process of which they are active participants. As study abroad programs assume a greater role in the general university curriculum and in the "college experience," higher education institutions will perceive a greater need to create (or co-sponsor with other institutions) programs not only for their students but also for faculty and staff to engage in study abroad opportunities and to further develop 
themselves as professionals. There is a need to further encourage staff and faculty to participate in international travels not only to broaden their knowledge base but also as a continuation of the globalization of higher education. It is encouraging that in many cases the faculty and staff also become the students who are hopefully "enlightening their perspectives through thought-provoking scenarios, self-reflection, and dialogue" (Perry, et al., 2012, p. 683) and they, as well as the students with them, may well develop and learn in the areas highlighted by the studies, including global awareness and expanded career aspirations, to name two of the possibilities.

This chapter focused on the relevant literature and provided an understanding of how the researcher used this literature to frame and add to the research regarding student affairs professionals in their personal and professional development. 


\section{CHAPTER III}

\section{METHODOLOGY}

This chapter presents the study's research questions, the research design, and descriptions of the samples and data collection procedures. In addition, this chapter explains the decision to conduct this study. This study was designed to have a better understanding of the impact that study tours have on student affairs professionals. A qualitative study was designed for this research to explain and understand the value of study tours and the impact these tours have on the participants. The research question that guided the study was "In what ways, if any, do student affairs administrators involved in study tours perceive their experiences as furthering their personal or professional development?"

\section{Qualitative Research Design}

In keeping with the guidelines of qualitative research, the researcher was able to "turn the world into a series of representations, including field notes, interviews, conversations, photographs, readings, and memos to self" (Denzin \& Lincoln, 2011, p. 3), on the basis of readings that thus far show that study tours are of value to the university administrators/faculty as well as the students who participate in these tours. To accomplish this, the researcher intended to perceive the study tour from "the participants' point of view" (Saldaña, 2014, p. 74). A qualitative research design for the study provided insight into the experiences of the participants, in particular, the significance the participants placed on these the visits and the study tour in which they were involved. 
The researcher believes that the "more open-ended the questioning the better, as the researcher listens carefully to what people say or do in their life settings" (Creswell, 2013, p. 8). The researcher conducted this study with a multitude of open-ended questions. In general, qualitative research is concerned with the systematic collection, ordering, description, and interpretation of textual data generated from talk, observation or documentation" (Kitto, Simon \& Grbich, 2008, p. 243). The researcher used vignettes to tell the stories of the participants interviewed. As stated by Merriam (2002), it is important that a study is presented in a "format appropriate to the audience" (p. 15).

Qualitative research designs "provide a more narrative grounding to the story of lived experience" (Saldaña, 2014, p. 74) because in this case, the experiences were gathered post trips with reflective questions and discussions. The information gathered from these interviews has shaped the articulation of the promotion of international study tours and identified the value placed on study tours by the student affairs participants. This process shaped the participants' articulation of their experience on any type of study tour and how it affected their professional and personal development. Through the use of this methodology the researcher was able to achieve the purpose of this study by soliciting participant stories of his/her international study tour experience, because the researcher is "actually talking directly to people" (Creswell, 2009, p. 175). The use of a qualitative study permitted the researcher to use a variety of procedures for collecting and analyzing data, in particular, "interviews, observations, and documents, rather than rely on a single data source" (Creswell, 2009, p. 175). Qualitative methods suited this study because it was important to understand the lived experience of the participants. The researcher wanted the participants to shape the data that were collected which allowed the 
exploration of the outcomes of these international study abroad experiences, particularly those discovered during the study tours.

This study gave voice to student affairs professionals who embarked on international study tours and their perceived value on their personal and professional development. In keeping with qualitative research, the researcher viewed the subject matter by "adopting different lenses, filters, and angles" (Saldaña, 2014, p. 4) because of the type of study tours participants may join as well as how those individuals determine the significance and meaning to themselves of their trips. The researcher wanted to know if the student affairs professionals were able to articulate this thought-provoking experience, particularly in their current professional positions and their possible impact on student affairs, and if they had assimilated these new ideas into other facets of their lives.

A qualitative research design for this study provided insight into the experiences of the participants, in particular, the significance the participants placed on the visits to not only universities or institutions of higher education but of cultural and tourist locations and the study tour in which they were involved. The use of semi-structured open-ended questions permitted the interviewee to "use whatever words they want to express what they have to say" (Patton, 2002, p. 354). The interviewees were able to share their memories and make connections from their trip experiences to other aspects of their careers or personal lives.

\section{Role of the Researcher}

The reason for choosing the topic of study tours for this dissertation was a personal one. The researcher was fortunate enough to attend a first tour in the summer of 
2006 with Bowling Green State University, which was in their second year of planning tours to the United Kingdom. The researcher would have attended in 2004 with the first tour but this was not possible because of scheduling conflicts. Seven years later the researcher was able to take a second trip with Bowling Green State University, this time to South Africa, and having just started a third professional role in Student Affairs, was more than conscious of and had a greater understanding of the experience. Thus on the second tour the researcher was able to have more in-depth conversations with colleagues and was more able to process and reflect upon the significance of what was observed and the participation itself.

The topic of study tours and being able to interact with professionals from other countries helped to develop and further professional growth including interactions with other professionals at universities within the United States and within the State of Florida where the researcher works. Being able to interact with other professionals to discuss methods, procedures, systems, et al has been educational. These trips opened the door to look at the greater world and the opportunities to learn from everyone and be able to create partnerships and connections for professional growth. For the researcher, the tours have also provided a rich context of examples and helped articulate the need and willingness to approach situations and create innovative solutions.

Finally, the last two tours in which the researcher was been able to participate, New Zealand (2016) and Europe (2017) led to a reflection on the researcher's understanding of the future of higher education and the internationalization of student affairs. These tours have had an impact on the researcher's everyday work with of being able to draw on the experiences and challenges to be creative and appreciative of the 
opportunities and resources in the researcher's current position. The experience of these tours has enhanced work with students as well as provided the ability to challenge colleagues to look at the university through different lenses, and to adapt to changes that may be happening on a college campus.

To minimize research bias the researcher followed Bogdan and Biklen (2007, p. 37) "acknowledge and take into account their own biases as a method of dealing with them." Having been a participant of these study tours, the researcher wrote descriptive reflective field notes on my past international study tour trip to address any inherent bias. A third party transcribed an interview and used the transcription services provided in the Pro Service portion of gotomeeting.com subscription and the researcher reviewed all the interviews for the answers to the research question and then conducted member checks with each of the participants to ensure the accuracy of the information the participants provided. The individuals who participated in the study were able to provide clarification of any information. There was a follow-up period with each interviewee to ensure that they had enough time to read their interview transcripts, provide feedback, and participate in the next round of questions.

As the researcher, I found that the concept of reflective field notes, as pointed out by Bogdan \& Biklen (2007, p. 122) is that the "emphasis is on speculations, feelings, problems, ideas, hunches, impressions, and prejudices" were very important as I contemplated the results of my study. As Ortlipp (2008) states "critical self-reflection is a way of considering the ethics of the power-knowledge relationship with participants" (p. 702). These reflections were helpful in maintaining an appropriate balance of a relationship with the study participants. The researcher had a number of hunches and 
feelings about the study results and was interested in learning more about the outcomes for this study.

\section{Site Selection}

Four different four-year public institutions served as the research sites for this study. These institutions all have hosted a week to three-week international study tours for graduate students - Masters' and Doctoral levels, as well as full-time professionals. The tours are hosted by higher education programs with either a K-12 or a Higher Education focus. These institutions have hosted these tours for more than a decade.

\section{Bowling Green State University}

Bowling Green State University (BGSU) has been hosting International Study Tours since the Summer of 2004. The first trip of two weeks duration to England (Great Britain) was coordinated by the faculty members within the program and a recent Masters degree graduate student. Since then the University has coordinated several trips for students to England, Scotland, Ireland, and Wales in 2004 through 2018. New Zealand was added as a study tour location in 2007 and students have traveled there in 2007 , 2008, 2010, 2011, 2012 and 2016. The Transatlantic Dialogue trip, which is every three years and depending on the schedule, enables students to travel to England, Scotland, Luxembourg, Belgium, Germany or France and trips took place in 2008, 2011, 2014, and 2017. In 2013 with the addition of a new faculty member, South Africa was added to the study tour experience; these trips have taken place in 2013, 2015 and 2017.

Participants in each of these study tours visit at least seven higher education institutions. Prior to the actual travel, the students participate in pre-departure sessions which provide basic background information on what to anticipate regarding the trip, the 
history and current issues of the tour country(ies) and a discussion of the general education system as well as university programs. General tourist information on the cities that will be visited is also shared.

\section{Central Michigan University}

Central Michigan University (CMU) through its College of Education and Human Services provides several international study tour opportunities. The study abroad experiences began in 2007 and have a K-12 and Higher Education focus. The international study tours have been to China (Beijing), Ireland, Hong Kong, China, South Africa, Costa Rica, Spain, Singapore, and Malaysia.

Prior to the tours, a pre-departure course is given during which students are assigned readings and discussions. A faculty member is assigned to the course who leads the discussions and attends the trip with the students. A South Africa trip was hosted with Bowling Green State University.

\section{Florida State University}

Florida State University (FSU) has been hosting a week-long international practicum course since 2012 in the UK. The course was designed for masters' students but in 2017 doctoral students were invited to attend. The students participated in an oncampus course prior to their departure to London. The students stay at housing provided by Florida State in London which has security, library access, computer labs, and other resources for students.

The course is designed to be a seminar format, with discussions on European Higher Education, as well as connecting the U.S. higher education institutions to the English higher education tradition. Participants visit institutions of higher education in 
London and Oxford. The course is designed to provide students with an international perspective, review student services and understand college student culture in the United Kingdom.

\section{Miami University}

Miami University in Oxford, Ohio has hosted study tours since 2006 and offers a study tour program and course called "International Perspectives on Student Affairs." The tours have included five European tours, one New Zealand tour and one China tour and have been open to others outside of Miami University. The tours compare and contrast U.S. and selected countries' student services, developing a philosophy of student affairs practice by incorporating a global perspective.

Participants meet prior to their study tour in a class setting, reviewing materials and hosting discussions on topics related to the tour. In addition to visiting several different higher education institutions, tour participants had several sightseeing opportunities.

\section{Study Participants}

Participants for this study were selected using a "purposeful sampling method" (Creswell, 2003, p.185). The solicitation of interviewees was conducted following the approval from the Florida International University (FIU) Institutional Review Board (IRB), (IRB -18-0264-CR01). To participate in this study an interviewee had to have

previously attended a short-term international study tour of at least a week as a full-time Student Affairs professional or as a masters or doctoral student in a higher education program. Additionally, a participant had to be employed as student affairs administrators, within one year to six years from the date of the start of this dissertation 
study. The researcher's initial hope and criteria for participants for this survey had been for individuals who had more than two years of full-time student affairs employment experience following their study tour experience but that proved to be difficult. Snowball sampling was used to solicit participants from past study tours in which the researcher had not participated.

Those who participated in this study were currently employed in universities, in a field and/or functional area in student affairs. The researcher found twelve individuals who had been participants of international study tours through a method which Patton (2002), stated as "by asking a number of people who else to talk with, the snowball gets bigger and bigger as you accumulate new information-rich cases" (p. 237). The method for seeking interview participants was intentional: individuals who had participated in a Bowling Green State University (BGSU) sponsored international study tour. Initially, seven possible candidates responded to the invitation to participate in the study. As a past participant, the researcher knew some of the individuals from having been on a tour with them and having limited interactions post the international study tour. These potential participants, in turn, suggested other individuals with whom the researcher was not familiar, who had also participated in an international study tour. No one recommended the same person. Initially, snowball sampling did not yield rother pertinent key participants because those interviewees did not have the necessary contact information for their suggested candidates or there was no response to the request to join the study. At that time, the researcher began interviews with the initial seven participants who had accepted the interviews and had participated in a BGSU sponsored international 
study tour. Among the initial seven participants, one was from the BGSU/CMU international study tour.

Once the interview process was started it was determined there was a need to increase the pool of participants from 7 to 12 . The list from the initial request was reviewed and another round of solicitation requests to participate in the study was sent. The second request yielded a past participant of the BGSU/CMU international study tour and one participant of the BGSU/Miami University international study tour. A further participant was obtained from the Florida State University's (FSU) one-week international study tour to London in the United Kingdom and from that participant the researcher was able to connect and conducted interviews with two other former FSU participants. These three interviewees were all also the inaugural doctoral students to attend this international study tour.

Once the researcher was able to obtain contact information for those possible participants, they were emailed through their work (university) email address and asked whether they would be interested in participating in the study. For those individuals the researcher did not know, the researcher was provided with an introduction by someone who knew them. The communication was formal and the researcher provided the individual with information regarding the study which included the purpose of the study, the role, and rights as a participant, and the type of interview mechanism being used gotomeeting.com. Once the individual agreed to participate in the study, they received the consent form and an interview time was selected. Demographic information for all of the interviewees in this study are presented in Table 1 below. 
Table 1

Summary of Participant Site Tour Information

\begin{tabular}{|c|c|c|c|c|}
\hline Name & Tour & Year & Tour Host & Current Employer \\
\hline Aryn & $\begin{array}{l}\text { South Africa } \\
\text { United } \\
\text { Kingdom }\end{array}$ & $\begin{array}{l}2015 \\
2016\end{array}$ & $\begin{array}{l}\text { BGSU } \\
\text { BGSU }\end{array}$ & $\begin{array}{l}\text { University of } \\
\text { Minnesota }\end{array}$ \\
\hline Ashley & Europe & 2014 & BGSU & Georgia State \\
\hline Brandon & Europe & 2017 & $\begin{array}{c}\text { Miami University } \\
\text { w/BGSU }\end{array}$ & $\begin{array}{l}\text { Washington } \\
\text { University in St. } \\
\text { Louis University }\end{array}$ \\
\hline Calvin & $\begin{array}{l}\text { Europe } \\
\text { United } \\
\text { Kingdom }\end{array}$ & $\begin{array}{l}2016 \\
2017\end{array}$ & $\begin{array}{l}\text { BGSU } \\
\text { BGSU }\end{array}$ & $\begin{array}{l}\text { McKendree } \\
\text { University }\end{array}$ \\
\hline Colleen & $\begin{array}{l}\text { Hong Kong \& } \\
\text { China } \\
\text { South Africa }\end{array}$ & $\begin{array}{l}2011 \\
2013\end{array}$ & $\begin{array}{c}\text { Central Michigan } \\
\text { Central Michigan } \\
\text { w/BGSU }\end{array}$ & Central Michigan \\
\hline David & London & 2016 & Florida State & Florida Memorial \\
\hline Jessica & $\begin{array}{l}\text { New Zealand } \\
\text { Europe }\end{array}$ & $\begin{array}{l}2016 \\
2017\end{array}$ & $\begin{array}{l}\text { BGSU } \\
\text { BGSU }\end{array}$ & $\begin{array}{c}\text { University of } \\
\text { Wisconsin- River } \\
\text { Falls }\end{array}$ \\
\hline Kerry & New Zealand & 2016 & BGSU & $\begin{array}{c}\text { Cal State Long } \\
\text { Beach }\end{array}$ \\
\hline Michelle & New Zealand & 2016 & BGSU & $\begin{array}{c}\text { Haverford } \\
\text { College }\end{array}$ \\
\hline Nathan & $\begin{array}{l}\text { Hong Kong \& } \\
\text { China } \\
\text { South Africa }\end{array}$ & $\begin{array}{l}2011 \\
2013\end{array}$ & $\begin{array}{l}\text { Central Michigan } \\
\text { Central Michigan } \\
\text { w/BGSU }\end{array}$ & Central Michigan \\
\hline Trisha & London & 2016 & Florida State & $\begin{array}{l}\text { University of } \\
\text { Denver } \\
\text { Florida State }\end{array}$ \\
\hline
\end{tabular}


The purpose was to fulfill the IRB request and a 12 participant's interview scheme was developed.

\section{Data Collection}

Data collection was completed via interviews of participants listed in Table 1. All of the interviews took place virtually using gotomeeting.com; each participant was provided his/her own meeting link and the interview was recorded and transcribed. Each individual was provided with a copy of their transcripts for review.

\section{Interviews}

For this study, twelve participants were interviewed twice online. The interviews conducted were semi-structured interviews of individuals who were at least one year into their professional career since their participation in their international study tour/s. Seidman (2006) explains interviewing as "an interest in understanding the experiences of other people and the meaning they make of that experience" (p. 9) and that conducting interviews "provides access to the context of people's behavior and thereby provides a way for researchers to understand the meaning of that behavior" (p. 10). Although Seidman (2006) recommends a three interview structure, for this study a two interview structure was utilized; the structure provided an opportunity for the interviewees to begin their reflection process regarding their trip experience. In the interview process the researcher established a relationship with the interviewee and listened to the interviewees' experiences. By modifying the three interviews to a two interview system, the researcher was able to establish longer interview times with the participants. Selecting twelve participants provided the required descriptive information gathered from their interviews and twelve participants was deemed an appropriate number of 
interviewees. While there is no required number of participants to conduct a qualitative study, the researcher referred to Meriam (2009) which states that the study must have "an adequate number of participants, sites, or activities to answer the question posed at the beginning of the study" (p. 80). With the awareness that "each interview serves a purpose both by itself and within the series" (Seidman, 2006, p.19), the researcher interviewed each participant individually and during the interview the researcher asked follow- up questions. The interviews ranged from 30 to 60 minutes each, which allowed sufficient and reasonable time for participants to answer questions fully and for themes to emerge from collected data. Each interview was recorded with the consent of each interviewee.

During both interview sessions, questions were asked in order to elicit details of how the participant's experiences in international study tours affected their professional and personal development. The dialogue and conversation during the interviews were dependent on what the participants shared in response to the researcher's primary questions. The researcher asked a question and listened for the answer while at the same time formulating an appropriate follow-up question for clarification while reviewing the list of questions to be asked to each participant. Using the responsive interview techniques provided descriptive interview content. As stated by Rubin and Rubin (2012), this technique "allows you to modify your design in real-time" (p. 57). As the interviewees provided information, the researcher was able to change/modify questions or the direction of the discussion within the interview. All interviewees were asked the same questions but there were slight modifications and follow-ups to ensure an understanding and meaning of what was being said. 
The participant follow-up interviews were no longer than one month after the initial interview. Each individual was provided the transcripts of their interviews for via email for review purposes. There were slight edits to transcripts for misspelling or minor name corrections but there were no major changes to the original transcripts. The electronic recordings of the interviews, as well as the transcripts, were saved and stored in the online cloud storage attached to the researcher's work email account which can only accessed through a password-protected computer.

\section{Data Analysis}

Prior to the data analysis, the researcher used the transcription services provided in the Pro Service portion of the gotomeeting.com subscription. These transcriptions did not punctuate, nor did they completely translate particular fillers or words that were not clearly pronounced. All transcriptions were read once while listening to the interviews to ensure that the information captured was correct in the thoughts and ideas shared.

Grammar and syntax errors were manually corrected. Rev, a professional transcription company, was utilized to transcribe one of the participant's interviews because at the time the researcher was unaware of how to use the incorporated transcription service in gotomeeting.com.

The data analysis for the study began upon completion of the first interview. The transcription was reviewed line by line along with an examination of researcher notes. As stated in Merriam (1988) "data collection and analysis is a simultaneous activity in qualitative research" (p. 119). Using inductive analysis allowed the researcher to discover "patterns, themes and categories in one's data" (Patton, 2002, p. 453). Following the transcription of the interviews, each interview was read thoroughly and 
each interview was coded separately. The transcriptions were checked line by line for relevant information for the purpose of coding for themes. Coding took place following each interview once it was transcribed to make notes of possible themes. From the field notes, the researcher created a list of possible themes. The open coding method was used for each interview, making sure of "tagging any unit of data that might be relevant to the study" (Merriam \& Tisdell, 2015, p. 229). The initial codes were used when reviewing the next set of interviews, creating a longer list of themes and subthemes which provided linkages to the data. The initial codes from the transcripts included professional development and personal development, reasons for attending and exploration to name a few. The researcher used Axial coding to reveal possible relationships between categories and concepts. Once the themes were created and identified, the researcher reread the transcripts to look for more commonalities and identified the appropriate relatable themes, using the literature on outcomes of study abroad to guide the study. The themes that emerged were: intercultural communication; global awareness; selfgrowth; and career paths. As the coding of themes continued the researcher kept Patton's quote in mind

Qualitative analysis transforms data into findings. No formula exists for that transformation. Guidance, yes. But no recipe. Directions can and will be offered, but the final destination remains unique for each inquirer, known only when-and it-arrived at (2002, p. 432).

The researcher continued to complete the analysis and interpretations until the data provided an understanding in accord with the research question. 


\section{Data Organization}

For this study, field notes were taken in a journal and all interviews were digitally recorded to ensure the researcher captured all the information provided by the participants. The interviews were conducted using gotomeeting.com and extensive field notes were taken during each interview and maintained in a journal used only for interview notes. The coding process was an inductive process. To ensure the credibility of the data, the researcher replayed the recorded interviews and compared the transcribed interview notes to ensure accuracy and to ensure an understanding of the answers being provided to the questions from the participants.

\section{Data Management}

Each participant in this study provided consent to the researcher to use their first names for the study. The researcher kept a log in a field notes journal with each participant's name and interview dates as well as current university employment. All handwritten notes and files were kept under lock and key in a lockbox at the researcher's home and all files are secured on a cloud service attached to a work email and only accessed through a university password-protected computer at the institution or at home. Upon completion of this research study, all notes and recordings associated with the participants were destroyed.

\section{Data Integrity}

\section{Credibility \& trustworthiness}

This study was conducted ethically as stated by Merriam (2009) that "all research is concerned with producing valid and reliable knowledge in an ethical manner" (p. 209). The researcher had prolonged engagement with the interviewees and using a two 
interview structure allowed the researcher to achieve engagement with participants. The small number of participants along with a two interview structure allowed the researcher to learn more about the interviewees, their experiences, and allowed for more follow-up regarding their responses in the interviews. The researcher explained "the assumptions and theory underlying the study, by triangulating data, and by leaving an audit trail” (Merriam, 2009, p. 234) as well as conducting the study and investigating the findings from the data.

Lincoln and Guba (1985) discuss credibility, transferability, dependability, and conformability in a qualitative study. With respect to credibility, the researcher conducted member checks throughout the process of interviewing participants and used triangulation methods. As to transferability the researcher provided "thick descriptions necessary to enable someone interested in making a transfer to reach a conclusion about whether transfer can be contemplated as a possibility" (p. 316). Credibility and dependability were seen together by Lincoln and Guba (1985). If one produces a credible study, then dependability may not need to be shown separately. Conformability was conducted by member checks and cross-checking as well as keeping a reflexive journal. These were conducted throughout the research process.

\section{Member checking}

For this study, the researcher used member checking 'by combining both interviewing and observations" (Patton, 2002, p. 248) by using different methods of data collection interviews, audio recordings, and field notes. The researcher provided and made sure that each participant received a copy of their interviews transcribed and provided a time to respond with any edits and clarification of any information. These 
transcripts were sent via email as an attachment. Then the researcher reviewed the materials and conducted follow-up interviews to clarify any missing information as well as to ask additional questions. Following each interview, the researcher used a reflective journal to separate her own thoughts about the study tour experiences and to ensure the proper processing of the information provided. The journal provided a reflective method of processing information and helped with the initial thoughts regarding themes being developed from the interviews. For example, the researcher became discouraged when some of the individuals were not answering the questions in an expected way or if the responses were not as articulate as they could have been, given some of the travel locations the interviewees were describing. The journal helped to derive more follow-up questions and revisit topics without leading for an answer.

\section{Summary}

This study sought to understand the professional and personal development of the research participants regarding international study tour participation. Data for this study was primarily obtained through interviews of participants who were recruited through a purposeful sampling process. There were 12 participants of international study tours who shared their experience by explaining the purpose of going abroad, what they had experienced, and what they had learned. Data analysis was conducted using coding methods and several themes emerged from the data.

Chapter four presents the findings of the research conducted for this study. 


\section{CHAPTER IV}

\section{PARTICIPANTS AND THEMATIC ANALYSIS}

This chapter reveals the findings from the analysis of participant interviews. The chapter begins with a brief description of the universities that sponsor international study tours, as well as the profiles of each of the participants describing each participant's story and background regarding their international study tour experiences, the country(ies) they visited, and an understanding of the educational components of their trip experiences.

\section{The International Study Tour Sites}

Four different four-year public institutions served as the research sites for this study. These institutions all have hosted a week to two-week international study tour for graduate students - masters' and doctoral levels as well as full-time professionals. The tours are hosted by the higher education programs with either a K-12 or Higher Education focus. These institutions have hosted these tours for more than a decade. The four-year public institutions were Bowling Green State University (BGSU) started its program in 2004, Central Michigan University (CMU) started its program in 2007. Florida State University (FSU) in 2017 opened week long study tour to doctoral students, and Miami University started its program in 2006. Participants meet prior to their study tour in a class setting, reviewing materials and hosting discussions on topics related to the tour. In addition to visiting several different higher education institutions, tour participants had several sightseeing opportunities.

\section{Participants Overview}

This section introduces each of the twelve participants, four males and eight females, and their relevant summary demographic data. The participants were willing to 
share their first names for this study and these names will be used throughout the remaining chapters. The researcher chose twelve participants for this research project which was deemed a sufficient number to provide a diversity of experiences and show any possible patterns. All participants had attended an international study tour associated with Bowling Green State University (BGSU), Central Michigan University (CMU), and Miami University during a two to three week period from mid-May until the end of May, or a week long international study tour with Florida State University (FSU). All participants are or had been student affairs professionals when they attended their international study tour trip. Participants varied in their length of time working in the profession and in their level of education when they participated in the international study tour. Since attending an international study tour, they are now all working in full-time positions in student affairs.

The voluntary interviews took place weeks apart via gotomeeting.com; each participant was provided with his/her own $\log$ in/call information and no one received any payment for their participation. Interviews were conversational in tone and lasted from 35 minutes to an hour. Follow-up interviews were also conducted via gotomeeting.com and clarification questions as well as new questions were asked; each interview was approximately $20-30$ minutes and was conversational. This process as Seidman (2013) asserted "crafting a profile in the participant's own words... allows those words to reflect the person's consciousness" (p.122) and provides rich context for this qualitative study. The profiles are shared in alphabetical order. 


\section{Individual Participants}

As part of this study the voice of the participants provides the backdrop to understand the ways in which the international study tours impacted the professional and personal development of student affairs professionals. Sharing the tour experiences of the participants in their voice is important to understand the themes that emerged from the coding process. Each participant answered a series of open ended questions for the researcher to understand the participants lived international tour experience post trip (about a year or more since traveling on the tour).

\section{Aryn}

Aryn was a master's student when she attended two different international study tours. Her first study tour, upon completion of her first year of graduate school at Bowling Green University, was to South Africa in May of 2015, while her second tour at the completion of her master's degree the following year in May of 2016 was to the United Kingdom, when she also served as student coordinator. Aryn currently is the Student Engagement Associate at the University of Minnesota.

Aryn was an engineering major as an undergraduate and was unable to attend or participate in a study abroad experience. She shared "I felt like I had missed out." She was intentional in her search of graduate programs and was equally discerning in her selection of her first international study tour. She selected South Africa as her first international study tour because she "thought that there would be bigger differences and more things that I would gain from going to South Africa." She believed she would be exposed to more differences with the U.S. system and that she would gain more experiences not only personally but professionally. She also believed she would more 
likely be able to personally visit the United Kingdom at a later time but not so easily South Africa, where she would have not "felt comfortable to travel completely on my own." She shared she once had family that lived in South Africa following World War II and still felt a connection.

Aryn explained that prior to the trip a course was held one Friday a month with reading and other assignments. Those attending the study tours had to do presentations regarding the institutions the group would visit. Information was provided to give a fundamental understanding of the countries and higher education. During the first tour the classes were held at Bowling Green State University and attended in person, but the second year while the classes were still at Bowling Green State, they were taught via a gotomeeting set up because some of the participants were not studying physically at the institution.

The tours helped Aryn challenge the system and think differently about her ideas of what student affairs should looks like. It broadened her perspective. She commented that the student affairs model in South Africa is remarkably similar to that of the United States, whereas in the United Kingdom student affairs as a profession is viewed very differently. She stated that she interacted with a few professionals in the United Kingdom and learned and understood that the staff cared about students and the work they were doing. It just looked and played out differently than what one is accustomed to in the United States. She shared that observing these differences helped her to think about the ideas she had previously held and how student affairs and higher education play out differently in different countries. Additionally, she shared that the tours have 
broadened her perspective and have helped her to be able to see how things can be done in different ways.

Aryn was well aware that the educational experience her students will encounter during international study tours and semester abroad programs will look very different than what they are accustomed to in the United States and she tries to prepare them for what they will find. She shared that she thinks about her tour experiences, particularly in conversations with her students and she tries to tie them together and share what she had learned. It has provided her with potential solutions to problems. She shared that it has been very powerful for her.

She described how she has changed the way she discusses social justice issues since her trip to South Africa. It has provided her the push to become involved in social justice issues and to research other opportunities to further evolve her approach and thoughts related to social justice. She mentioned that she observed similar support staffing and responsibilities in the universities in the United Kingdom and the United States although the positions were derived from different approaches and methods. She shared that in some cases there are students who are in the positions, in particular in student unions in the United Kingdom, that possibly would be able to be done by students in the United States. She stated that these different approaches opened her up to broader perspectives. In her observations she stated that she felt that in the United States, some positions were expected to provide more supportive services, i.e. holistic, than in the United Kingdom. She shared that it is not transactional and that she did not want to adopt that approach completely but it did change the way she viewed the profession a bit. 
Aryn shared that following her trip she shared information with others and that the experiences collectively were brought up in class discussions. She said she realized that not all her peers were able to connect with the experiences because they had not attended an international study tour.

Aryn said that after her study tour experiences, she recognized that she had a very U.S.- centric approach and realized she was not well-versed in particular aspects of history or in current events. She shared it was easy to know what was happening in the United States but not what was happening elsewhere. She shared that she was trying to do a better job about learning about the history of other countries and cultures as well as learning about what was happening around the rest of the world. For example, Aryn shared that her South Africa tour experience was during the "Rhodes must fall protest," and she stated:

it felt so critical and so important to those of us going through the class recognizing how many people around us had no idea what was happening and just how easy it was to be ill-informed if you don't put the effort in to learn about it. The Rhodes must fall protest is about removing a statue of Cecil Rhodes at the University of Cape Town.

Aryn stated that honestly, she would be interested in going on another study tour and that if her employer would be supportive of and would be interested in paying for it, she would attend another tour. However, she shared that if a hundred percent of the cost would be coming out of her pocket and her vacation time, it would be a very significant decision. She saw it as a barrier to be doing it and she shared that the financial aspect of any trip could be an obstacle for many. If she were to go on another study tour, she 
shared that she had an interest in learning more about China and, in particular their K-12 and universities, because of the large number of Chinese students coming to the United States. She also indicated an interest in learning about Central America, as she knows nothing about higher education in those regions.

The tours provided her with opportunities to see different communities and helped to reinforce her personal commitment to equity work and seeing how that work is being done in different spaces. She shared the South Africa trip changed "how I talk about social justice," she continues to "push or evolve my approach and thoughts related to social justice." She also shared that it helped to influence her critical thinking skills as well as her problem-solving skills. In addition, she stressed that the tours gave her chances to build professional relationships with people who were working in different areas of higher education. However, she was forthcoming that as a young professional, particularly a master's student, she did not foster the relationships and connections as much as she could have. She reflects now that it is something more within her professional capacity and that she is striving to accomplish better communications within the academic community.

\section{Ashley}

At the time of the interview Ashley worked at Georgia State University as a fulltime professional in Residence Life. She was a master's student at Bowling Green State University, completing her first year of graduate school, when she participated in the European study tour in 2014 which ended with the Transatlantic Dialogue conference. The study tour was her first time abroad for school and the first time not accompanied by 
her family. Ashley shared that she is Jamaican and had traveled to Jamaica but not to any other country.

She explained that she had not had the opportunity to study abroad. She had been introduced to the concept but knew it was not going to be a possibility. When visiting graduate schools, she shared that it was a huge selling point that students were able to go abroad. She chose this particular study trip because it had multiple countries and that "Dr. Coomes was going to be leading [the tour]" as well as being able to "attend a conference." During the study tour the tour participants learned about European Higher Education and met with several student affairs professionals from several different universities.

Ashley works in housing and educating students on cultural competencies at Georgia State University. In her current position she was able to travel and attend the Transatlantic Dialogue with the college students she worked with in May of 2017. She explained that following her time on the 2014 study tour, she stayed connected to the conference and served on the planning committee for the 2017 conference and helped on the editorial team. During the 2014 tour she served as a transcriber of the session she attended and had to write "an editorial piece on my thoughts about the session" also the “editors put all the sessions together to encompass a conference review as a piece of history, so I really enjoyed my experience." She is currently serving on the planning committee for the 2020 conference as part of the steering committee. Being connected to the conference and being able to travel and be supported for that travel enabled her to accompany the students to the conference in 2017 and expose them to Luxembourg. She 
was there to be supportive to the students and expose them to international travel. The students were able to attend the conference and present to a diverse audience.

Ashley shared that on her 2014 study tour she was with peers who were reluctant to ask for help because they had gotten lost searching for a restaurant, they wanted to try even though she would tell the group that she was willing to ask for directions. She talked about her frustrations of "trying to coach them through and getting to a comfortable place of doing that."

She also shared that the group she was with on a train in Paris was accused of pick pocketing a woman's cell phone. The group and particularly the accused person in the group had not taken the phone but the most important and stressing part for her was just processing the accusation. She was faced with the fact that someone would make an accusation without reason based solely on the basis that she and her peer were the only persons of color on the train. She explained that they processed the situation and came to realize that it could happen anywhere.

Ashley stated that once she returned from her study tour experience, she focused on multicultural education and participated in a practicum for her program in that functional area. She stated she had always wanted to do multicultural work "being somebody of color, being a woman and a first-generation college student" and talk about differences in cultures. She was interested in teaching about multicultural competencies and she selected a position that offered those opportunities in residence life. She shared that because of her experience she is now open to working internationally, particularly in the field of diversity. 
Ashley shared that she has stayed in residence life but has been able to move into a different role working in multicultural education within the same department and has gone from a hall director to an assistant director. As part of her position Ashley discussed the assessment

Intercultural Development Inventory (IDI), and as a qualified administrator for it, you must take [the inventory] yourself and through taking it [the inventory] you learn where you fall on the continuum and create your own Intercultural Development Plan. And through the process I started to realize more and more how much that experience [the study tour] really shaped or like I would say kind of sparked my passion about giving back after coming back [to the Transatlantic Dialogue] as well as I knew exactly what I wanted to do and I felt excited about the world. I felt like my world expanded a bit and that the experience [study tour] was really impactful.

She stated that she was intentional in the position she applied to because it would provide her the opportunity to work in cultural competency education.

Ashley spoke about the personal qualities she gained from the international study tour experience. In particular, she spoke about the encouragement she was given on the tour regarding her personal reflection and the need to participate in reflection during and after the trip; this was encouraged on a daily basis on the trip. She shared that reflection helped her solidify her growth because she was able to think about the experiences and that the reflection was structured.

Prior to taking the study tour trips Ashley commented that she would have never thought about going abroad alone. However, since the international study tours she has 
taken more personal trips to other countries like the Bahamas and Jamaica and has been thinking about and planning trips to Honduras, Belize, and Mexico, which may be "single trips," her alone. She shared that she has been pushing her friends to be more open to international travel. These travel experiences "fall naturally within the continuum of lifelong learning” (Bodger, 1998, p. 29).

In terms of professional and personal development, Ashley shared that through the study tours she learned much valuable, practical information and skills for future travel. For example, she mentioned travel methods of which one is not necessarily familiar, how to be safe navigating from country to country, the types of visas you may need, financial needs, as well as general information like how to book a hotel. She shared that since she is now part of the planning committee for the upcoming 2020 Transatlantic Dialogue conference, she has had to navigate all her own bookings. She said that it has helped her to talk about traveling and understanding the various languages and money and that she felt pretty confident about what she has had to get done thus far.

Ashley shared her belief that professionals should attend study tours because of the growing international student population arriving to many universities and colleges. It is to be assumed that a study tour experienced professional staff can provide some context or knowledge to what international students may be experiencing upon arrival in the United States. She also shared that for her, personal experiences are as valid and, in many ways, even more helpful because it is more adaptable than quoting from an article or textbook. So, for her, a study tour is highly recommended and certainly most helpful. 


\section{Brandon}

Brandon was a master's student at Miami University when he attended a combined Miami University/Bowling Green University international study tour to Europe, ending at the Transatlantic Dialogue conference in May of 2017. Brandon is currently completing his first year as the Residential College Director at Washington University in St. Louis.

Brandon, as a Miami University student, did not attend the France portion of the trip. He and his peers joined the Bowling Green State University group in Belgium. He explained that he had decided to attend the study tour because he knew a few of the classmates who were attending. As the tour was being organized by his home institution, scheduling it was easy and he would also earn academic credit for the tour experience. The European tourism aspect of the tour in particular interested him, in addition to studying the European educational system.

Although the Miami University study tour was in conjunction with the Bowling Green State University tour, it held its own educational class sessions with a few joint sessions via Google Hangout. The readings and discussions were led by a faculty member at Miami University. The participants discussed the European Union and its influence on higher education as well as the historical context of the European Union educational standards. In addition, the students were informed about the educational systems of Luxembourg and Belgium. Upon arrival in Europe, the two university groups were united, and the study tour proceeded as scheduled. University campuses were visited, meetings were arranged with administrators and other individuals within similar functional areas of higher education, and local governmental and European Union 
personnel were met and gave presentations. Brandon shared that he "really did enjoy our institution tours; it was pretty cool to get to see just what another space looks like, the physical campus" as well as "explore new cities, culture, and new foods."

Because of this study tour Brandon shared that he began to reflect upon his own college experience and how his experience might have been had he attended a European higher education institution such as those visited on the tour. He stated:

I was having a newfound appreciation for the vast amount of services that I was certainly privy to as an undergraduate student and gave me a greater appreciation for the field and the work I do in Residence Life since many of the institutions that we saw did not involve housing that is provided by the institution or if even if the housing is provided positions like mine don't exist [live in housing director]. The impact of the international study tour experience happened once he began his second year of graduate school. He shared he realized that student affairs in the European context is more bare bone than in the United States. Brandon stated that the study tour for him was both professional and personal development because he was exposed to several different approaches to higher education. It has influenced his approach to how he works with students.

Brandon shared that he remembered having a conversation with peers on the study tour about diversity inclusion, particularly in the European context. They spoke about their impression that the institutions that were visited were not overly inclusive and did not seem to provide a lot of support, although he admitted that they were looking at it from a U.S.-centric viewpoint. 
Brandon recalled a moment, possibly in Belgium, at one of the institutions being visited where he was able to speak to a student from the United States who was studying abroad for a semester. She was able to talk to him a bit about her experience. She shared that the U.S. institutions where she went to school and those she had encountered in Belgium were very different. He stated that he remembers that she had a sense of disappointment. He shared this story because he said he uses it to remind himself of students' perceptions and their expectations and it has influenced his attitude toward supporting students and their expectations.

Brandon shared that the study tour experience has not necessarily changed the way he learns new things but has solidified the fact that you cannot take anything for granted. He stated in various ways that when you are learning new things, you really have to do so with an open mind. He shared that even when he does not necessarily agree with something or sees that it is not the most effective way of doing something, there can still be a lot of value in it. He knows he needs to be more open-minded.

Brandon shared that the international study tour is a really cool opportunity to put yourself outside of your comfort zone. He said that he believed it essentially forces you to take a critical look at the system in which you operate. He shared that something important that he took away from the study tours is the ability to remove himself from his immediate environment and take an outward-looking perception of the higher education system of the United States. He found the tour experience to be a powerful way to really force a new perspective and to become a stronger professional because of it. Brandon also shared that because of the study tour and visiting Europe he has a "greater appreciation for student affairs and all that we do because again we certainly have more 
student services and student focused offices." He also shared he realized that there is a need "to take a critical eye to what we [U.S.] do as well."

Anyone interested in student affairs and professional development can attend an international study tour and should attend a tour. Brandon stated:

I don't think you need to be a graduate student, $\mathrm{PhD}$ level, master's. Anyone from entry level to tenured Vice President for Student Affairs can really take an opportunity to learn from it [study tour] and have a positive impact on their career.

This is in keeping with Perozzi, Seifert and Al-Sharif (2016):

Depending on the person, staff members may seek opportunities to strengthen their international competence and career skills either through formal educational coursework and credential pathways or informally through self- directed learning (p. 98).

Brandon is interested in one day possibly attending another international study tour. He shared he enjoys traveling and that he found it to be something very exciting. He is interested in one day visiting China, a country which he has seen a lot of students at his current institution attend, and possibly also visiting South and Central America.

\section{Calvin}

Calvin was a master's student at Bowling Green State University when he attended both of his international study tours. The first tour in May of 2016 to the United Kingdom was between his first and second year of graduate school. The second study tour, a tour to Europe ending with the Transatlantic Dialogue Conference, followed his graduation from the Bowling Green State University Master's Program in May of 2017. 
Currently Calvin works at McKendree University, serving as the Assistant Director for Residence Life and Greek Affairs.

Calvin had taken a study abroad experience to England in 2006 as an undergraduate student. He chose to attend the undergraduate experience to join friends who were attending, as well as having had a positive experience of his family's hosting of an international exchange student from China. He had an interest to expand his travel abroad but admitted that he never made it a priority. Calvin selected the two study tour experiences because it would be a learning experience tied both to an area of interest and to the field he was studying. He noted that the tours were well-structured, and lodging was provided.

Classes were held before each of the two international study tours of which he was a participant. In the classes the participants not only looked at the higher education systems of the countries being visited but also discussed the culture of the various areas and countries. Additionally, discussions were held about safety and what to expect.

Regarding the tours, Calvin stated that he enjoyed connecting with alumni from the Bowling Green State University Higher Education program, both those who were presenters to the tour group and those who were tour participants. In addition, on both of the tours he also connected with his peers and enjoyed having conversations about what they were experiencing. He commented that these conversations helped him to reflect upon his experiences and gave him greater clarification and new perspectives of what he was observing.

Calvin recalled discussing mergers with some of the different university staff on the European visit. In particular, the university was a major provider of translators to the 
European Union; it was one of the university's biggest educational programs.

Furthermore, the university staff provided needed information regarding public transportation, making it possible for students to take classes, then take a train or bus to the European Union and then reconnect again and head to the other university campus for additional classes.

Calvin shared that because of his study tour and abroad experience he has earned social capital with his family. He has become a family resource regarding travel and shared that his family asked "how do you do this, how do you get a passport?"; he has become the connector for obtaining the information needed. Calvin further reflected that he has become more willing to explore and try different things. For example, he shared he has experienced new restaurants in the city of St. Louis where he currently resides and he is now willing to venture out both alone or with friends. He now enjoys speaking to restaurant and store employees, discussing with them about what led them to their employment path. As a result of his travel experiences, he stated that he has become a more patient individual and has developed diplomacy, not only with staff members but with friends. He said he has developed a more open-minded outlook. He wants to assist others and tries to navigate that social capital for the betterment of others.

Calvin remarked that he has observed that there is something magical that happens in the period from the first year of graduate school to the second year of graduate school; an individual begins to connect the dots and attempts to make a meaning of the learning process. He shared that for him the international study tour trip did not "click" until his last semester of graduate school when he realized he could connect a lot of the information he learned to what he was observing in whatever work or social work or in 
situations at the time. He shared that it was probably after five to six months when his brain started naturally to remember and incorporate what he had seen on those other campuses during his study tour experiences.

Calvin was able to use a previously seen concept in January of 2018 at Ashland University where he was doing his graduate assistantship in housing. The University had a lack of student study spaces available. He had seen the concept in social media in a space called Engage 15 which consisted of local business sharing their spaces with students and creating perks, encouraging them to study. He shared the idea with some staff on the campus, suggesting the use of office spaces and local businesses as study spaces. An appeal went out to the local businesses, particularly coffee shops and a game store on Main Street, and the concept worked. The students liked studying in the spaces and shared their positive experiences, including that the coffee shop provided a discount! He shared that educational goals and business goals could align and that there was synergy.

In regard to his professional development, Calvin shared that he has become better at articulating about himself in interviews and when he has to speak to his boss, the Vice President for Student Affairs and even Board of Trustee members. He shared he understands he needs to state "this is how it benefits our students" or when speaking to the Vice President for Student Affairs "here is how I think it is better for the institutional business, it lets us accomplish our mission better because our revenue is matching up with our goals." He shared that he understands the Vice President for Student Affairs is focused on a business model approach and now he can articulate his ideas under that approach. He is better able to share his ideas and how his plans relate to the mission of 
the University. He shared that it has provided him with more terminology to be able to better connect with and communicate his thoughts with others in the profession who may have a different orientation or educational philosophy than his own in higher education.

Calvin also shared that the study tour experience changed his view of perfection and his belief that it all had to go correctly. He now realizes that if he constantly does the work for the students and does not let them do it for themselves, he is doing them a disservice. Because of his tour experience and speaking with other professionals while abroad, he shared that he has changed his approach to his job. He shared "I'm here to provide advice and assistance; I'm not here to do this for you." He also shared an example about getting policy change done.

Students still have quarter washing machines and students don't want quarter washing machines. In the feedback surveys they [the students] want to pay housing a fee to have free access to laundry machines anytime they want without having to carry quarters. I'm going to have the students fight for it, so I went to the residence hall association. I'm going to leave it in your hands to do something with it because I would like to change this policy.

He has seen the need of having the student support, discussing the policies with them so that they feel connected to the decisions. He shared "the residence hall association is taking it on and they are trying to pull together the student voice and leverage it for creating the change." Calvin shared the data with the students and he stated, "I definitely have more value in how I can intentionally create spaces for students to step into that will help them grow versus just trying to make sure the space is perfect 
for them." He also shared that the tour experience helped him become more gregarious and extroverted. He developed more confidence in his knowledge and his skills.

He stated that the international study tour experience and his own study abroad experience has provided him some instant connections with individuals who have traveled to those locations or have also had those experiences. He described an interview and making a connection with someone because they both had been in Luxembourg. Professionally because of the tour experiences, he shared that he is more willing to visit other campuses to learn how things are done, what can be incorporated to his current role, and sharing responsibilities in a collaborative nature with others. He shared that he tries to be more aware of others present and to give matters more consideration.

At the follow-up interview Calvin shared he had thought about resiliency and mental health and had remembered a conversation and discussion about Mental Health in the United Kingdom study tour. He discussed mental health and mental well-being and the tools available. He was pondering the questions on how do we help students. He was thinking about the direction the United Kingdom is taking; it was mainly thoughts, but he had been reflecting on some trip items.

Calvin confided that when he first signed up for the international study tour, he was not looking at it as professional development. He thought about being marketable but shared that he had looked at it more for the social enjoyment and the ability to be in a new location and learn something different. He shared that it was really initially about satisfying his own curiosity and being able to enjoy a different experience. He thought about maybe one day working in a European or in a British higher education institution, but he did not think about the trip helping him be a better American professional. $\mathrm{He}$ 
then said that in the last six months he has realized that what he learned can and may translate into the United States at a professional level. Now reflecting upon his new fulltime role at McKendree University, Calvin talked about being in a small town and town gown relationships. He is anxious to apply what he learned from his experiences in Oxford and Antwerp.

Calvin shared that these international study tours are short trips and while there is some growth he believes if the trips were longer -- a month or a semester between higher education institutions -- that we may see more growth and development in autonomy and confidence. Calvin also shared his thoughts about international study tours as professional development, providing professionals with a different view "get an idea of what things [offices, departments, institutions] may look like outside the box, it is sometimes hard to see outside your own frame of reference unless you leave it;" it is "the ability to physically as well as mentally step out of their frame of reference and maybe critique it against another [frame of reference]." It is taking the professional development into one's interest and become a broader professional.

\section{Colleen}

Colleen currently is the director of Native American Programs and the Student Transition Enrichment Program at Central Michigan University. Colleen has attended two international study tours with Central Michigan University, the latter being partnered with Bowling Green State University. Her first international study tour was to Hong Kong and China in May of 2011 and her second tour was to South Africa in May of 2013. She was a master's student at the time of her first study tour and just beginning her doctoral program for the South Africa study tour. 
The Hong Kong and China study tour was selected because she wanted a distant travel site with a distinct educational component. She would be able to obtain both cultural and educational components along with the travel experience. The Hong Kong and China trip was a K-12 and higher education experience tour. There were tour stops at actual K-12 facilities and discussions with staff as well as tours of the higher education facilities and discussions with higher education administrators and staff. The study tour participants were able to observe the educational process from the start of schooling to the completion of a degree, resulting in a well-rounded demonstration of the educational experience. Colleen commented that the two Central Michigan faculty members who led the trip had a bit of conflict resulting in some disorganization to the trip agenda and complicating the tour experience. She shared that the first week was with "one professor and then we met another professor in week two in a different location, and her agenda was not put together very well, it was not as organized as what we had seen previously." She remembered this because Colleen shared that she as a person is "very organized and I want to make sure that I am getting from point A to Point B, and obtaining the knowledge."

Colleen expressed that both international study tours had readings and discussions with peers in the pre-departure course. For the Hong Kong and China tour, she shared that the tour participants were provided with cards that stated the name of the hotel or locations they were staying at to be able to navigate transportation or taxis. She stated, "we could literally just point to the card and they [taxi drivers] could read it off our card and it helped us during the trip." There were also educational materials to enable them to 
be prepared for the site visits and for in depth conversations with the administrators and individuals the participants would meet. She described it as

with both trips, we had to meet prior to come together as a cohort. Have discussions, we had readings that we had to make sure we had read. Making sure that we were prepared to go and answer an questions. So I know that people had a lot of questions about where [we were] staying, locations, and the language. In particular, Colleen stated that participants of the tour were "put in contact with people in the education realm, so we can have that dialogue with the individuals that are working in those institutions, and going to those institutions was a good aspect." Colleen also shared she had to journal and keep notes regarding her tour experience so that she could "write a 20-page paper about the experience and had to compare it [study tour country visited] to the American educational system." This is one form of reflection that participants were able to do once they had returned from their study abroad experience.

Both tours provided her opportunities to explore the areas and cities the tours visited. She shared about her Hong Kong and China trip: we were able to venture out to go to certain historical markers, museums, and really get a good understanding of what that culture and their history was firsthand from them as opposed to reading it in a book over here [the US] that might be watered down we were actually able to have those in-depth conversations with people which was really enriching.

Also, she was able to meet with administrators, some government officials, and students on both of her international study tours. Colleen stated that on the South Africa study tour there were many visits to the residential accommodations of the students and 
she felt very odd walking into someone's home to look around. The South Africa tour had many more residential life tours than the Hong Kong/China tour.

The tours provided her with a different perspective and understanding of policies and how different institutions handle student concerns and needs. Colleen said "I think it's just broaden my perspective of how we handle things at our institution compared to other institutions in other countries." She also shared that it prepared her to be able to work with individuals from different departments or from different backgrounds. She also shared that the international study tour helped her have more empathy of where they might be coming from [international students] and being willing to listen. I now give presentations about my culture to international students here on campus, and that opens the door to have those conversations as well.

For the study tours Colleen shared that they journaled every night and had time to talk about their impressions and perceptions of the day. There was also a chance to discuss and answer questions about the next upcoming day or evening activities. Particularly important, time was provided at the end of the tour to debrief as a group about their individual and group experiences. She shared she had to write a 20-page paper about the experience and compare and contrast what they had seen with the U.S. educational system.

Colleen expressed that from the tours she gained knowledge from the different professionals and administrators that provided information. She reflected on an issue expressed at one institution that there are students who want to come to that institution, but if there is no available housing they cannot attend. She considered that in the United 
States every possible effort is made for a student to attend a university via financial aid packages, scholarships, special loans, etc.

Colleen shared a moment of frustration that she had with the tour in South Africa. She stated that there had been a group dynamics issue. Two groups had some conflict, with not everyone on the trip behaving as professional as others. On one occasion the two groups separated and had group reflection time per university, the groups divided into Bowling Green State tour participants and Central Michigan tour participants. Because of the group dynamic situation, Colleen shared that she wished that the trip organizers had provided more opportunities for the two groups to come together and to interact with some programming beforehand during the pre-departure monthly sessions.

She shared that because of her study tour experiences she is more intentional about her travels, that she loves to travel and that she finds museums and other places to visit. She is intentional about finding the museums and making time on her trip schedules to experience something typical from the area she is touring.

\section{David}

David was a doctoral student at Florida State University when he embarked on his international study tour experience in May 2016. He worked at Florida International University following the completion of his doctoral degree in enrollment management, and now has transitioned to a new role at Florida Memorial University working with international admissions. His tour experience was part of the international component of

his international practicum program. The tour consisted of being at the London School of Economics, London City, and Oxford University. The purpose of the international tour which David shared was to obtain a worldwide perspective as it relates to student affairs 
higher education services and how these institutions were working with their student populations.

David's interest in participating in this study tour came from his past undergraduate experience. He participated in an international exchange program with the University of West Indies, located in Jamaica. He was a student leader and he was fascinated with building relationships so he was able to participate in the program while an undergraduate at Florida State University. He shared that the cultural exchange was his first introduction to international education. He shared "we got to interact with students and staff and faculty members, we got to talk about tuition academic load/courses of students." He was able to attend some classes and was able to see their dining and student living options for students.

He chose to attend the United Kingdom, "I knew that this particular opportunity was right for me" particularly the London experience because of the convenience and the ease of access to the program was well-established. David shared that the group of doctoral students was a much smaller number compared to the Master's students, and that the curriculum would be similar and yet different for the two different educational levels. The students stayed at the Florida State University Center in London and this was helpful for navigating the airline transportation.

There were at least one or two orientation sessions prior to embarking on the international study tour. There were conversations about the travel logistics including the itinerary, travel safety, and timing at each of the locations. 
David shared he wished there was more time to have conversations with administrators at the different institutions they visited. He was very engaged with those colleagues and wanted to further his understanding of the information they were sharing.

David stated he had been processing his thoughts regarding the need to do some more collaboration with other higher education institutions, some more immersion, and some more awareness programming encouraging our students to travel abroad. He shared that it could be of any length; it is just the simple exposure to something that is outside of what we know as the norm. He was sharing his thoughts and is hoping that he could provide these opportunities to others he interacts with.

David particularly appreciated that he had an opportunity while on this tour to research his roots. He shared that as a Jamaican he had historical relationships to the United Kingdom. He said that he does not have a common last name, so it was amazing to find historical reference to the name. Everywhere he saw the name in the supermarkets, the local library, passing by restaurants and knowing it to be a reference to his name. He shared that it actually helped him come to terms with his identity by seeing "the landscape" of where he came from.

Asked if the tour impacted his work, David responded that "yes, it has impacted"! He shared that the international study tour has not only increased his knowledge but it has changed the way that he interacted with family and friends. He has challenged his friends and family to increase their cultural relevancy. The problem is that some of these persons do not necessarily have sufficient knowledge, particularly since they do not know what international travel looks like or what an international experience is. He shared that he has thought about checking "his privilege" being aware that he has been given an 
opportunity to go abroad and to be a participant on this international study tour experience. He stated that the experience has reminded him to slow down in his approach and to dig deeper. He wanted to spend more time with colleagues processing the information that was being provided to them from the different institutions visited.

David stated that there were moments on the tour and particularly at some locations that the group attended that he needed to stay a little longer to further a conversation In this regard, to assimilate what he was learning he realized he had to take his time, slow down and process all of what was being presented. In terms of the study tour, this meant that he had to catch his own ride or take the train alone to get to the next destination.

David shared that after his London international study tour, he went on his own to the University of Bahamas where he met with student affairs professionals and campus life staff members. He attended and hosted workshops for their student leaders. He also mentioned that in the near future he will be going to another university in the Caribbean to establish some more systematic pipelines for student affairs in higher education to go beyond the two week immersion experience.

In summary, David shared that international study tours for him are part of professional development and that they are a worthwhile investment financially. He advocated and stated:

that there is value added and some of these professional dollars that staff are receiving to [attend conferences] rather than going to a conference stateside. 2,000 or 3,000 dollars as an investment to our practitioners... to become immersed globally and being able to spend time outside of the United States. 
Allowing more time outside of the United States than four days at a conference stateside.

International study tours are a mechanism for professional development beyond the traditional workshops that are offered through Human Resources and go beyond stateside retreats. He discussed looking at how resources are being deployed and budgeting is being done. In particular, he mentioned looking at benchmarking strategies of how student services are being incorporated. He believes that the same investment can be made for a student affairs professional to be able to travel abroad and to gain some real world experience beyond the United States. He believes that the knowledge gained by the professional through the travel would be beneficial to the institution where employed by providing new ideas for change and improvement.

\section{Jessica}

Jessica currently serves as a Hall Director at the University of Wisconsin - River Falls. She did not participate in any study abroad program as an undergraduate student. However, Jessica explained that during her first year of graduate school at Bowling Green State University she was told about the tour opportunities. Both her international study tours and her international internship were done while there studying for her masters.

For her first international tour following the completion of her first year of graduate school in May of 2016, she had two options, the United Kingdom or New Zealand. She chose New Zealand because it appealed to her more because of the amazing things she had heard about the country. Following her 3 week study tour she went to China for an international internship with New York University. The second tour 
was upon the completion of her master's degree in May of 2017 when she went on the Europe study tour once again with Bowling Green State that concluded with the Transatlantic Dialogue conference. Her options had been the European tour or South Africa; she was interested in either one. However, she became the student coordinator for the European and did not have to pay for the trip outside of fees, making it even more appealing.

In describing the New Zealand tour, Jessica stated that the group visited eight different institutions of higher education and that the locations were in urban centers as well as Maori-centered institutions similar to US tribal colleges. She shared that she had been able to meet with university administrators to discuss the programs and academic structures as well as "how their systems operated with their student demographics and some of the social justice topics and issues." Also, Jessica shared she was invited to attend a Fijian Kava Ceremony; she described it as we "sat in a circle and participated in the ceremony," she shared how meaningful it was to be invited "when I had the opportunity to participate I didn't want to say no." Jessica also shared that "there was just a lot of welcoming and openness and acceptance for those of us who were guests participating and I thought that was very special." There was also some time to visit cultural centers as well as museums depending on the city in addition to sightseeing and just being a tourist.

The European Tour consisted of France, Belgium, and Luxemburg. However, the main focus of the European study tour was the Transatlantic Dialogue conference. Jessica described the Transatlantic dialogue 
is a conference for three days where student affairs professionals from all over the world, primarily from Europe and the United States come together and it's a traditional conference style setup for the first half of the day. There were 50 educational sessions [throughout the days of the conference] with a presenter or panel discussing a title topic and educating us through the session. The second half of the day was more European style where it was really more artistic and longer sessions some of them focused on being aware of your body in space and how we move. So they are very different from traditional conference style. The participants were able to experience a conference that was not as traditional as conferences she had attended in the past, being more artistic and interpretive. Jessica was selected to serve as a participant on a panel at the Transatlantic Dialogue regarding cultural diplomacy. Her discussion points were actually about the New Zealand study tour and how it was meaningful and helped her grow in cultural diplomacy. In regard to the European portion of the study tour, there were stops at several universities to meet with the administration and to understand the roles of staff who discussed their student demographics.

Because of her study tour experiences and her international internship in China, Jessica was placed in a residence hall that is the global living community for the University of Wisconsin - River Falls as well as the primary residence of the international students on campus. She shared she has been able to relate with some of the students' experiences like finding a grocery store (she shared a story about her search for one in China). She explained that she also is intentional in making connections with the students who reside in her building, particularly the internationals, and with the 
international student services office. She believes it is important that the students know the services and resources available.

Jessica commented that the tours helped her develop patience with others. She shared that before the international study tours, she was quick to make assumptions or judgments of others. However, she now believes that she has learned to sit back and listen. She shared that she believes she would have not learned these skills if it had not been for these trips and resulting experiences. Jessica shared she is a quiet learner; she takes time to process what she learns and hears. She reflects upon what she has learned and now she looks at her encounters with a different lens because of the tours and her international internship experience. She also shared that she has gained an appreciation for the "differences." After traveling through so many places and meeting and comparing with so many people, she has realized that everyone has so much more in common with each other than differences.

Jessica shared that the study tours provided her personal growth. She shared an example of being able to be a tourist on the New Zealand tour and challenging herself to say yes to things she would have normally said no. She said a barrier was the financial cost as she was a graduate student but realized that the cost of something did not have to be a barrier. She sought out a new experience which was zip lining. She stated that because of that experience she was more willingly to try new things. Jessica also shared that she is now more willing to meet new people with different perspectives and to engage in different conversations. She realizes that is important to connect and discuss with others and not to be apprehensive about the conversations. 
Jessica declared that international study tours were professional development. Had it been just on her, she would not have gone on a trip to visit other colleges and universities. However, these trips provided her with opportunities to connect to different level professionals at the different universities. Jessica stated that she is now interested in attending other tours if possible, because it is the best way to travel.

\section{Kerry}

Kerry was a doctoral student at Bowling Green State University in May of 2016 when she attended a three week study tour to New Zealand. The international study tour focused on higher education in New Zealand, visiting numerous universities and technical colleges throughout the country. Kerry served not only as a participant, but as the student coordinator of the study tour as well. In this role, Kerry shared she had researched current trends in education of the country and helped with the logistics for the tour as well. She described it as "I was responsible for helping to facilitate the preconference travel." She now works at Cal State Long Beach, as an Assistant Director for Assessment.

Kerry shared that this was not her first international educational opportunity visiting universities; in 2010 she visited Poland on a Higher Education visit with the previous institution at which she had been employed. She shared that she only had to pay for her plane ticket to Poland. The New Zealand trip was a very similar situation and the timing of the trip had been essential to her participation. She described it as "if I would apply to be a student coordinator at the time, my trip was mostly funded, and this is a good year for this to happen.” Her interest in attending the New Zealand study tour was "curiosity and an interest to explore higher education and student affairs." As she had 
been selected to be the student coordinator, the trip's expenses were mostly covered. In preparation for the New Zealand tour, readings, presentations, and discussions were incorporated into once-a-month sessions in the semester until the trip in May. Included were pre-departure information and educational components for all those attending the trip.

For this study tour, the participants visited several different types of institutions of higher education within New Zealand, including universities, technical colleges and those considered Maori education centered. The participants also participated in Maori opening ceremonies at a few of the higher education institutions visited. A moving experience for Kerry was that at each of the universities the tour participants participated in a welcoming ceremony. She found it to be very special and meaningful. In some cases the group was introduced to a prominent sacred space, with the university building being almost an afterthought.

Kerry verbalized that this trip was a life changer for her in that she was totally present in the moment. She was totally aware of her surroundings, of the institutions she visited, and the persons with whom she was traveling. Kerry emphasized that she had to stop focusing the U.S. lens on the conversations, and really try to understand the New Zealand environment. During her interview Kerry shared that one of the highlights of the trip was visiting a Technical College. She said that

it was just amazing because that component of the tour spoke to the country's support of education and that it does not always have to be a four year degree. The Technical college is really similar to our [U.S.] community colleges that used to be about certain trades, skills, and services. The technical college was a great 
example of thinking about how higher education can produce life-long learner without necessarily having that four year bachelor's or master's degree. It was being able to see the spaces and how they are situated in the country.

She shared that the tour had made her think about her personal and professional motivations as well as becoming aware and taking an interest in whom she was spending time with and their motivations. Kerry spoke about the importance of these types of study tours for professional development, and while the trips can be costly, the experience is well worth the expense. She stressed that the experience helps you to learn and transform your approach to your work and who you are.

Kerry shared that she wishes the U.S. colleges and universities could support specific populations the way she observed and understood what administrators were doing in New Zealand. She shared "an important part of the tour was thinking about the culture, and how that [culture] in the country influences higher education" also important was understanding the "landscape of which the institutions are situated." Kerry described the landscape as "the water, land, the mountains and being able to see how closely connected the physical space of the countryside was so important and how that connected the higher education".

She discussed funding staff members to specifically work with minority and underrepresented populations. In New Zealand there were professional staff, i.e. financial aid staff, academic advisors, etc. and resources for Maori and Pacifika students. She appreciated being able to interact with the staff in her visits to each of the different higher education institutions and observing how each structured the support services. Kerry also reflected on how she realized New Zealand Student Affairs were more similar 
to the U.S. model than the student support services she observed in Poland, which were more managed by the faculty. She shared "it was a lot easier to connect higher education and student affairs and New Zealand because they've pulled in similar types of students services that we would offer in the U.S."

During the interview Kerryreflected on her current position and compared it to what she saw in New Zealand. She described one of the sacred spaces and housing options for students which were rooms to stay in overnight. Looking at the situation now a few years post trip, she reflected upon what that could mean for the students at Cal State where she currently works. She mentioned that the University of Otago was not only student-centered but also faculty-staff centered in regard to the well-being of all. This became a light bulb moment for her as she was working on her doctoral degree and the topic on mental health. She commented that she had reflected on the possibility of using some of the research she had studied but decided not to use that model in her dissertation.

Kerry professionally shared that on her New Zealand trip she attempted not to make comparisons of U.S./New Zealand residence halls and which countries are better. She had realized that this was an example of being U.S.-centric in the visiting or viewing of others. She described and asserted that if it worked for the institution they were visiting and the retention numbers are good, there is no need to judge that one system is better than the other.

She shared that currently in her assessment role at University of California Long Beach she is helping her division go through a strategic 10 year plan looking at the future. She shared that the tour experience helped her apply what she learned, but also to 
be innovative and not think inside the box. She has realized that she must look at higher education in a broader scope and visualize how it could be in 2030. She also shared that prior to the international study tour 'I didn't necessarily have that lens or thought process.” The international study tour provided her a new frame of reference.

The study also changed the way in which she views student affairs. She shared that she is not sure if we need Divisions of Student Affairs, so I think we can do our work without having to be situated with a division and it may be more effective and impactful. And so I think about that and the example of that model where [New Zealand] had liaisons in every office and I think we could extend that to just student affairs. Could we have a student affairs representative in each office. The student meets with that person who's making helping them make sense of things. It is kinda disrupting the norm and thinking about how we could really challenge the structure of student affairs.

She shared that this idea came from her time in the academic affairs and doing student affairs work in that job. She shared she is "constantly thinking about what are new ways that we can share about student affairs, how can we be good student affairs stewards in the sense of better support to the students because that is really what this is about."

The international study tour reminded her of her ideas and thoughts, and she discussed getting to know faculty. It reinforced her thoughts and ponderings she had about student affairs. 
Kerry explained that now she looks at travel as something more. She described it as "I think for me the study tour spark something more for me and think about that's an avenue to explore a country, a system, a people in a way that connects to my values." While some of her friends may see travel as wanderlust, she believes in travel as an opportunity to explore a new space, lining it up with her values of education and equity, and observing it through the lens of higher education and student affairs. She shared that she "does not want to travel just to travel", but wants to travel to "learn about education." She further stated that she does not believe all her friends and family would see travel with the same lens. She did share that she "probably actually look to go with friends who went on the study tour or go on more study tours" and believes that study tours are untapped experiences.

Kerry shared that she turned 30 while on the New Zealand study tour and it truly became a reflection year for her. She said the trip provided her an opportunity to check her assumptions about higher education and about herself. She took time to reflect on who she wanted to be with and what she wanted to study. She explained that the study tour did change the way she goes about learning and how she puts herself into situations and locations. She stated that the study tour gave her experience in and an understanding of being vulnerable, particularly traveling with 20 strangers, sharing spaces, and making meaning of how everyone else was learning. She discussed doing research and reading and shared that she took time to journal and process what she was learning. This meant that she was very aware of monitoring her actions even to the point of checking her surroundings and being aware of her assumptions. Kerry shared she does reflect on her past experiences. She did go back to her journals for this study and she reflected on her 
notes regarding each of the institutions. She realized that there were a lot of comparisons done about each institution.

While on the tour Kerry connected with as many individuals as possible. She shared part of her desire to connect came from her role as the student coordinator, but additionally she genuinely wanted to learn about the folks on the tour and what they were experiencing. Study tours let you connect with folks you may not have had the opportunity to connect with in other locations.

\section{Michelle}

Michelle was a master's student at Indiana University when she attended the New Zealand study tour in May of 2016. Michelle currently is the Director of Student Engagement and Leadership at Haverford College.

Michelle explained that as an undergraduate student she had not had the opportunity to study abroad due to her choices in her education as an undergraduate “changed my major late in my sophomore year and it wasn't an opportunity" and hoped to have the travel experience in her graduate study years. It so happened that Michelle was able to travel following her first year of her two year master's program and then was able to take advantage of a summer internship opportunity. She shared that she found out about the Bowling Green State University study tour through regular communication from her higher education program. She had received information about other tours but was interested in New Zealand.

Michelle described the pre-departure course as a hybrid class because she attended virtually from Indiana University in the spring semester. She connected with other participants as well as with the faculty member and program coordinator via the 
internet and everyone finally met in person once in New Zealand. The study tour was about 3 weeks.

Michelle described the trip as a growing trip for her; she had to manage her luggage and "managing going through airport security and customs" as well as her free time. She shared that this was the first trip that she had taken without her family. She also shared that it was learning through different methods as well as being in a different type of learning environment. It was about connecting the information to which she was exposed and learning and determining how she could apply it to the position she was in or would be in. She explained that she had to learn to best utilize her time on both her free days/down time for exploration and personal needs as well as the travel and study time shared as a group.

Being able to visit the actual institutions that were discussed in the pre-departure course was a big highlight for her as well as being able to physically tour the sites she only knew through photographs. She shared that she particularly enjoyed being able to interact with the staff and ask questions about their goals and their accomplishments.

Michelle spoke about her wish that there had been more time at the institutional locations and for the tour itself, "that if only the trip had been-just a little longer." Michelle was honest about her hesitation about the trip with individuals she did not know. She shared that as a person born in India, she has had a very different experience traveling and was nervous about the American stereotypes abroad. She shared she entered the trip cynical and critical of her peers but ended the trip renewed and with "faith in the field" and had positive interaction with peers and potential future coworkers. 
As a master's student, Michelle shared that at the time the study tour provided her with opportunities to reflect and think about the type of programming and marketing methods needed to recruit students, and it was helpful in what she was doing at the time. She actually connected with a staff member at one of the New Zealand institutions who later sent her the materials they had discussed concerning the programming process. She shared that she is holding onto those documents for the right institutional fit for that particular program to be built and further developed.

Thinking critically on the work done with students in the U.S. is something Michelle reflected on and shared, particularly when thinking about the welcoming ceremonies on the different New Zealand campuses visited. Michelle was truly impressed with how the New Zealand institutions create a sense of belonging true to the Maori culture and how they work to support the indigenous population. She described what she experienced as "the Maori traditional welcoming ceremony that they invited the families to be part of welcoming the students into the campus community." It had her reflect regarding the students of color and marginalized identities and their experiences on U.S. campuses. She explained that in her current full-time role, she is thinking about those welcoming ceremonies and how could she be able to impact the students and create something similar. She is hoping to achieve the same sense of meaningful welcome.

Michelle works with orientation currently in her professional position. She explained-that in preparation for the follow-up interview, she began to review some of the photos she had and thought about the Maori spaces and other sacred spaces she was shown on the trip. She thought about being able to process the information she had received and being able to think about adapting the ideas to what she was doing in her 
graduate assistantship. She shared that she was currently thinking critically about the spaces she could create for students. She mentioned a customs week, where the spaces could be shared not only as a space where students could see themselves in, but also as a space where the students could evolve while at the university.

Michelle shared that the tour experience reinforced the values she already carried regarding travel and being open and accepting of others. She shared that she has always been interested in new ideas. She is interested in attending future tours and the possibilities of those tours being in Asia or Africa. She is particularly interested in going somewhere

where English is not the primary language because I found working with students in higher education who are from different international backgrounds that their expectations of higher education and college are very different from what they sort of end up getting... so I'd love to see what other institutions are actually doing.

She is interested to see what the staff and universities are doing in terms of programs and in terms of student affairs. She highly encourages others to apply and attend study tours, pointing out that one meets new individuals, makes professional connections and continues to learn and evolve. The tour experience helps you "broaden your horizon" and "these kinds of programs are essential as the world of higher education evolves." She enjoyed this experience and would like to do it again with Bowling Green State University. 


\section{Nathan}

Nathan was a doctoral student and full-time professional at Central Michigan University studying higher education when he attended his first international study tour in May of 2011 visiting Hong Kong and China. His University's faculty-led tour lasted 14 days, focusing both on K-12 and university education. Nathan embarked on another 14day international tour in May of 2013, traveling to South Africa. That study tour was a combined educational opportunity between Central Michigan University and Bowling Green State University, focusing on higher education, with emphasis on visiting colleges and universities.

Nathan shared that he grew up in Indiana and had not left the state until he attended graduate school in Michigan. He explained that his undergraduate institution did not share information with students on how to participate in a study abroad program and he saw no opportunity for any international studies while an undergraduate student. Therefore, Nathan shared that he had not contemplated while in graduate school the possibility of an opportunity to study abroad. However, his doctoral program strongly emphasized the value of study abroad tours and the importance of students to have global experience. As a result, his interest in attending international study tours grew.

Nathan selected the Hong Kong and China tour partially because it was available but also because there is a Disney Land in Hong Kong, and as a huge Disney fan, he could check off the experience on his bucket list! Although perhaps an unusual basis for such a determination, it proved to be an exceptional choice for him. For the second international study tour, Nathan explained that he had always had an interest in Africa 
and particularly South Africa because of Nelson Mandela. He stated that although there were other offerings of tours, at the time these two tours were of the most interest.

Nathan shared that his trip to Hong King and China was not only his first international flight, but it was also the longest flight he had taken at the time. He added that going through Customs not only in the countries they visited but also the return to the United States was a completely new experience.

The international study tours were academic in focus prior to the trip departures, meeting once a month with classmates, discussing readings and conversations about the countries' history, and considering what to expect. The study trips included visits to universities and Kk-12 institutions (for his Hong Kong and China portion) to speak to administrators of those institutions. In South Africa the group met with students and took tours of housing facilities. In addition to the academic components, the international study tours also had tourism mixed into the schedules. Nathan described tour highlights as being able to see the Great Wall of China, the Forbidden City and visiting Kowloon Bay in Hong Kong. During the South Africa study tour they visited the cities of Johannesburg, Durban, Cape Town, but also managed a few touristy things like joining a safari.

Nathan discussed how both international study tours were transformational learning experiences for him. In particular, he shared that he fell in love with South Africa and would like to go back with his children and see the country through their eyes. Having participated in these tours, Nathan shared that he is now an ambassador for study abroad. He shares his experiences with the students in the class he teaches as well as those persons he interacts with at the university. He shared that he encourages other 
professionals to attend study tours and that he would like for others to see the world through another lens. Nathan has an interest in participating in future international study tours and visiting other countries once he has completed his doctoral degree. As he shared, he learned that you should not believe everything seen on television but must experience it for yourself.

Nathan shared that these tours were professional development for him because it shaped his understanding of what higher education is like, particularly in South Africa. The tours also influenced his global perspective. He also reflected that he was little older and a few years more seasoned in his professional career when he went to South Africa compared to his Hong Kong and China trip. He also stated that possibly the language differences of the professionals he met with influenced his reflections.

Regarding his personal development, Nathan stated that his values had not changed but that he definitely values education even more than before his study tours. He shared that he realizes that not everyone has the same opportunities, but it became more pronounced to him when visiting other countries. He shared that it was learning about the rigors of China's national exams and testing high enough to attend college, that he realized there is socioeconomic and cultural status intertwined in taking the national exams.

A question asked to Nathan was why should student affairs professionals attend any type of international study tour? He shared the following thoughts:

The personal growth and professional growth that you get, just getting another perspective and seeing how another part of the world navigates higher education. I also think it really does help you better understand international students. It is 
important that student affairs professionals get that global experience and see things through a different lens.

Professionally the trips have influenced his view of higher education and as previously mentioned, he promotes the international experience, reminding those who are interested in the student affairs professions to travel and to possibly work abroad. He also shared that he thinks a lot about the international students on campus and realizes how much they are putting on hold, or giving up, or sacrificing just to be here. He brought up the topic that international students pay more in tuition yet they may not be receiving anything more as far as resources.

Because of his tour experiences, Nathan has applied to represent his institution and to gain more professional development by being part of the Association of College and University Housing Officers International Housing Institute. He's hoping to be able to attend as the selection process is highly selective.

Nathan shared that personally the international study tour experience he participated in has also shaped his children, who at the time of the interview were ages nine and half and eleven. Because of the way he has spoken about it, they have come to share their father's experience. He shared that they talk to people about each one of his study tour countries with a confidence as if they've already been there.

In the follow-up interview with Nathan, he was directly asked if the international study tour trip was professional development. He shared that it helped him understand what higher education was like in South Africa and to some extent what primary school was like, even though they did not physically visit the many school buildings they saw as they drove by. 
As part of the concept of personal and professional development, the researcher asked about personal qualities that may have been created or are now possessed because of tour experience. Nathan shared that he is more aware of his empathy and his empathy towards others. He shared that he could not articulate a particular word to describe his thoughts, but he described his capability to speak first-hand about his experience to others. Nathan did share, however, that as a result of the tour experience, he did believe that professionally he was now more patient and understanding.

Nathan also reflected on the concept of U.S. views and spent a bit of the interview discussing how he now realizes the U.S. educational system is so different from the three countries he was able to visit. He gave the example that in South Africa, collectively the students have a strong voice in deciding upon fees and tuition and room and board rates

which is not the case in U.S. Universities. He stated that the power of the student voice is something he has reflected upon.

\section{Trisha}

Trisha was a doctoral student at Florida State University when she embarked on her international study to the United Kingdom, with particular interest in the London experience where she participated in the week study tour experience in May 2016. The tour consisted of visiting a few different higher education institutions in and around London to learn about and compare the United Kingdom University system and the United States higher education system. Trisha described the "course was structured, we has some course readings that we discussed and a big major project that we did as a group and an individual project that gave context to your experience." 
Trisha also explained the group research project as doctoral students that was a comparison project and their focus was on the Oxford student protests compared to the what was happening at Harvard University. She explained they selected the institutions because they were "comparable types of institutions and how they came about and how they handled those situations very differently." Added to their research were other institutions and the paper became about student activism and different representations at different institutions. She shared it was "really cool to see how it was either similar or different than the United States." Trisha also had participated in an international study tour to Norway and Sweden in May of 2014 where she worked on a research project in preparation to teach a course regarding gender equity. At the time of the 2014 tour she was working at a small liberal arts women's college. She currently works at the University of Denver as an Assistant Teaching Professor.

Trisha shared she had not studied abroad as an undergraduate student but wished she would have had the opportunity. However, this was not her first study tour and she referred to a study tour to Norway that she had helped lead as a staff member with the institution she had worked at prior to starting her doctoral program.

Trisha shared she is a huge proponent of travel and the opportunity to travel within her doctoral program was something she wanted to do. She learned about the possibility of the international study tours when visiting the institution regarding the doctoral program. Her philosophy is that you learn any time you travel regardless if there is curriculum associated to the travel or not. She shared she did not look into any other international study tour program; the program was accessible, and it was the only tour experience offered in the higher education program. 
Regarding the London study tour, Trisha stated that it was historically a master's student experience and this was the first year the doctoral students were invited to attend. The course is a practicum course and it is the exploration of comparing the higher education system of the United Kingdom versus that of the United States. The doctoral students used the same syllabus as the master's students but a research component was added to that of the doctoral students. The group toured all the same locations and had the same schedule. The participants met with university administrators and discussed higher education. Trisha explained the administrators held a presentation for 20 to 30 minutes as well as a tour of the facility. She explained further about the site visits:

Usually they gave us like a 20 to 30 minute presentation and the we would get a tour and we would get to talk to them [the professionals] and ask questions. It was really formal for some of places and it was really informal for other sites and we got to ask a lot of questions and get more in depth.

Trisha shared her other study tour experience traveling with students and a faculty member to Norway and Sweden as a staff member at her previous institution before going to Florida State University. She told a story of resiliency and growth as she explained how she helped navigate the group of students, assisting in their departure of the United States and arrival to their destination. The group had terrible flight connections and their initial flight out of Salt Lake City was cancelled. She described physically heading out to the airport to work through the logistics. She managed to get the students to their destinations via other routes, separating the groups of students among the faculty member and herself. She described the logistics of getting to the needed airports and cities to be able to connect with their international flight. The students were 
grateful that she navigated them through the process and she shared how much she had learned.

In terms of professional development, Trisha shared that it is professional development to attend any type of international study tour. The one she staffed helped her think about how to structure the process and the course of study. In terms of the London trip, she was a doctoral student and the trip focused on higher education and in particular, exploring higher education in a different country in a different capacity. It helped her to obtain a different global perspective. She expressed:

you always know conceptually that there are different systems of higher education in the United Sates that were pretty unique and that other than Canada and Australia, our systems are very different than other places in the world but to go and see that yourself and experience that and really learn the how's and the why's of how they decide to structure education.

Trisha shared that it was a huge developmental piece for her to learn how to structure a course in the best way, to connect research that the students read with people the students meet and places that students go. She shared that the entire experience was positive and a beneficial learning experience. She stated it was a huge professional development piece for her; she shared it made her feel a whole lot more comfortable about the future.

Because of her international study tour experiences, Trisha shared that it has increased her global perspective. She now looks at global citizenship and how she shows up in those spaces both as a faculty member and then as a student, discussing her presence and her role in higher education. She understands what it means to be perceived 
as an American, what it looks like in terms of conversations, and how as Americans we present ourselves. Trisha's philosophy is that she is not just traveling to be a tourist. She is traveling to be a learner and focused on a particular subject for the time that she is on tour. She shared that she should be expanding her knowledge in a global capacity.

Trisha also shared that she traveled to Scotland a week before the official study tour trip of London with a classmate that had never traveled abroad. She explained how she helped to facilitate some of her experiences. She shared that traveling with someone who had not been abroad was very powerful for her personally and unique tor her experience. She said that she believes it was because she had traveled so frequently and was more used to doing the unusual that it was "really cool" to be able to observe someone seeing and doing something for the first time. She shared that the trip was a powerful thing for her personally.

Trisha shared that you learn really amazing things about how things work and make connections with people that you would not have met, especially if it is a type of focused study. If you take advantage of the opportunities that the student affairs study tours provide, you are able to explore higher education done in a different way. She encourages student affairs professionals to explore being open and "to go learn in different capacities." Trisha also shared that the international study tour experience regardless you're going to grow, you're going to learn, and I think our profession that's one of our top goals is to continue learning and show that we can be role for students.. I think everybody should go if they can. Also recognizing that there are lots of different barriers to being able to access these sorts of experiences. 
She shared that she already had the values and attitude that were promoted by doing the study tour experience. Trisha believes that international study tours are part of professional development; you can have positive interactions and networking experiences with all levels of people. You can be strategic in making connections whether you are interested in facilitating your own study abroad tour or whether you are wanting to try to work internationally and trying to translate your student affairs experience.

In her current role at the University of Denver, she is interested in directing a study tour regarding leadership. She shared she would probably travel to Norway and Sweden as she has made connections there and a colleague that worked with her at Florida State University is now in Stockholm, "it is really helpful to have connections whenever you're trying to establish something in an international space." However, she would be interested in going to a non-western centric and non Northern Hemisphere space in the future as well. She shared that the study tour would look at "a different cultural perspective that's not in a space that may be as comfortable or translatable, and how does leadership look in whatever framework", it would have a leadership twist how she is currently teaching leadership development.

Because of the nature of the prior interview, Trisha shared that right after it she reflected about what she had said and thought about the study tour a bit more. In the follow-up interview she shared that she had had a positive experience on her tour and she would like to continue those opportunities.

\section{Xiomara}

Xiomara was a doctoral student in May of 2016 when she attended the week-long London international study tour with Florida State University, where she was studying. 
She was one of a handful of doctoral students who were able to attend the tour which in the past was for the masters students of Florida State University 's Higher Education program.

The participants of this international study tour stayed at the Florida State University Study Center in London. The participants visited Oxford University, the University College of London and a few other institutions. The tour highlighted student affairs in the United Kingdom. In addition to the general tour syllabus, the doctoral students were required to collaborate on a research project. They chose the topic of Activism comparing the United Kingdom and the United States. Xiomara shared her portion of the topic of Activism was regarding "tuition fees, and that was their biggest thing that students were protesting on their campus about the increased rates of tuition.

Xiomara shared that she had several reasons for attending the study tour. She had never studied abroad as an undergraduate or a master's student, and this would be her first time abroad. Also, this was the first time the study tour was being offered to doctoral students. The fact that she would be able to travel with peers and a faculty member with whom she was familiar was also a determining factor. She was also interested in the ability to choose a topic to research in the context of higher education. This international study tour also fulfilled the international education requirement for the doctoral program. Xiomara also had the opportunity to be the Teaching Assistant working with the following year's set of participants and the faculty-lead. She helped to prepare the 2017 set of students and worked with the doctoral student who attended in 2017 as well. 
Prior to the study tour the participants met in a classroom setting where they did readings and research, analyzing with both the U.S. lens and the UK lens viewpoint. The doctoral students also had a mini seminar with the faculty-lead. The participants all met for a meeting with the International Programs Office. They were also able to take tours around the city and partake in sightseeing activities. The doctoral participants had to write a paper and send it to a publication. She shared "it did not get published unfortunately." Additionally they had to create a presentation to execute-at a conference, and she shared "we did do a presentation at a conference about it."

She shared that she was nervous about being a Latina woman on the trip, particularly if she was going to be treated differently than the other participants. She shared that she came from a Puerto Rican family but she was from mainland U.S. and a U.S. citizen. She shared how it was her first time abroad, she had to set parameters with her family.

When I landed in London, I told my best friend to call my mom, just so she knows I got there safely because to her that was just definitely something very foreign. She wasn't aware if I would be safe, etc.

She had done some traveling with a classmate prior to connecting with the rest of the study tour participants. She did share happily how she had connected with a couple on the Tube (Metro) where they were speaking Spanish. Xiomara that shared that learning to navigate the cities and streets via maps while touring alone, getting lost in the process was part of the experience. The group Xiomara was with would go into coffee shops to use the Wi-Fi and connect to google maps, downloading the maps to find out where they were located. 
As a result of her study tour experiences, she shared that she now has more international news feeds on her twitter than she had before. She is more intentional about her internet usage and now is more aware of international issues being discussed in the news. She stated that the tour provided her with a greater appreciation of culture and reaching out of her comfort zone. She is exploring the possibility of one day living and working in London. She stated that she previously would have never thought about living abroad.

She shared that she speaks to her students about going abroad and that it will broaden their horizon. She encourages them to go beyond their comfort zone, telling them they will grow because of the experiences. She shares that students will learn so much about themselves.

As previously mentioned, as part of the course work the doctoral students had to write a group paper to be submitted for publication. It unfortunately did not get published. However, the group was able to present it at a conference the following year after the international tour. She explained that the peers she presented with planned a trip following their conference and she was lucky that those she went to that conference with were her travel buddies. As well as presenting the presentation topic, she was there to seek grants.

She stated that the international study tour experience has helped her build up courage. She shared that as a Latina she has come to realize that the Latino community is everywhere and she should not be afraid. She has realized there is diversity the world over and to not let that hold her back from going anywhere. Overall, she shared that she is willing to explore other places. She stated that it is important that we examine our 
institutions and compare-them with other institutions abroad and do what-we can to learn more from each other.

\section{Why Did They Attend?}

This section reviews the variety of responses; while some comments were very similar, a few were not. For many of the participants who had not traveled abroad as an undergraduate, the interest and motivation for embarking was simply having an international tour experience. For some it was the opportunity to travel to countries they had an interest in visiting. A few shared that they traveled with individuals they knew and that familiarity was enough of a deciding factor. Understanding why participants attend is important in creating the correct messaging to encourage travel as well as providing the right support for these future student affairs professionals.

From a personal perspective, the researcher first learned about the international study tour because it began the year of graduation from a masters' program at Bowling Green State University. Although unable to attend for financial reasons and timing issues the researcher was deeply interested and knew that if presented with the opportunity. Two years later in 2006, although looking at it as more of an opportunity for a meaningful vacation, the researcher attended an international study tour and found it to be impactful and much appreciated the experience. Years later in 2013 the researcher went on a second study tour again with Bowling Green State University but this time as a more seasoned professional, more focused and interested in higher education and motivated particularly by a desire for a greater understanding of how student affairs functioned outside of the United States. 
The participants shared their travel decision factors in their interviews. Conceição and Skibba (2008) stated that "many travelers participate in educational trips is to learn and experience a new place and culture" (p. 25). For example, Xiomara, traveling abroad for the first time, believed the trip would be "a good experience to at least be in an environment with my peers, with my advisor, and just learning about London and the UK with people that I know."

For David the cost of an international study tour was a determining factor since travel costs and study tour costs were separate factors. However, he knew how to navigate flights into London and once there, Florida State University had a facility they use for the tours. David also used the experience to explore some of his roots, speaking of having ties to the United Kingdom from his Jamaican family. He explored some of the history and was able to find last name ties at supermarkets and the local library which he said helped him with his self-identity. He described it as

I was able to travel during my time on this trip to the town that is my last name. I don't have necessarily a common last name and so historically finding the ties, seeing supermarkets that were named after me, seeing the local library name after me, going into restaurants that you know reference this particular account in their name. I think it actually helped in in terms of some identity and looking at a landscape of where do you come from? Where do we originate?

Nathan wanted to see Disneyland in Hong Kong and felt fortunate that the strong emphasis on study abroad of his doctoral program led to the study tour in China and his global experience. His strong respect of Nelson Mandela helped him decide on a later study tour to South Africa. 
Trisha was particularly attracted to the study tours for the professional development she hoped to obtain to enable her to assist and eventually lead international tours. She expressed that being on the tour as a student was "a huge developmental piece for me to learn how to structure a course in the best way," particularly that it was a nontraditional environment. The trip reinforced her skills so that she feels more comfortable about creating a study tour experience in her current work environment.

While some of the participants saw the study tours as a chance for an escape vacation, others saw it as so much more. Colleen expressed "you can go on vacation, but you're really not going to gain the cultural experience and educational components to travel." She believed it would be a great idea to see Hong Kong and China as a master's student and as a doctoral student visiting South Africa. She saw it as a gain in additional professional knowledge.

Michelle was a graduate student at the time she participated in the New Zealand study tour, choosing that country because she had always wanted to visit and the timing was ideal for her because she could then participate in her internship following the trip. She hoped that this one great experience would help her prepare for her second undertaking.

Kerry's interest in attending the New Zealand study tour was curiosity and an interest to explore higher education. As she had been selected to be the student coordinator, the trip's expenses were mostly covered. She also shared that the timing was right for her to take on the opportunity.

Numerous reasons were given by the participants for their desire for a group experience. Aryn described the study tour experience to South Africa as "I had some 
anxieties around traveling there [South Africa] and getting to go with a group of people made it more accessible." The ability to attend an international study tour with others helped to relieve the anxieties and to actually make the trip possible. Aryn shared that "traveling internationally was not really an opportunity that was available to me growing up" but also now "having some opportunities to do it in my adult life has been really amazing." Being able to travel "to South Africa was a place that for me I was very excited and interested in going to."

\section{What is Professional Development for Participants?}

The guiding question of this study concerned the professional and personal growth of student affairs professionals as a result of their international study tour experience.

All the participants in this study believed that the international study tour was part of their professional development. There were conversations about the costs associated with traveling abroad and a few participants shared their opinions and insights on the financial aspects of professional development. Aryn shared that she would be interested in going on another study tour but it would be a very significant decision and she would feel a huge financial burden. She shared the financial aspect of any trip could be an obstacle for many.

As a professional it feels in some ways easier but in some ways harder to spend some of the money [on a study tour], but if it were 100\% coming out of my pocket and my vacation time like that could feel significant and feel like a barrier to be doing it, but think like if it was something that I would be supported in from a profession development. My employer would be supportive of it. 
Kerry discussed the financial aspect of study tours stating that

it is a cost but want more professionals to think about study tours as one of those types of experiences it's expensive but it's an important expense if you can make it work because it helps you learn and transform your approach to your work and who you are in a way that is more essential than people will know and so, I was thinking a lot about that even in the next couple of years.

The participants spoke about professional development, alluding to their interactions with the professionals they met on the tours, hearing about other educational perspectives and observing how the other educational systems function. Trisha mentioned that it is about having a willingness to learn what you do not know and expanding oneself. As Trisha stated, she wanted to "expand my own understanding and I would say even if it is not a higher education or student affairs." She shared she travels to learn in different capacities. Colleen shared she loves to travel but because of her experiences abroad, she now adds educational components such as museums and other venues to her travel schedules. She is more aware of possibilities and researches into the areas in which she is traveling. Calvin shared he is

more excited to go and learn how others do things, the ability to visit a school here in St. Louis that is a public institution or another private institution and find out how they do things that I might be able to incorporate to improve my practices is something that I am more comfortable with.

The ability and willingness to learn from others, to be able to expand one's knowledge was discussed by participants.

Colleen shared that international study tours 
give you a different perspective of student policies and procedures that they're undertaking at their own institution because sometimes you can bring that back [policies] and you can utilize it at your own institution. You don't have to reinvent the wheel and you know taking it from that experience. You can see what they're doing over there and you can have in-depth conversations with your colleagues that you're over there [with] to really brainstorm different ideas of what you could be doing better or even maybe providing them information of what they could potentially be doing better so that cross-collaborative efforts. Experiential learning happens during international study tours and Michelle said she realized that she liked this hands-on-learning. For her, the New Zealand trip was just that. "Getting to go abroad, meet people, talk to people, very hands-on, very experiential-based, and I didn't know that about myself that I was so passionate about this kind of experiential-based learning before that [Study tour]." She would like to incorporate this way of thinking in a future doctoral program. Within the study abroad literature Franklin (2010) stated: "knowledge, skills, and self-awareness gained by studying abroad are professionally applicable in the form of intercultural competencies and personal growth" (p. 186). Growth for many of the interviewees was a common theme that was discussed in terms of student affairs and higher education. Xiomara also commented that student affairs professionals should attend international study tours because the experience can be reinvigorating. There are "points" in the career of student affairs professionals where they may feel burnt out and may question whether or not they should stay in the profession. She stated that sometimes "we are in positions that have gone stagnant." These types of trips can provide that reinvigorating stimulation that is 
needed for a professional as well as something positive that can be added to a resume. She believes it can "enhance our practice" as well as bring back useful and functional information.

Trisha shared that student affairs professionals should take the leap and that "growth does not happen unless we are in some element of discomfort." In other words, for advancement and development, you need to have cognitive dissonance. Ashely shared "personal experiences are just as valid and can even be more helpful than sometimes an article you pick up, and so I think that will be most helpful.” This is her response to why student affairs professionals should attend an international study tour.

There were several international tour participants for this study that shared they were able to connect an idea, or information shared to their home institution where they were working once returning from the tour or post in their current positions.

Michelle shared she is currently working in orientation and she thinks about the welcoming ceremonies she witnessed in New Zealand. She is looking at ways to incorporate something similar in her work. She discussed that the welcoming ceremonies would be important because

for our first-generation students they don't often have that experience, as well as our low-income students, have the same experiences with the campus community. There is often a sense of divide and nervousness around coming onto campus because they can feel differences and feel like there are feelings of lack of acceptance on the campus community. So finding ways to incorporate firstgeneration students, parents, and family support networks into campus experience is something that I'm trying to think of how we can do that kind of event working 
with Parent and Family Programs to make that an opportunity to sort of further develop bonds between the university and our first-generation students and their parents. Make the student experiences holistically better and improve their access and retention.

She also discussed being a "little more critical about how we are supporting different groups of students." She also shared she liked receiving tangible items from the different university visits because she is able to reflect and review the materials for future projects.

Kerry shared that in her work she challenges the staff she works with to "think outside the box" and provides examples of the experiences she had in New Zealand. Kerry, in particular, shared how she used her New Zealand experience to frame a conversation regarding strategic planning and having a new approach to rethinking student space. She stated "the study tour provided me that lens to not stay within the box" and "how we can be innovative and look to other countries and other models, and thinking through what are new ways we should be thinking about this." They contemplate how to solve university or job-related situations and some shared how they applied what they learned or experienced where they are currently working. Once again, the participants have found that their international tour experiences become a valuable framework for new ideas and solutions to old problems.

Colleen revealed that she had gained information on housing, which had not been a functional area in which she had ever worked. She described her experience in South Africa as feeling very "intrusive, literally walking into people's homes on a daily basis and were all very welcoming." She stated that she was surprised and very much appreciated them for being so welcoming. She learned about how the buildings are 
managed and how the systems are established. She joked that she now understands housing but she is not interested in that functional area.

Through working with underrepresented populations and advocating and encouraging students to participate in study abroad, Colleen has been able to apply her international tour experiences in her current position. She talks to her students about the rewards of international travel, describing the trips she was able to attend, and explaining how to travel economically. She spoke about showing the students the photo books she has created from her tours and provides information on short term trips as well as semester studies. She realizes that for many of her students, international study tours can be both a financial and time-restraint problem, but that some of her students have surpassed the challenge and gone abroad. As she tells them:

you can do a short trip, especially if you are parents, you have a job, you can take a couple of weeks off work, and you can have someone watch your kids as opposed to a whole semester. If you do not have the means [for a full semester] you can do that [for a short two week] trip.

Colleen explained that she has traveled with classmates and co-workers from the institution where she is employed and has been able to create a contact list of individuals with whom she can contact and reach out to when she needs to connect students with resources. She sees networking as a contact opportunity not only on a domestic network but the global network as well.

Michelle shared that she keeps in contact with several of the individuals with whom she traveled to New Zealand. She shared "we still talk on Facebook about how much we wish we can go back" but also they connect about 
what we're doing in our jobs and in our fields, we keep track of when one of us gets a promoted or we're getting new position or if someone is doing some program related to New Zealand or to study abroad, we will chat about that. It is a really strong support network.

Michelle shared it is a way to continue to talk about their experiences together.

Calvin was able to use a previously seen concept in January of 2018 at Ashland University where he was doing his graduate assistantship in housing. The University had a lack of student study spaces available. He had seen the concept in social media in a space called Engage 15 which consisted of local businesses sharing their spaces with students and creating perks, encouraging them to study. He shared the idea with some staff on the campus, suggesting the use of office spaces and local businesses as study spaces. An appeal went out to the local businesses, particularly coffee shops and a game store on Main Street, and the concept worked. The students liked studying in the spaces and shared their positive experiences, including that the coffee shop provided a discount! He shared that educational goals and business goals could align and that there was synergy.

In the fall following his trip to Europe and the Transatlantic Dialogue Conference, Calvin shared he applied a process he learned about with the students in housing he worked with. He described it as:

We had a floor disagreement, the residents [were] divided on sides [of the floor] and clicks were created very easily. They weren't getting along and there was infighting. I decided in talking with my RAs we would use some of the things I learned from that session. We had them [the residents] do a personality test 
because they are very popular for college students, and everyone wants the personality test to tell them what they are and how to improve. [The residents] had them sit down and they were given canvases and they painted the colors that went with their values that came from the personality assessment and they had a chance to talk about what that painting represented and why they think those values are so important to each other.

Calvin shared the students displayed their art pieces and were more respectful to each other. He shared he was then able to talk about his trip and say "this is working over there, that is what they are doing, this is something that would benefit us here."

Applying concepts and ideas from their international experiences was something a few of the interviewees implemented, although the results were not always as intended. She has given a lot of thought about what she can do to implement the welcoming parts to support the different groups of students on the campus she works at currently. She discussed being a "little more critical about how we are supporting different groups of students."

Ashley was able to travel with undergraduate students to the Transatlantic Dialogue conference and was happy to serve as a role model for those students because she shared "that it was their first time abroad." She was able to navigate the experience for them. Özturgut (2007) supports faculty being role models on study tours particularly to "send a positive and encouraging message to students with their instructors being rolemodels" (p. 45). Trisha's view is that "regardless you're going to grow, you're going to learn and I think that one of our top goals as a profession is to continue learning and to 
show we can be role models for students." David also shared he is a role model to students he works with. He shared that he

recognizes that the exposure to travel even down to taking overseas flight was beneficial to what I needed to be doing and facilitating conversations with my students back stateside because there are a number of students who may have traveled but may not have necessarily had an international experience.

He also shared that as a role model for students and as a student affairs professional we need to do some collaboration, some more immersion, some more awareness programming, encouraging our students to travel abroad, if not for an entire semester there are week-long experiences during spring break or other opportunities in the summertime which may not be a full summer but maybe two or three weeks. I think the simple exposure to something that is outside of the norm, I think creates a catalyst, a spark for change and will allow students to tap into a portion of themselves that they necessarily didn't see or tap into a portion of the world that they haven't necessarily seen before.

Indirectly Colleen discussed working with underrepresented populations and she shares her experiences and encourages students she works with to go abroad, particularly in short-term international trips if they are able. She provides examples from her experiences and shows photo books from her past trips. She is there to help them with the process.

\section{Themes}

For this study themes were developed from the participants interviews following the coding process. Within the development of themes, the literature guided the 
researcher, and the following themes are presented in this chapter: transformational experience; global awareness; career paths; intercultural communication; and selfgrowth.

\section{Transformational Experience}

Several participants shared that the international study tour experiences were transformational in the way they look at the world. As with the findings of the Orndorff (1998) study, "meaningful, and sometimes transformational learning took place" (p. 111). As the study has discussed, participants "became more aware of their self-worth as professionals, sensing that they were of value" (p. 104). According to Trisha, she felt more worthy because she grew from helping students travel from one location to another on a past study tour. She spoke about how the trip made her resilient and responsible, able to manage the movement of 21 students from Salt Lake City to Oslo, Norway. Being from Jamaica, Ashley had traveled there with her family, but this was the first time she traveled abroad for school and to other countries. She shared that it was an impactful experience. "Sparking an interest" is how Ashley described her feelings from her international tour. While she worked in her first job following graduate school, she explored and created an intercultural development plan. There is reflection that needs to take place and she realized "how much that experience really shaped, or like I would say, "kind of sparked all these other things which is partially why I felt so passionate about giving back." Ashley has volunteered on the planning committee for the TransAtlantic Dialogue conference as well as committed to traveling with students to the conference. "Impactful experience" was how Michelle described her international study tour

experience. It came to her when she returned to her second-year master's classes and she 
shared she would talk about it in class. She said, "I was talking about different ways I was approaching programming because of my New Zealand trip and that was when I had that moment of okay, this was truly an impactful trip and this is truly something that I would recommend other students to go on."

Kerry shared that the study tour experience was "life-changing in the sense it gave me time for me; it allowed me to have this space to really invest professionally." On the other hand, Calvin shared he enjoyed being able to connect with colleagues on his trips, especially being able to process the information learned, discussing "how does that work in our context?" and framing what he was experiencing with what he already was aware of from the course information. For many of the participants, there were several different levels of reflection. For example, there were moments of reflection occurring on the trip, more serious review post-trip, and years later realization of deeper meanings for this dissertation study. Participants commented on being able to sit down and process what had been learned with peers was key. This is in keeping with the literature, particularly Younes and Asay (2003) who stated "including meetings for group reflection were critical to their learning, not only about their areas of interest but also in learning about themselves" (p. 146).

Nathan shared his reflection of his trip experiences from Hong Kong and China and his trip to South Africa. Being able to witness and learn as much as he did was very important to him. He was honest though, that being a few years older and a couple more years matured in the profession, he perhaps more than the other participants appreciated his South Africa experience. He shared it might have been the language difference in Hong Kong and China, but he felt he was able to interact more with professionals on his 
South Africa trip. He shared that the South Africa international study tour is the one he talks about the most with others.

Nathan shared he has reflected upon the professional and social resources provided in the United States and it has changed the way he interacts with others. Xiomara explained that she had not reflected on her study tour experience until she wrote a piece for a professional association knowledge network where she shared her experience and realized the nature of what she had learned. Xiomara also expressed how important the study tour had been for her as a professional, especially as she progressed through her career. She mentioned that networking is important and having a broad experience background.

Trisha shared that because she had been asked for her responses to this dissertation study, she had begun to reflect on the international study tour. She stated "I still have a high value even for those types of experiences, even if they are short-term" and she shared that she is aware that in the literature regarding study aboard that this not always the case. She says that she continues to reflect "I really have positive experiences from it [study tour] and I would want to continue those opportunities for others." She considered the reflections to be mental notes and thoughts in her perspective.

Brandon shared his thoughts and reflections about his own undergraduate experience and imagined what his experience might have been like had he studied at one of the universities he visited on the tour. He understood that it was a limited view but he was reflecting on how fortunate he had been and how much he had grown because of the developmental theories he had learned in graduate school.

Aryn shared in a reflective moment in the interview that 
I think about how beneficial it would be at a different point in my career because I have been working in a professional role for about two and a half years, but I think about how much more depth there is to my understanding of student affairs. I think if I were to go back and do a similar experience, some of the things I would be able to take away from it would probably be much deeper than what I got from it two and a half and three and a half years ago.

She also discussed that she thinks and wonders how "we can make these opportunities more accessible beyond the graduate training aspect."

Because of the tour and the learning that took place, particularly the reflection that occurred during and post-trip, Ashley revealed that it had provided her with the space to "grow." She reflected on the trip experiences and as the time passed, she had more structure to reflect about the international aspects of the trips. As Ashely created an Intercultural Development Plan because of her current full-time position, she began to realize how much the study tour impacted her

own professional and daily work and how much it has started to impact everything that I do and most of my development in my professional life and how much it's helped me as a person be a lot more adaptable to folks who are different from me, and that I don't think I fully grasped it until maybe my second year as a full-time professional.

She shared that she has become more curious about different cultures and has increased awareness about the cultures that are present where she currently works.

As part of a transformational experience, many participants also discussed their need for exploration based on the study tour experience. For Xiomara, the exploration 
came from being a topic for a group research paper. She explored the politics of activism, comparing the actions of college students in the United States and the United Kingdom. In preparation of this paper, Xiomara had to do research on a particular topic, but more importantly for her, she had to reach out to individuals to converse about what she had found and to seek additional information. It also meant "picking up a university newspaper and looking to see if the paper reflected the topic they were working on." The team was asked to submit the paper for publishing but it was not accepted. However, she and her peers were able to present at an international conference in Belgium regarding the topic. She shared that she explored her sense of "place" on the tour. She was worried about being a Latina Woman in a foreign country and if individuals would treat her differently. Now Xiomara states that planning a trip abroad for her personal exploration will have the added component of a university. She shared "it would be really cool to learn about their makeup in terms of higher education" regarding finding other universities when one travels. From the experience of researching and working on a group paper, she said that in effect she ended up learning more about herself.

Colleen reflected upon what she had become aware of the educational systems and the different standards of living in South Africa from her interactions with students and staff. She expressed remembering a conversation about student housing and if there is no housing available, it is harder or impossible for a student to be able to attend the university. In particular, in South Africa, that student may then be "stuck at home." Attending another international tour was a possibility; Aryn discussed having an interest in learning more about China, particularly their K-12 and universities, because of the large number of Chinese students attending universities in the United States. Nathan 
shared because of his tour experience he was interested in exploring doctorate programs outside of the United States, the differences in their process.

David was asked whether the study tour experience had changed the way in which he views student affairs and his response was both positive and negative.

Student affairs is extremely important to not only the student experience but to retention and graduation. We have some opportunities to increase retention, increase engagement, increase student buy-in, increase citizenship, increase student ambassadors, increasing our marketing and our reach through more of these types of experiences [study tours]. Have students who can go abroad and gain knowledge and bring that back. We can market ourselves internationally and have students who are more interested in coming stateside here to some of our institutions.

\section{Global Awareness}

Several tour participants shared their growth in global awareness. Some admitted they were not particularly familiar with what was happening outside of the United States and attending the study tour/s has influenced their desire to learn more. These international study tours influenced their need and desire for more information and the use of social media, in particular, twitter accounts as well as other media outlets, became important sources to follow for news.

Having an understanding of what student affairs and higher education may look like outside of the United States was a topic several interviewees discussed. Xiomara shared she had gained a greater knowledge of how the higher education system of the United Kingdom functions and stated: 
I think sometimes for those that don't leave America, you don't realize how young we are as a country and so going to Oxford was wild and learning about the history of this institution that's been around for like hundreds of years and historically it was just eye-opening and knowing that there's more out there. Aryn described herself as "having a broader perspective on what our work could look like or might look like in other places."

Colleen mentioned (as did other participants) various educational topics and policies she had observed and discussed in China, such as how education is provided, if it is free or if there are fees, and how a student may continue on to college. Colleen realized that in China not everyone can go to college. The government places students "in a trajectory to go to college or to go out into the workforce" and she contrasted that policy with that of the United States and the broader access to higher education. In her discussion, Colleen expressed that study tours provide the participant with a broader outlook, stating it:

gives you a different perspective of the student policies and procedures undertaking at your own institution because sometimes you can bring back [information, policies] that you can utilize at your own institution.

Ashley expressed that her study tour to Europe had her "thinking about what was happening, not just in an American context" and that she was able to see higher education not only in the "usual American context." It helped her to reshape the possibilities as to what we do in our work" and certainly "reframed" her work. Ashley shared she did this by traveling more. She had visited several different countries and because of these travels, it has widened the way she sees the world. 
Having embarked on the international study tour experiences, several participants shared and processed their views of higher education, moving away from a U.S.-centric lens. Some shared their thoughts on U.S. higher education compared to what they had learned about at the institutions visited as well as to reflect on the resources and opportunities that are available in the United States. Some of the interviewees commented that they had a new ability to view student affairs and higher education from a new point of view.

Xiomara shared that she realized that in the United States higher education has a tendency to coddle the students. Students actually have time to figure out what they are interested in and what they would like to study. She shared that in the U.K. the structure of higher education does not follow this model and the students are guided towards careers.

The international study tour provided Trisha with the higher education focus she was searching to find; for her the trip was to broaden her higher education focus. She became immersed in having "a conversation about what is higher education?" but also a focus on leadership as her other interest.

Brandon shared that the international study tour is a really cool opportunity to put yourself outside of your comfort zone. He said that he believed it essentially forces you to take a critical look at the system in which you operate. He shared that something important that he took away from the study tours is the ability to remove himself from his immediate environment and take an outward-looking perception of the higher education system of the United States. He found the tour experience to be a powerful way to really force a new perspective and to become a stronger professional because of it. 
Colleen shared she is usually intentional in her behavior and manner. She always looks around the room and asks questions to gauge her audience when presenting to students. She tries to be aware of international students and intention in her use of inclusive language. Being able to take in information from different areas is important in student affairs. An international study tour can help develop the ability to understand how another country operates and uses its resources, which in turn can be helpful and valuable to student affairs personnel. Kerry stated she was interested in using the research studies she learned about while in New Zealand in her own dissertation study. She shared that she finally did not use the information in her thesis but she did use it as a frame of reference and a guide.

The act of traveling and the ability to go from place to place are something that many of the interviewees appreciated, particularly those who were on the European or Hong Kong and China tour because they went to several different countries on one tour. Kerry shared that "I don't want to travel just to travel and do this like a tourist experience" but "I want to learn about education and so thinking about how I would travel internationally now would probably be though that lens." Nathan stated, "it is important that student affairs professionals get that global experience and see things through a different lens."

Michelle discussed understanding the interrelatedness of the world when she explained why student affairs individuals should participate in an international study tour. For Michelle, it was "essential that as the world of higher education evolves and especially as funding decreases" one should be aware of how to maximize funds and to have student affairs professionals "think critically about the field and the future of the 
field." She expressed that having traveled, you can have ideas about how to use your resources differently. The importance is in utilizing the concepts or ideas learned from these travels.

Brandon viewed global awareness from his perspective as an educator. He stated that:

He would not call himself a global educator but at least a globally or internationally aware educator, which I think influences my practice and more an international lens per se than an individual who has not had the opportunity to travel outside of the United States that works in the field. To an extent, I would agree that there is a sort of internationalization of student affairs through folks who take advantage of opportunities to study abroad to look at systems of higher education around the globe.

Yakaboski and Perozzi (2018) state:

practitioners who have a solid understanding of the global stage and its influence in higher education can contribute meaningfully to internationalization process and dialogues taking place on their campuses, prepare themselves to operate in this challenging milieu, and prepare students to be global citizens who can incorporate intercultural inclusive practices (p. 1).

Ashley spoke about understanding global and international trends of universities and the enrollment of students who are from "everywhere" and that student affairs professionals should recognize "the context in which they are coming from to be certainly helpful." She emphasized there are a lot of universities that have a "strategy plan or mission statement about developing global citizens." However, she stated that 
she is not aware of how a student affairs professional can help to create global citizens if they have not experienced anything outside of the United States.

Kerry stated that international study tours serve as "one gateway" to understanding the international context of student affairs. She said it is "information sharing and learning from both sides" and that it is important to connect with other professionals to share ideas, resources and possibly work together. Global awareness and understanding is being able to make the connections and add to the work student affairs professionals accomplish. It is being able to give different perspectives and not having a one-way centric view. Kerry also described the institutional visits as "eye-opening of thinking through, that it is possible to rethink some of our systems and how can we may be better leverage other research and experiences from other countries." Kerry also viewed having a global perspective as an opportunity to see how "other countries are doing things far better [than the U.S.] and that we should be pulling from them [ideas, or operations]."

Kerry also shared that there are several institutions in the U.S. going abroad to open campuses. She stated it "is pivotal that there is talk about what student services look like." In the context of the interview Kerry shared she would hire someone with international tour experience, she stated:

If someone has had a study abroad or study tour experience, particularly in the context of student affairs, they are going to have been exposed even just two or three weeks. They are going to think about it from such a way that is going to help and that is the staff member I want to hire. 
Kerry, in discussing if sending staff to help open new facilities abroad because that person should be able to view student affairs and higher education with a different lens, that it is not about "this is how we do it in the U.S."

Jessica viewed international study tours as providing insight into student affairs as "you are going into a field and you know that you will be serving students from all over the world." However, it is also "important to have that perspective and be able to have experiences of what it is like being away from home, being away from what you are familiar with, what you are used to." She talked about the need to be able to relate to students and help prepare U.S. students to travel abroad. She focused on study abroad and the sharing of information with students about those experiences available.

\section{Career Paths}

Witkowsky, Mendez and Arminio (2018) stated that their study participants "were exposed to new career options outside the US, changed their perspective of their role in US higher education, expressed interest in furthering their knowledge of and exposure to new cultures and ideas, and committed to supporting campus-wide internationalization efforts" (p. 773). For this study a few of the interviewees shared that working internationally would be something they would like to explore. Some looked at it in terms of professional positions; another was interested in possibly serving in a staff role on a tour. Tucker and Weaver (2013) study reinforced that those who participated in international study tours were willing to consider opportunities that they may not have considered previously until this experience. Ashley was willing to explore possible international employment positions and said if it was "the right position and a good salary, I would accept in a heartbeat." Because of her study tour, Xiomara is also 
interested in researching and possibly applying for international job opportunities.

Nathan discussed an interest in serving as a mentor for a professional association and be able to participate in a professional exchange to South Africa, for which at the time of the interview he had applied.

While David was being interviewed for this dissertation study, he stated that he was looking forward to working in international admissions which he is transitioning to as part of his new partnership with a university in the Caribbean. He shared that he had begun to review notes from his trip regarding organizations, affiliations, and partnerships. Other interviewees also shared their interest in applying for positions abroad, possibly working for an American university with a satellite campus.

For Trisha, international study tours were an opportunity to review and to connect with the notion of leading a tour herself in her current role at the University of Denver. She shared she is particularly interested in leading a tour to Belize, but she also shared she is interested in leading a study tour to Norway and Sweden relating to the topic of leadership currently her focus at work.

After her experience in Luxemburg at the Transatlantic Dialogue Conference, where she was a presenter and had a taste of helping with the conference as a transcriber of an educational session, Ashley was able to find employment (post-graduation from her master's program) using this experience. As part of her current full-time position, she was able to connect with the Transatlantic Dialogue Conference again. She was able to travel with six undergraduate students to the Conference, as well as being part of the planning committee for the 2017 Conference. She shared that she is fortunate to have an employer who is supportive of her plans to introduce to her students a chance for 
beneficial international travel and an opportunity to attend an impacting conference. She currently serves on the 2020 planning committee and is very engaged in ensuring that once again the Transatlantic Dialogue Conference will be successful.

As a result of an international tour, professionals may develop an interest in particular topics to research or learn more about, even if not a direct part of their functional area or direct work. Nathan shared that he is interested in understanding the masters' and doctoral degrees in other countries, particularly the process in South Africa because of the conversations he had with individuals. Colleen shared she liked marketing and helping students gain awareness of AIDS in South Africa. She shared possibly using the awareness pieces she saw and combining those concepts together with other marketing efforts topics like Mental Health and/or other student issues to the United States.

Because of the international tour, Ashley became interested in learning more about multicultural programming. She shared that being aware of the historical context of a country is important. During her tour, she shared there was a lot of discussion about social justice in Europe. She chose a job after graduate school in housing but the department was committed to teaching cultural competency. She applied for a position to continue her work within residence life while allowing her to continue teaching and advancing cultural competency education.

Colleen reported the South Africa tour as having a lot of housing components, particularly housing tours. She wished that the tour participants could have "seen more of the institutions" and could have taken "a leisurely stroll through campuses." However, 
because of the schedule, many of the planned activities were very structured and did not allow for deviation from the planned itinerary.

\section{Intercultural Communication}

Participants within this study shared and discussed how they handled variations of intercultural communication following their study tour. The definition used for this study is "the ability to behave effectively and appropriately in interacting across cultures" (Martin \& Nakayama, 2010, p. 47).

Aryn described how she has changed the way she discusses social justice issues since her trip to South Africa. It has provided her the push to become involved in social justice issues and to research other opportunities to further evolve her approach and thoughts related to social justice. Xiomara also shared that she had modified her language usage because of her tour experiences.

Calvin enjoyed having dialogue and conversations with his peers and with the international colleagues he met on the international study tours. He pointed out that the usage of particular words or vocabulary in regard to higher education were sometimes different in the United States compared with the United Kingdom or European higher education. It was important to be aware of the differences to understand what the professionals were really discussing. He provided the following example to illustrate the

differences. In the United States, "socio-economic status" is referred to often in higher education while in the United Kingdom the conversations and descriptions revolve around "class status." He said that "it was interesting to see that there were similar desires for impacts with two different paths for how they would accomplish those" referring to working with college students. 
For others, there had been problems with the organization of the groups or the group dynamics. Colleen spoke of a group dynamics situation while on her tour to South Africa. She explained that sometimes when groups are brought together some individuals were more professional than others and that caused the conflict amongst all of us. Everybody noticed it [and] at the end of week one everybody was getting on everybody's nerves and at one point we said we need to be debriefed separately.

The separate debriefings provided her group a chance to vent about the issues being faced and come up with a solution to their frustrations. Even in a negative experience, providing these moments of reflection and providing moments for conversation are important to process what is being experienced. Younes and Asay (2003) supports and "suggested that including meetings for group reflection were critical to their learning, not only about their areas of interest but also in learning about themselves" (p. 146).

In keeping with group dynamics issues, Kerry, as the student coordinator for the New Zealand tour, reported that she was always aware that there could be group dynamic issues. Calvin also expressed that during his tour there had been some moments of "drama or pettiness or disagreements" but also there were "breakdown in communication and people had frustrations." When traveling with large groups of individuals with different personalities and priorities, disagreements or moments of frustration can happen. However, it is how the groups and individuals react during those moments that determine the effect on the group. The moments of frustration did provide learning opportunities in interacting with others. 


\section{Self-Growth}

Developing new skills was a common theme of the participants, such as navigating public transportation, becoming familiar with "how to travel" and what to bring. For a few, it was the growth of confidence in their ability to manage travel to other countries in the future.

Ashley explained that her traveling has increased since she went on her study tour. She has gone to the Bahamas and Jamaica, and at the time of the interview, she was planning on visiting Honduras, Belize, and Mexico. She expressed her desire to continue traveling and she has been pushing her friends to travel more as well. She commented that

it was so foreign to say 'like I'm gonna go to Europe' and like just travel through Europe.... that seemed like such a scary idea because this is a big thing that we talked about that looks cool, but I've never been outside the United States except for Jamaica, so it just didn't seem feasible.

These sentiments were true of a few other interviewees. Ashley described it as "practical confidence" and "understanding and navigating the various different kinds of languages as well as like money." The study tour participants expressed the need to be aware of their surroundings not only in terms of location but also in the social and educational environment.

Ashley further discussed how international study tours can teach some real-world lessons. She shared that one learns about "booking hotels, learning how to be safe abroad, navigating going from country to country, and the different kinds of visas or travel documents or travel options and methods that we do not necessarily always have in 
an American context." She stated that as a member of the Transatlantic Dialogue planning committee, she had to coordinate her own travel for their meeting.

Some of the aptitudes the interviewees shared that they had learned from their international study tour experience, especially being on a tour with a large group of participants with different personalities, were the important soft skills such as patience, especially in learning to work with others. Calvin described as a "low light" of his European international study tour a van ride from France to Belgium. Particularly it stated:

We had a very small van and a lot of stuff and the AC was not working and people [those on the trip] were just hot and frustrated and I think some of those frustrations carried over to the rest of the day. Because of the temperatures no one wanted to talk to each other and it cut down on the amount of time you could actually process [what had been experienced earlier] or converse with individuals. Being hot and tired and just really needing a break from people, it was a hard time to engage when the group stopped at locations.

A few of the interviewees shared that the international tours were with peers or friends from their educational program, either masters or doctoral. Aryn spoke of having peers on the trip who "may have had different goals of what they were hoping to get out of the experience was sometimes challenging."

For others came the challenge and a willingness to try new things. Calvin and Jessica shared their willingness to try new food. Jessica also stated that her growth came from saying "yes" to new adventures, in particular, she described an opportunity to go zip lining in New Zealand. She described it as "I really challenge myself to just say yes to a 
lot of things I wouldn't normally say yes to" and she stated she is now "more willing to try new things and new experiences." Jessica also explained that is she is now open to meeting new people and has become more comfortable "engaging in conversations about global perspective, diversity, inclusion; those types of things are not as high risk for me because I feel comfortable having conversations about differences because I have had my experience abroad."

Travel is an opportunity for growth and in this study, Xiomara shared in her interview. Xiomara expressed that her trip to the United Kingdom was her first international trip abroad and it was an opportunity for personal growth, stating that she learned about herself and that the trip provided her now with confidence to travel. Speaking in regard to the personal development aspect, Xiomara stated she was happy to share that because of her study tour experience she would like to travel more and would like to go to Spain and Italy. She shared that because of the tour, she is open to more opportunities and experiences, not just travel, and that she has a greater appreciation for "some of the things we have" and "our country is not just the end all be all." She then shared that there are other places to go and that there "are other things happening in other countries" referring to the news, politics, and other cultural conversations. Because of her experience, she adds more news feeds to her twitter account, particularly international news. Xiomara story fits into Boyatzis (1995) explanation that "people learn most effectively when they are in control of the learning process and can choose developmental activities best suited to their personal situation" (p. 51).

There were several participants that shared that they were role modeling travel and other opportunities for peers and family. Xiomara shared that she hopes to be a good 
role model for her nieces and nephews. She wants them to know that it is okay to step outside of one's comfort zone; she said to "go somewhere different, try something new." She also commented that her family is very much invested in her life and needs to know that she wants to "keep exploring." She wants to travel more and she does not "want to move back to Chicago and work."

Calvin served as a role model for the family regarding travel. He discussed sharing with his family about his international travels, particularly siblings who are planning on going abroad and had questions about passports, so he shared, that his experience abroad gave him "navigational capital" and he can share the information he learned with them. He has become a resource to his cousins as well who would like to have similar experiences.

Xiomara also shared that she hoped to be a role model for her family regarding travel and being exposed to the world. Xiomara expressed it as:

I hope that I role model the behavior that my nieces and nephews can take in and how I've been the type of person just to step out of their comfort zone, go somewhere different, try something new and showed my family how invested I am in my life and how I want to take the time to see the world especially in the age that I am now.

Xiomara also shared because of some cultural norms she is helping her family understand her process academically.

David has served as a role model for his family. He shared with me that the international study tour has provided him with cultural relevancy. He shared that it has changed the way he interacts with his family and friends. He said "because some do not 
necessarily have the knowledge base about what international travel looks like", but because of his tour experience, he has gained those skills. He shared as a black male "we do not travel a lot or at least that's the narrative that is portrayed" and he let me know that he "studied before going overseas and that he learned about the institutions to help frame the institutions stateside." He shared he has conversations with his family members and friends about their "desires to go abroad" and he helps so that they "can gain their knowledge base."

Xiomara shared that frustration with the schedule but also with herself. She shared:

I wasn't as privy to doing everything or going on excursions on my own and I regret that because of where the study center was located, right by the British Museum, literally two blocks away. Also in terms of scheduling we were so packed like the whole day, we would leave at eight in the morning, we wouldn't come back until five or six in the evening. You are just exhausted, you walk everywhere and take the tube. So when it was six or seven I was too exhausted to do anything else while all my other friends went out and did stuff, so I wish I had more time and stamina to actually enjoy the city.

Sometimes scheduling and activities were in the hands of the participants which enabled them to be able to explore the cities and locations to which they were exposed.

Xiomara shared about the self-perception of her identity as a Latina woman traveling to the United Kingdom. This aspect was not part of the research study but her views of how she felt she may be or would be perceived created a slight negative to her international tour experience. Xiomara shared she had gone to Scotland prior to 
connecting with the London tour experience. She traveled with a classmate and expressed:

So when we were in Scotland I had incidences where I perceive that my friend who I was with, as a white woman was treated better than me and that kinda freaked me out. I'm privileged that I didn't have any direct incidences of that.

She shared:

I was worried as a Latina woman to be in this country [United Kingdom] and like I don't know if people are gonna look at me sideways, if they're gonna respect me. So I carried that experience with me to London.

\section{Experiential Learning Theory}

For this study, Kolb's Experiential Learning Theory provided the conceptual framework to understand the data collected as well as the experiences interviewees have experienced. Several interviewees (Michelle, Calvin, Jessica) described taking learning into their own hands, which meant they controlled their experiences and what they were learning. Ashley described herself as a doer.

I learn best by actually doing and experiencing so the study tour for me fit my learning style because I did not have to sit in a room and learn about Europe but I also got to be in Europe and explore it hands-on engage with people and by doing that [speaking with people] was just a lot more effective [for my learning style] but did not necessarily change my [learning] style.

Several described their learning as about new food, willingness to try new food, obtaining new information that could be used in their current or future positions, as well as looking at new opportunities such as international employment (Xiomara, Ashely). 
Several interviewees shared that their learning occurred during moments they were not expecting, Ashley in the case of getting lost and not wanting to ask for directions, Xiomara exploring future possibilities of work outside the United States, Trisha realizing that she could lead a study tour and help students get to their destination even with travel delays and cancellations. Working through coding, reviewing journal notes, and transcripts from the interviews conducted, the researcher understood what is "meant to be a continuing spiral where the learning achieved from new knowledge gained is formulated into a prediction for the next concrete experience" (Montrose, 2002, p. 6). Other participants shared their realization of removing the U.S.-centric lens to how they were approaching international education which was the information shared about higher education may be unlike the United States. As Montrose stated, "stepping back from the experience and noticing difference, comparing and contrasting what is familiar with experiences that are new" $(2002$, p.6). There was questioning by Trisha about the U.S. educational system compared to the educational system in the United Kingdom, questioning whose was more effective. The learning continued during and after the international study tour trip concluded. There were several interviewees who articulated the need to continue learning and applying what they had experienced and learned.

Experiential learning is supported by the international study tour and Michelle said she realized that she liked this hands-on-learning. For her, the New Zealand trip was just that. "Getting to go abroad, meet people, talk to people, very hands-on, very experiential-based, and I didn't know that about myself that I was so passionate about this kind of experiential-based learning before that [study tour]." She would like to incorporate this way of thinking in a future doctoral program. 


\section{Summary}

This chapter presented the findings related to the research question, "In what ways do student affairs administrators involved in international study tours perceive their experiences as furthering their personal or professional development?" Participant profiles were introduced to have a clear understanding of those involved in the study.

Participants provided responses to questions regarding their tour experiences, including why they attended the tour they chose, whether they perceived changes in their values, the ways in which they interacted with peers and friends on the study tour, and if the study tour impacted the way in which they view student affairs. Participants were also asked if these study tours are professional development in their opinion and with resounding support, the participants articulated that international study tours are professional development. For several participants, the opportunity to go abroad was a reason to attend a study tour.

The 12 participants provided insight that was helpful to understand the international study tour experience. The themes that emerged provided an understanding of the impact international study tours have on professional and personal development. The themes that emerged from the study were: transformational experience; global awareness; career paths; intercultural communication; and self-growth. 


\section{CHAPTER V}

\section{CONCLUSION}

\section{Summary of Study}

The purpose of this study was to gain an understanding and insight of the role that international study tour experiences has on the professional and personal development of student affairs professionals. This study was conducted to fill the gap in the literature regarding student affairs professionals' reflections on the value of international study tours on their professional and personal development.

The researcher interviewed participants who attended an international study tour sponsored by Bowling Green State University (BGSU), Central Michigan University (CMU) or Miami University which host tours that are two weeks in length or Florida State University (FSU) which hosts an international study tour of a one-week duration. Those interviewed were asked about their international study tour experience and demographic information about their tour. In addition, they shared information about their pre-departure education sessions, which country or countries were visited, any educational components required for their courses, and any required readings, papers or presentations. Participants willingly shared information about what they learned from their tour as well as their view of higher education and student affairs.

In this chapter, the researcher discusses the implications and provides conclusions about the findings of this study.

\section{Review of the Study}

This study was developed to understand the ways in which international study tours contribute to student affairs professionals' personal and/or professional 
development. This area has not been explored in the study abroad literature which mostly focuses on undergraduate students' development and growth, graduate student development and growth, and faculty professional growth. The results of this research may inform student affairs professionals and decision-makers of the importance of participation in international study tours in terms of professional and personal growth and development.

Interviews were conducted via gotomeeting.com with twelve participants who were student affairs professionals who had previously attended a one-week to three-week international study tour. A semi-structured interview process was used to be able to obtain rich data. Participants were asked a succession of questions to obtain an understanding of as many aspects of their international study tour experience as possible. Member checking was conducted with each interviewee to ensure accurate transcript information and each interviewee was provided copies of his/her transcript for review. The researcher used journaling as a means of validity for the study. This journal served as an instant source of reflective material, allowing the researcher to recall and review the participants' conversations and statements. These reflections revealed possible areas in need of clarification and a reframing of questions for the follow-up interview to capture explanations and additional thoughts.

\section{Research Question}

This qualitative research study addressed the gap in the body of literature, seeking to gain an understanding of and insight into the role that international study tour experiences have on the personal and professional development of student affairs professionals. The research question for this study was: 
In what ways do student affairs administrators involved in international study tours perceive their experiences as furthering their personal or professional development?

\section{Revisiting Experiential Learning Theory}

Kolb's Experiential Learning Theory, which is learning from doing, particularly learning from experience (Kolb, 1984), served as the conceptual framework to explain the type of learning described by international study tour participants. The theory has four specific learning styles and a four-step cycle of learning that includes opportunities for experiencing, reflecting, thinking, and acting based on an experience or opportunity. Knowledge is created through initial experiences, followed by reflections, thoughtful development and eventually alterations of experiences (Kolb, 1984).

The findings of this study support Kolb's experiential learning theory. They add to other studies that use experiential learning theory as a framework and establish an explanatory theory to support international study tours as professional and personal development of participants. In support of Kolb's experiential learning theory (1984), participants learned from the pre-departure information sessions and from the institutional visits as concrete experiences. Reflective observations of the international study tours were obtained from the journal entries and random moments of reflections as well as group discussions. Abstract conceptualization was derived from applying lessons learned to their own professional positions or institutions of employment and finally, active experimentation consisted of the actual implementation of the lessons or ideas learned.

This section expands on and discusses each of the points of the theory. Participants in this study often discussed within their examples of their tours their own 
experiential learning that took place within the international study tour. Participants reflected on their international study tours by sharing that their institutional visit information included opportunities to connect with other professionals and a chance to learn about programs or develop an understanding that these professionals were dealing with similar issues or concerns as students. For some of the participants, the favorite part of the tour was the opportunity to take time to speak with professionals at an institution and make arrangements to continue the conversations at a later time. The participants believed that these visits provided a deeper understanding and connecting of the information learned in their pre-departure sessions and gave more context and support to the materials such as readings, presentations, and information shared as background for these institutional visits. For some of the participants traveling abroad was a first time experience. They spoke about how the whole travel experience - from learning to navigate the whole travel process including visas and passport applications and airline travel, to the actual arrival to the study tour country(ies) - was all was part of their personal development.

With respect to reflective observations, participants shared their thoughts about how important it was to process the information they were learning during their actual international study tour. There was a need for reflection with their peers as well as for the moments for personal reflection which had been scheduled during the tours. The participants shared that at times they had needed to process what they had observed and connect it with the pre-departure information previously received. Even at times when there was group discussion regarding personalities, the reflection time was needed to process the feelings resulting from said dialogue. The reflection process was not limited 
to the educational components of the international study tours, but also there was a need for reflection regarding personal growth.

The abstract conceptualization for the participants involved the subsequent application of the lessons learned on the tour to their own professional positions or institutions at home. Several participants shared that their views of higher education had shifted or were now more questionable because of the international study tour. They also pointed out (if they were master's students) that they were more willing to share information in their classes, as well as provide context to others regarding international study tours.

Regarding active experimentation, several participants described their implementation of an idea from start to finish following their international study tour, and their joy at having been able to see their idea unfold and be successful. Other participants expressed their sense of personal development as a new sense of independence and a willingness to travel internationally. They are interested in traveling with others and feel confident that they are now able to do so.

The researcher proposes that the findings in this study makes a case that Kolb's experiential learning theory is applicable in terms of international study tours and the personal and professional development of student affairs professionals who participate in international study tours. This study adds to the studies which use Kolb's experiential learning theory to solidify the impact of these tours on professionals.

This study also has implications for furthering the use of Kolb's experiential learning theory in support of international study tours. The findings relating to how the participants professionally and personally developed from their experiences supports this 
theory. Several participants discussed examples of their learning from doing. One participant stated, "the whole tour is experiential learning." For many participants the personal development was reflected in their observations about the challenge of new food and the willingness to try new food. For others it was going abroad, meeting new people, and learning to travel with others. Getting lost and figuring out how to navigate a different city was the valuable learning experience for other participants. For some members of the tour, the experiential learning came from the institutional tours and the opportunities to have conversations with other student affairs professionals who are doing similar work. The sharing of ideas among the participants, and being able to connect in reality with the information researched prior to arriving at their destination also contributed to personal and professional development,

As part of this theory, reflection is an important piece. Within the international study tours, there was time set for reflection and participants were encouraged to journal and keep notes of their experiences. Several participants shared their happiness about having time to reflect either alone or within the groups with whom they were traveling. Some participants shared that they continue to reflect on their experiences because of the international study tour and even though it is not daily, there are times they think back about those travels.

As part of the international study tours group, discussion was also programmed into the schedule and several participants shared how they enjoyed that time of reflection. Being able to speak to others about what they had learned as well as being able to process what they may not have understood and just being able to process general thoughts with the other participants became an important part of the study trip. 


\section{Perceptions of International Study Tours}

In this study, all the participants stated that their international study tour experience provided them with professional and personal development that has influenced their lives. Several participants who stated that they have been shaped professionally by the tour experience, reflected upon what they had learned while on their tour.

The personal development expressed by participants were mostly soft skills with several stating they had learned how to travel. In particular being aware of their surroundings and learning how to communicate and travel with others with whom they are were not familiar, was considered personal growth and self-acknowledgment.

As part of the international tour experience, participants were able to not only visit educational facilities but also have leisure time to explore the cities, towns, and tourist locations within the countries visited. Participants involved in international study tours gained new perspectives, new cultures, and new experiences. Traveling can influence the development of the personal character of participants (Roberson, 2003). While the participants may not be able to completely remember the museums, or the sites visited, participants do keep "authentic learning about self, trust, home and the world" (p. 138). This learning takes place because of the educational scope and design of the instructional nature of international study tours.

Within the tour and post-tour, several participants shared that the tour provided them with opportunities to reflect on their experience. As Conceição and Skibba (2008) state "it is important to allow time for participants to share their experiences with each other and also reflect on their personal experiences" (p. 28). 


\section{Furthering Professional and Personal Development}

This study addressed the outcomes of the research question regarding in what ways student affairs administrators involved in international study tours perceive their experiences as furthering their personal or professional development. From the interviews and analysis of the data, it was clear that the international study tours were perceived as furthering their personal as well as professional development. There was excitement from many of the participants regarding their tour experiences and being able to articulate what they had learned. Several participants shared they learned more about themselves because of these tours.

Responses to this research question were answered through the following themes: transformational experiences; global awareness; intercultural communication; career paths; and, self-growth. Global awareness, intercultural communication, career paths, and self-growth were themes supported by the literature.

\section{Transformational Experiences}

International Study tour participants believed that the tour experiences were meaningful and impactful on their views of higher education as well as student affairs. Being able to travel with peers with similar interests provided participants an opportunity to connect and exchange ideas, as well as taking the time to reflect on the information gathered and shared, and then to review what was being learned. Understanding higher education and student affairs was common in this theme as well as the possibility of attending future tours. During the interviews, the researcher learned about the interest of participants regarding different topics within higher education and student affairs. 


\section{Global Awareness}

From the interviews the researcher gleaned information from the participants which revealed that several of them were not familiar with what was happening outside of the United States until after their involvement in an international study tour. Several participants shared that because of their experiences they now have a broader perspective of their work within student affairs. Participants shared their realization that they had to remove a U.S.-centric lens from their way of looking at the world. This finding is supported by the study of Jessup-Anger (2008) which emphasized participants reconsider the framework in which they view the world. Several participants attended the international study tour to gain more perspective regarding higher education. Kruger and Dungy (1999) support student affairs professionals attending abroad programs to gain global awareness within student affairs. For some participants, an expansion in global awareness meant an increased interest in the international news and an understanding of

what is happening in the world around them. This finding is similar to that of Younes and Asay (2003), whose research on international study experiences of college students highlights intentional and incidental learning, and who found that the international study experiences led to life-changing experiences and provided context and content for participants.

\section{Career Paths}

Several participants shared their interest in furthering their careers within student affairs either internationally or domestically because of their international study tour. Witkowsky, Mendez, and Arminio (2018) and Tucker and Weaver (2013) support the findings regarding participants furthering their interests in exploring other career 
opportunities because of their tour experience. There was an interest from several participants that the possibility to work internationally was something they would be willing to explore. During the tours participants were able to be involved in open conversations, asking questions that they were then able to process and exchanging relevant information. A few participants shared that after the international study tour, they were able to continue their study tour experience by serving as an ambassador for the programs, sharing information with colleagues and with undergraduate students, encouraging study abroad - short-term and long-term, as well as volunteering to be part of other tours.

\section{Intercultural Communication}

Within intercultural communication, several participants shared their appreciation for being able to create a network of student affairs professionals, with those with whom they attended the international study tours as well as a network of international colleagues with whom they would be able to share ideas and resources once they returned to the United States. Forsey, Broomhall, and Davis (2012) supports participants developing confidence from their abroad experience particularly in the form of communication. Because of the international study tour a few participants shared that they are more confident in sharing the information they gained from the tour but also feel comfortable with terminology, word usage, and educational themes. Clarke et al., (2009) supports participants being more proficient and comfortable with intercultural communication after having participated in a study abroad program. Participants also shared their frustration with their peers while on the tour regarding group dynamics and 
the need for reflection to take place separately because of personal interactions and conversations.

\section{Self-Growth}

For several participants, the international study tour provided them with the confidence to travel more, particularly internationally because for several participants the tour was their first time abroad. The new ability to navigate customs, long flights, managing money, and public transportation was commonly acknowledged among participants as personal growth and development. For others self-growth was the realization that all the travel and educational observations along with the resulting thought processing made them see that travel was a great opportunity to learn. Travel “especially when designed to be a learning activity, can foster personal enrichment and development of lifelong learning skills" (Dapko, 2016, p. 16). In keeping with personal development, several participants shared their willingness to try new things and to be open to explore, such as choosing new food options or zip-lining, and a willingness to investigate other options and new ideas.

\section{Limitations}

Initially, the limitation on this study was the similarity of the participants in terms of the years in professional service and the university study tour they attended. Eventually, more participants and universities were added to become more diverse creating the profile of: Bowling Green State University (BGSU) 6 interviewees, Central Michigan University (CMU) 2 interviewees, Miami University 1 interviewee, and Florida State University (FSU) 3 interviewees. FSU's study tour was a week in length compared to BGSU, CMU, and Miami University. The tour participants were from different years 
of travel as well as a number of years post international study tours. Not all participants traveled to the same country or countries but all attended a similar tour set up. There were a few participants interviewed who did not attend BGSU as students but were participants of the study tour coordinated by BGSU.

Each of the study tour participants who were interviewed attended international study tours that lasted from one week to two weeks in length. The study tours predeparture sessions were all very different, some used technology to connect tour participants with each other and some were only held on the participants' campus; all those interviewed discussed having readings and assignments, but the reflection pieces and assignments all varied. In addition, the type of reading materials varied for participants. Some expressed they were given group projects or were assigned research projects. The type of preparation provided for the participants of study tours were all different yet from the interviews, it was determined that each participant was prepared for the experience.

Another limitation of the study was that the researcher had participated in several of the study tours and was familiar with the tour and the experiences that many of the participants described. In addition, the researcher knew a few participants, having traveled with them on their trips. However the researcher was careful to be as objective as possible during the interviews and follow-up interviews. Notes were maintained during the interviews to review and to ensure the researcher understood the message the interviewees were expressing. The questions were open-ended and were created to ensure the participants could discuss their experience openly and honestly. 
A limitation of the study was that the interviews were conducted by

gotomeeting.com rather than in person. There was a video feature available but only two participants used it to connect face to face. The use of technology was necessary during the study because of the locations of the participants who were all over the country, between several states and time zones. Being mindful of the limitation of not being physically in the same space, there was an effort to make every interviewee have a personal experience. All correspondence was personalized, each gotomeeting.com link had their name, and every participant received a thank you email for participating after the interviews and the review of the transcripts. Some of the interviewees were timely in their responses to schedule a follow-up interview or to review and comment on their transcript.

Another limitation in this study was that while those interviewed applied ideas and programs to their current positions, not all of those who attended international study tours were employed in full-time positions. A few participants were in graduate programs when they first attended their international study tours. Many participants shared that it had taken them some time to grasp their experience and be able to share ideas or connect together the information they had learned. This is supported by the research of Tucker and Weaver (2013) which stated that participants "may not appreciate the full impact of participation in such study tours until they have entered the workforce" (p. 12). The number of years in the profession does have a significant impact on how professionals may process the information and ideas that were shared on the tour experiences. There were some who were able to apply an idea to a current position but 
from the interviews obtained, there were a few who are thinking about implementing an idea but have yet not been able to put into practice those thoughts or ideas.

Another limitation was the manner of reflection participants had taken in response to their trips. Some participants spoke of reflecting upon their experiences but that it is not something they do on a regular basis and that it may only occur in response to a particular situation. They shared that their reflection is not in a formalized occurrence, but they do believe it is something they do periodically. For several of the participants, the reflection occurred years post-trip and it was not until they were in full-time positions and a particular flashback situation. This is supported by Pond (2017) who stated that "critical reflection post-tour is necessary for students to reflect holistically on the tour experience to process the learning and construct a more integrated interpretation and understanding of the experience" (p. 166). For a few others, the reflection began to occur during the interview for this study.

\section{Recommendations for Future Research}

This study focused on the experiences of twelve past international study tour participants. The findings of the research study support that student affairs professionals perceive their experiences as furthering their personal and professional development. The participants shared their experiences and development through five themes: transformational experience; global awareness; career paths; intercultural communication; and self-growth.

More research needs to be conducted regarding international study tours as professional development. This study adds to the limited research advocating for professors to teach/lead study tours as professional development (Moseley, 2009, Evans 
et al., 2008, Koernig, 2007, Festervand \& Tillery, 2001, Immarino \& O'Rourke, 1999, Sandgren et al., 1999). Currently there is little research available specifically relating to Student Affairs. Chronister (2017) focused on intercultural competence as a professional disposition of student affairs professionals who attended study abroad programs as undergraduate or graduate students. This research study can help to advocate for professionals to attend international study tours to gain new perspectives and grow as professionals. Being able to add to the research would also provide incentives for universities to encourage mid-level professionals to attend study tours.

More research observing study tour travelers may help to create a reflection protocol and provide opportunities for the emergence of concepts and ideas they have learned. From this study, a few of the participants shared that the ideas and processing of what they experienced did not happen right away; that it took a few months to possibly a year to apply what they had learned. This reflection is key as it may take some time for professionals be able to articulate what it is that they had learned. This is in keeping with the research of Sherlock and Morgan stating travel "can shape a person, but taking a much deeper, reflective view of the experiences allows for more valuable meaning and development opportunities" (2005, p. 143). Particularly if a student affairs professional journals while on their journey and documents "an analysis of the people and culture of the country visited" (Iammarino \&O'Rourke, 1999, p. 171) they have a deeper realization of their travels.

In keeping with the research of DeMello (2011), it is important that those who participate in international study tours share their experiences. Several of the participants discussed sharing about the trips with colleagues, friends, and family. DeMello states: 
Students, colleagues, parents, and community organizations can all benefit for the knowledge, skills, and perspective acquired through the study tour experience. Yet, this is important not only for the audience, but also for the presenter because sharing affords the study tour participant with additional opportunities for reflection during both the preparation and presentation of the experience. As educators share their study tour experience, they relive their visit, and therefore continue to rethink their view and perceptions (2011, p. 182).

Being able to reflect and to share the knowledge to further ideas, student affairs personnel can entice and encourage other professionals to embark on a similar educational journey.

In regard to more research to further this study and expand on the experiences, those who attended the study tours would need to be available to be interviewed. Providing an alumni support or connection network for those who have attended international study tours and being able to reach out to others would enable greater research as well as helping to advocate for international study tours. Some of the participants in this study were the result of recommendations from other participants.

Another study could be conducted interviewing international study tour participants five years or longer after their experience. It would be interesting to learn if they had continued to reflect and expand upon their study tour knowledge and had been able to incorporate their experiences into their jobs or positions, as well as finding out if their career path had changed as a result of their international study tour experience. As professionals move within their careers, they may be in positions that allows for an implementation of programs or ideas from the post tours. 
To further this study there could be a focus on identity and how it is perceived on the tour. This study did not focus on identity and how that may affect a participant's navigation in a particular country. There were a few participants that discussed their perceptions of themselves within the country or area that they were visiting.

This study was focused on international study tours and the participants, not particularly on the international countries visited. The majority of those interviewed shared they had traveled to English speaking countries or particularly Western Countries. There were two participants who had traveled to Hong Kong and China on their tour, but both made only a few comments regarding the language barrier from the professionals who spoke to them on the tour. It would be of interest to host a study comparing international study tours, the locations visited, and if there were significant differences in participants' recollection of what they had learned or gained from the student affairs components of higher education of the tour.

For further research study there could be a focus on understanding the role of internationalization of student affairs in regard to study tour participant's perceptions of their professional role in the internationalization process of higher education and particularly within student affairs. The study could focus on what extent do participants of international study tours perceive their role in internationalization and if an international study tour meets the needs of the internationalization process.

This study did not discuss or focus on the internationalization of student affairs in terms of social justice and multicultural education within a U.S. framework. For future studies there may be an interest in focusing on social justice and multicultural education 
in context with internationalization and how these concepts work together and can provide student affairs with the needed raise of status within universities.

\section{Implications for Student Affairs Administrators}

It was apparent throughout the interview process that the participants questioned about their international study abroad experience found it to be enriching and beneficial, which in itself may not be surprising. As a result of their own experiences, the participants expressed their opinion that more professionals should attend an international study tour to gain new perspectives and understanding of higher education outside of the United States, and to step away from a U.S.-centric view. Many of the participants expressed an interest in attending another study tour as a full-time professional but felt that cost and requesting time off may be an issue. Young (2010) supports international study tours as professional development and states that the tours are an "effective professional development tool although they tend to be both time consuming and relatively costly." They advocate for more such opportunities, possibly using professional development funds. Perozzi, Seifert, and Al-Sharif (2016) state "by supporting sabbatical leaves and short- or long-term study tours, institutions can build organizational capacity by assisting faculty and staff in gaining in-depth international experience" (p. 99). Being provided time off and support for leave student affairs professionals from all levels could be encouraged to take advantage of the international study tour experiences.

Many articulated the need for professionals to go abroad during a study tour or exchange. David and Xiomara discussed the use of professional development funds and in particular, Xiomara shared that professionals can truly benefit. The more important 
point was that these new professionals through their international studies could become more valuable to the institutions they work at, because those individuals can "make relationships" that will benefit both the university and the co-workers who will learn from them.

Several participants discussed international students and particularly, there is concern about how student affairs staff should interact and be supportive of this student population and its composition at their institutions. Several interviewees discussed how the international study tour affected the way in which they work with students. For many participants, internationalization is seen as working with and understanding the international student perspective. As professionals these participants have become aware of the importance of language usage and its complications and the need of them to become a resource to international students.

There is limited literature regarding student affairs vice presidents who have attended any sort of international experience. It would be beneficial if mid-level to higher-level administrators would/could attend international study tours to gain insight and become advocates for those who may work in their divisions, departments, or areas. The senior student affairs administrators should become advocates to make "provisions of funds for international related initiatives" (Ahwireng, 2016, p. 174). The involvement of senior student affairs administrators may provide the prestige and the spotlight needed to develop further tours that can be beneficial to all in student affairs.

Student affairs professionals need to be made aware of higher education programs that offer international study tour opportunities. The announcements regarding study tours and recruitment of participants should be emailed to all employees within a Student 
Affairs Division. There is a need to increase the familiarity of the concept of international study tours and their intended outcomes among the professional student affairs staff as well as the encouragement to take vacation time to attend these tours. Funding in the future for additional study tours was a concern for some of the participants but they also agreed that the study tours are rewarding, and the cost could be justified.

Creating policy and opportunities for professional development funds to be used on international study tours is a major issue that needs to be addressed. Student affairs professionals who have traveled will be more effective administrators. Those who have traveled will be beneficial for a university and a Division of Student Affairs because they would have the potential to contribute greatly to the internationalization of the university as well as student affair. There would be more professional interest in such travel if there are polices or funds that could be dedicated for professionals to use to travel overseas and visit universities and create exchanges. Tuition remission or tuition credit that could be used by professionals to earn credits towards another degree may be a draw for some professionals. There is literature supporting that "faculty international travel funds influence faculty engagement in internationalization" (Ahwireng, 2016, p. 173). Several participants shared that if they had to pay out of pocket, they may not be able to attend another tour even though they would find the experience to be valuable. Another implication is that for international study tours, professionals have to use their vacation time and they may not be interested or able to do so. This also creates the impression that this type of travel is seen as more personal development than professional development.

Those participants who do attend international study tours should be encouraged to share their knowledge and experiences with others through formal and informal 
conversations and educational programs. Those who attend should host educational forums or be encouraged to create professional development materials to share with other staff members. Being supported by "leaders at all levels within student affairs can create contexts that support intercultural development for staff and students through local programs and resources" (Yakaboski \& Perozzi, 2018, p. 154). There could be a use for technology and the creation of blogs or posts of these professionals who attend a tour so that those who are unable to attend can still learn some of the information being consumed. Some of the participants said that they shared their travel information with friends or colleagues and a few were able to share with their supervisors or individuals who were supportive of the process. The sharing of these tour experiences may also provide Student Affairs with connections and understanding of other aspects of the university community and partnering with Academic partners. There are some universities that are merging their student affairs divisions with the academic divisions. Being able to justify, clarify and support the need for student affairs professionals to travel and giving them the opportunity to describe their experiences can help to solidify partnerships with the academic side of the university. In the literature, there are several studies that support the professional development of faculty who lead study tours (Mosely, 2009; Özturgut 2007; Brubaker, 2006; Festervand \& Tillery 2001).

\section{Summary}

The purpose of this research study was to determine in what ways do studentaffairs administrators involved in international study tours perceive their experiences as furthering their personal or professional development. While the extent of the impact varies from participant to participant, the research did reveal that there is a perceived 
impact and furthering in both the personal and professional growth of the individuals involved, through the following themes: transformational experiences; global awareness; intercultural communication; career paths; and self-growth.

Being able to interview a range of individuals who are in different stages of their professional careers in Student Affairs was helpful; the participants were also a few years removed from their first or second international study tour which provided time for selfreflection and processing what was learned from the experience.

This research was personal for the researcher who had been a participant of several international study tours and the reasons for the research study was to understand if other student affairs professionals perceived their experiences as furthering their personal or professional development. This study reveals that participants did perceive their experiences as furthering their personal and professional development. For several of the participants this study helped them process and articulate what they have learned and encouraged their exploration of topics discussed from their trips. There have been several participants who have been able to share their tour information and actually implement or create programs based on what they learned abroad. Some of the participants expressed that they grew as individuals in different aspects of their lives, and that the experiences of their study tours have shaped their views and how they perceive the world around them.

This study encourages the need to have more student affairs professionals attend international study tours and to provide the encouragement for student affairs professionals in "creating more inclusive campuses and can continue that leadership by developing global and intercultural competencies for all" (Yakaboski \& Perozzi, 2018, p. 
50). Also, it is fitting for student affairs professionals to become participants in university-wide committees "designed to internationalize and educate others on how student affairs areas are key elements in internationalizing the campus due to their connections with students" (Yakaboski \& Perozzi, 2018, p. 161).

This study provides the reader with an understanding of the ways in which student affairs administrators involved in international study tours perceive their experiences as furthering their personal or professional development. It also provides information about the impact and importance of study tours for student affairs professionals and their institutions, as well as the barriers to the accessibility and availability of such tours. The study also examines what other research could be done to continue to add to the body of work provided. 


\section{REFERENCES}

Ahwireng, D. (2016). Internationalization of Higher Education: A Comparative Case Study of Two U.S Universities. (Electronic Thesis or Dissertation). Retrieved from https://etd.ohiolink.edu/

Anderson, P.H., Lawton, L., Rexeisen, R.J., \& Hubbard, A.C. (2006). Short-term study abroad and intercultural sensitivity: A pilot study. International Journal of Intercultural Relations, 30(4), 457-469.

Back, M. (2013). Using Facebook data to analyze learner interaction during study abroad. Foreign Language Annals, 46(3), 377-401.

Bergsteiner, H., \& Avery, G.C. (2008). Theoretical explanation for success of deep-levellearning study tours. College Teaching Methods \& Styles Journal, 4(1), 29-38.

Bodger, D. (1998). Leisure, learning, and travel. Journal of Physical Education, Recreation \& Dance, 69 (4), 28-31.

Bogdan, R.C., \& Biklen, S.K. (2007). Qualitative research for education: An introduction to theories and methods ( $5^{\text {th }}$ ed.). New York, NY: Allyn \& Bacon.

Boyatzis, R.E. (1995). Cornerstones of change: Building the path for self-directed learning. In R. E. Boyatzis, S. S. Cowen, \& D. A. Kolb (Eds.), Innovation in professional education (pp. 50-91). San Francisco, CA: Jossey-Bass.

Bowen, G.A. (2009). Document analysis as a qualitative research method. Qualitative research journal, 9(2), 27-40.

Braskamp, L.A., Braskamp, D.C., \& Merrill, K.C. (2009). Assessing progress in global learning and development of students with education abroad experiences.

Frontiers: The Interdisciplinary Journal of Study Abroad, 18, 101-118.

Bretag, T., \& van der Veen, R. (2015). 'Pushing the boundaries': participant motivation and self-reported benefits of short-term international study tours. Innovations in Education and Teaching International, 1-9, DOI:

10.1080/14703297.2015.1118397

Brubaker, C.J. (2006). Student perceptions of self-identified cultural encounters during a short-term study abroad program (Order No. 3236287). Available from ProQuest Dissertations \& Theses A\&I; ProQuest Dissertations \& Theses Global. (305305084). Retrieved from http://ezproxy.fiu.edu/login?url=http://search.proquest.com.ezproxy.fiu.edu/docvi ew/305305084?accountid=10901

Callahan, K.M. (2015). The Internationalization in Student Affairs in the United States from 1951 to 1996. Retrieved from http://purl.flvc.org/fsu/fd/FSU_migr_etd-9563 
Carlson, J.S., Burn, B.B., Useem, J., \& Yachimowicz, D. (1990). Study Abroad: The experience of American undergraduates. Contributions to the study of education, 37. Greenwood Press: New York, NY.

Carpenter, D.S., \& Stimpson, M.T. (2007). Professionalism, scholarly practice, and professional development in student affairs. NASPA Journal, 44, 265-284. doi:10.2202/1949-6605.1795

Chieffo, L., \& Griffiths, L. (2004). Large-Scale Assessment of Student Attitudes after a Short-Term Study Abroad Program. Frontiers: The interdisciplinary journal of study abroad, 10, 165-177.

Christie, R.A, \& Ragans, S.W. (1999). Beyond borders: A model for Student and Staff Development. New Directions for Student Services, 1999(86), 3-11.

Chronister,D. (2017) “The Impact of Student Abroad on Intercultural Competence as a Professional Disposition: Narrative Stories from Student Affairs Professionals". Electronic Theses and Dissertations. 141. https://scholarworks.sfasu.edu/etds/141

Ciobanu, A. (2013). The role of student services in the improving of student experience in higher education. Procedia-Social and Behavioral Sciences, 92, 169-173.

Clarke, I., Flaherty, T.B., Wright, N.D., \& McMillen, R.M. (2009). Student intercultural proficiency from study abroad programs. Journal of Marketing Education, 31(2), $173-181$.

Clayton, K.M. (2016). International policy experience: Short term international travel courses in structure degree programs (Order No. 10141729). Available from ProQuest Dissertations \& Theses A\&I; ProQuest Dissertations \& Theses Global. (1807413517). Retrieved from http://ezproxy.fiu.edu/login?url=http://search.proquest.com.ezproxy.fiu.edu/docvi ew/1807413517?accountid=10901

Cochran, M.F. (2016). Student affairs, persistence, and the growing need for inquiry. The Journal of Student Affairs Inquiry, 2(1), 828.

Conceição, S.C.O. \&. Skibba, K.A. (2008) Experiential Learning Activities for Leisure and Enrichment Travel Education: A Situative Perspective, Journal of Teaching in Travel \& Tourism, 7:4, 17-35, DOI: 10.1080/15313220802033286

Coryell, J.E. (2011). The Foreign City as Classroom: Adult Learning in Study Abroad. Adult Learning, 22(3), 4-11.

Creswell, J.W. (2002). Educational research: Planning, conducting, and evaluating quantitative. Upper Saddle River, NJ: Prentice Hall. 
Creswell, J.W. (2009). Research design: Qualitative, quantitative, and mixed methods approaches. Sage publications.

Dalton, J.C. (1999). The significance of international issues and responsibilities in the contemporary work of student affairs. New Directions for Student Services, 1999(86), 3-11.

Dalton, J.C. \& Sullivan, M.H. (2008). Expanding global horizons. In Osfield, K. J. (ED). Internationalization of student affairs and services: An emerging global perspective. NASPA.

Dapko, R.J., “Travel Education: A Phenomenological Study on Self-Directed Learning and Personal Enrichment Through Foreign Travel Experiences" (2016). FIU Electronic Theses and Dissertations. 2726. https://digitalcommons.fiu.edu/etd/2726

Davies, I. \& Pike, G. (2009). Global citizenship education. In Lewin, R. (Ed.), The handbook of practice and research in study abroad: Higher education and the question for global citizenship, 61-77.

de Wit, H. (2002). Internationalization of higher education in the United States of America and Europe: A historical, comparative and conceptual analysis. Westport, Connecticut: Greenwood Press.

Deans, P.C. (2012). Integration of Study Abroad with Social Media Technologies and Decision-Making Applications. Decision Sciences Journal of Innovative Education, 10(3), 299-336.

Dean, K.W. \& Jendzurski, M.B. (2013) Using post-study-abroad experiences to enhance international study. Honors in Practice. 9, 99-111.

DeMello, M.A. (2011). The impact of study tours in developing global-mindedness among PK-12 educators in southeastern Massachusetts (Order No. 3525749). Available from ProQuest Dissertations \& Theses A\&I; ProQuest Dissertations \& Theses Global. (1039146222). Retrieved from http://ezproxy.fiu.edu/login?url=https://search.proquest.com/docview/103914622 2? accountid=10901

Denzin, N.K., \& Lincoln, Y.S. (2011). The Sage handbook of qualitative research. Sage.

Dirkx, J., Spohr, R., Tepper, L., \& Tons, S. (2010). Adult learners and short-term study abroad: Formation or transformation. In Proceedings of the Adult Education Research Conference, 122-127.

Donnelly-Smith, L. (2009). Global learning through short-term study abroad. Peer Review, 11(4) 12-15. 
Dorsett, P., \& Clark, J. (2015). The Learning Outcomes of an Australian Social Work Student's Study Tour to India. Artha-Journal of Social Sciences, 14(02).

Elola, I. \& Oskoz, A. (2008). Blogging: Fostering intercultural competence development in foreign language and study abroad context. Foreign Language Annals, 41(3), 454-477.

Evans, J., Finch, J., Toncar, M.F., \& Reid, J.S. (2008). Student Perceptions of and Preferences for a Short Overseas Study Tour. Contemporary Issues in Education Research, 1(3), 11-18.

Festervand, T.A., \& Tillery, K.R. (2001). Short-term study-abroad programs-A professional development tool for international business faculty. Journal of Education for Business, 77(2), 106-111.

Florida International University. (2011a). Global Awareness definition. Annual Impact Report of Florida International University's Office of Global Learning Initiatives.

Florida International University. (2011b). Global Perspective definition. Annual Impact Report of Florida International University's Office of Global Learning Initiatives.

Forsey, M., Broomhall, S. \& Davis, J. (2012). Broadening the mind? Australian student reflections on the experience of overseas study. Journal of Studies in International Education, 16(2), 128-139.

Franklin-Craft, A. (2010). An assessment of the intercultural competence of student affairs administrators (Order No. 3435119). Available from ProQuest Dissertations \& Theses A\&I; ProQuest Dissertations \& Theses Global. (815412147). Retrieved from http://ezproxy.fiu.edu/login?url=https://search.proquest.com/docview/815412147 ?accountid=10901

Franklin, K. (2010). Long-term career impact and professional applicability of the study abroad experience. Frontiers: The Interdisciplinary Journal of Study Abroad, 15, 169-190.

Goldoni, F. (2013). Students' immersion experiences in study abroad. Foreign Language Annals, 46(3), 359-376.

Gorlewski, Emily. (2016). The Engagement of Multicultural Student Affairs Staff in the Internationalization of Connecticut Higher Education Institutions. Retrieved from the University of Minnesota Digital Conservancy, http://hdl.handle.net/11299/185176.

Grandinetti, M.A. (2017). A Well-Rounded Experience: Connecting the Home Campus to the Study Abroad Experience and The Study Abroad Experience to the Home Campus. 
Hadis, B.F. (2005). Why Are They Better Students when They Come Back? Determinants of Academic Focusing Gains in the Study Abroad Experience. Frontiers: The Interdisciplinary Journal of Study Abroad, 11, 57-70.

Hill, B. (2016) within Helms, R.M.,(2106, June 16). Trickle-UP Internationalization: a.k.a How I Hope to Lose My Job [Blog post]. Retrieved from concordialanguagevillages.org/blog/villages/trickle-up-internationalization-a.k.ahow-i-hope-to-lose-my-job\#.XdSZbUF7k2x

Hirt, J.B. \& Strayhorn, (2010). Staffing and Supervision. In T.L. Schuh, J. H., Jones, S. R., \& Harper, S. R. (Eds.). Student services: A handbook for the profession ( $5^{\text {th }}$ edition). San Francisco: Jossey-Bass.

Hovey, R. and Weinberg, A. Global learning and the making of citizen diplomats. In Lewin, R. (Ed.), The handbook of practice and research in study abroad: Higher education and the question for global citizenship, 33-48.

Hunter, W. (2004). Knowledge, skills, attitudes, and experiences necessary to become globally competent. UMI Dissertation Services.

Hutchins, M.M. (1996). International education study tours abroad: Students' professional growth and personal development in relation to international, global, and intercultural perspectives (Order No. 9710583). Available from ProQuest Dissertations \& Theses Global. (304285852). Retrieved from http://ezproxy.fiu.edu/login?url=https://search-proquestcom.ezproxy.fiu.edu/docview/304285852?accountid=10901

Iammarino, N.K., \& O'Rourke, T.W. (1999). Planning and implementing an international travel/study course experience for health professionals and students. Journal of Health Education, 30(3), 166-172, DOI: 10.1080/10556699.199.10603397

Interis, M.G., Rezek, J., Bloom, K., \& Campbell, A. (2017). Assessing the value of shortterm study abroad programmes to students. Applied Economics, 1-15.

Jessup-Anger, J.E. (2008). Gender observations and study abroad: How students reconcile cross-cultural differences related to gender. Journal of College Student Development, 49(4), 360-373. DOI: 10.1353/csd.0.0015

Jablonski, M.A., Bresciani, M.J., Lovell, C. \& Shandley, T., (2006) Shaping Student Affairs Leadership Through Global Perspectives, NASPA Journal, 43:1, 183-202, DOI: $\underline{10.2202 / 1949-6605.1577}$

Jain, C.R., Apple, D.K., \& Ellis, W. (2015). What is self-growth. International Journal of Process Education, 7(1), 41-52. 
Jons, S.S. (2012). "Senior-Level Administrators Leadership In Internationalizing A Public Research University In The Midwest: A Case Study" (2012). Educational Administration: Theses, Dissertations, and Student Research. 96.

Jowi, J.O. (2009). Internationalization of higher education in Africa: Developments, emerging trends, issues and policy implications. Higher Education Policy, 22(3), 263-281.

Keefe, M.C. (2008). Short-term study abroad: Impact on the development of global competencies at a public college of art and design in the northeast (Order No. 3344292). Available from ProQuest Dissertations \& Theses A\&I; ProQuest Dissertations \& Theses Global. (304829161). Retrieved from http://ezproxy.fiu.edu/login?url=http://search.proquest.com/docview/304829161? accountid=10901

Kehl, K., \& Morris, J. (2008). Differences in global-mindedness between short-term and semester-long study abroad participants at selected private universities. Frontiers: The Interdisciplinary Journal of Study Abroad, 15, 67-79.

Kitto, S.C., Chesters, J., \& Grbich, C. (2008). Quality in qualitative research. Medical Journal of Australia, 188(4), 243.

Knight, J. (2003). Updated definition of internationalization. International higher education, (33).

Koernig, S.K. (2007). Planning, organizing, and conducting a 2-week study abroad trip for undergraduate students: Guidelines for first-time faculty. Journal of Marketing Education, 29(3), 210-217.

Kolb, D.A. (1984). Experiential learning: Experience as the source of learning and development (Vol. 1). Englewood Cliffs, NJ: Prentice-Hall.

Komives, S.R. \& Carpenter, S. (2009) Professional development as lifelong learning. In McClellan, G. S., \& Stringer, J. (Eds.). The handbook of student affairs administration:(Sponsored by NASPA, student affairs administrators in higher education). John Wiley \& Sons

Kruger, K.W. \& Dungy, G.W. (1999). Opportunities for international travel and professional exchange for student affairs professionals. New Directions for Student Services, 1999(86), 23-31. 
Lee, E.A. (2014). "To experience something greater than myself:" an exploratory case study of the impact of a faculty-led short-term study abroad on college student identity (Order No. 3582034). Available from ProQuest Dissertations \& Theses A\&I; ProQuest Dissertations \& Theses Global. (1655478811). Retrieved from http://ezproxy.fiu.edu/login?url=http://search.proquest.com/docview/1655478811 ?accountid=10901

Lewis, T.L., \& Niesenbaum, R.A. (2005). Extending the stay: Using community-based research and service learning to enhance short-term study abroad. Journal of Studies in International Education. 9, 251-264.

Lincoln, Y.S, \& Guba, E.A. (1985). Naturalistic Inquiry. Beverly Hills, CA: Sage

Lindquist, T., \& Bischof, L.D. (2007). Study Tours As Professional Development for Librarians: An Assessment of the 2006 WESS Study Tour to Eastern Germany. Collection Management, 31(4), 19-52.

Lutterman-Aguilar, A. \& Gingerich O. (2002). Experiential pedagogy for study abroad: Educating for global citizenship. Frontiers: The Interdisciplinary Journal of Study Abroad, 8, 41-82.

Manning, K., Kinzie, J., \& Schuh, J.H. (2006). One size does not fit all: Traditional and innovative models of student affairs practice. Routledge: New York; NY.

Martin, J.N., \& Nakayama, T.K. (2010). Intercultural communication and dialectics revisited. In T. K. Nakayama \& R. T. Halualani (Eds.), The handbook of critical intercultural communication (pp. 59-83). Malden, MA: Wiley-Blackwell.

McKeown, J.S. (2009). The first time effect: The impact on study abroad on college student intellectual development. State University of New York Press: Albany, NY.

Mestenhauser, J.A., \& Ellingboe, B.J. (2005). Leadership knowledge and international education. International Educator, 14(6), 36-43.

Merriam, S.B. (1988). Case study research in education: A qualitative approach. JosseyBass Inc., Publishers: San Francisco

Merriam, S.B. (2002). Qualitative research in practice: Examples for discussion and analysis. John Wiley \& Sons: New York, NY

Merriam, S.B. (2009). Qualitative research: A guide to design and implementation. John Wiley \& Sons.

Merriam, S.B., \& Tisdell, E.J. (2015). Qualitative research: A guide to design and implementation. John Wiley \& Sons: New York, NY 
Merva, M. (2003). Grades as incentives: A quantitative assessment with implications for study abroad programs. Journal of Studies in International Education. 7, 149-156.

Montrose, L. (2002). International study and experiential learning: The academic context. Frontiers The Interdisciplinary Journal of Study Abroad, 8(2), 1-15.

Morgan, A.D. (2010). "Journeys into Transformation: Travel to an 'Other' Place as a Vehicle for Transformative Learning." Journal of Transformative Education, 8 (4): 246-68.

Morse, J.M. (1994). Designing funded qualitative research. In Denzin, N. K. \&. Lincoln Y.S. (Eds). Handbook of qualitative research. (pp. 220-235). SAGE: Oakland, CA.

Moseley, W. (2009). Making Study Abroad a Win-Win Opportunity for Pre-Tenure Faculty. Frontiers: The Interdisciplinary Journal of Study Abroad, 18, 231-240.

NAFSA (2008), "Strengthening study abroad: recommendations for effective institutional management",

DOI:www.nafsa.org/knowledge_community_network.sec/international_education _4/chief_international_education/practice_resources_14/internationalizing_the/im sa_epub (accessed April, 2008).

NAFSA. (2011). Senator Paul Simon Study Abroad Act. Retrieved from http://www.nafsa.org/public_policy.sec/commission_on_the_abraham/

Nyaupane, G.P., Paris, C.M., \& Teye, V. (2010). Why do students study abroad? Exploring motivations beyond earning academic credits. Tourism Analysis, 15(2), 263-267.

Norris, E.M., \& Dwyer, M. (2005). Testing assumptions: The impact of two study abroad program models. Frontiers: The Interdisciplinary Journal of Study Abroad. 11, 121-142.

Norris, E.M., \& Gillespie, J. (2008). How study abroad shapes global careers: Evidence from the United States. Journal of Studies in International Education, 13(3), 382397. DOI: $10.1177 / 1028315308319740$

OECD (2018). Global Competency. Retrieved from https://www.oecd.org/pisa/pisa2018-global-competence.htm

O’Reilly, A., Ryan, D., \& Hickey, T. (2010). The psychological well-being and sociocultural adaptation of short-term international students in Ireland. Journal of College Student Development, 51(5), 584-598. DOI: 10.1353/csd.2010.0011

Ortlipp, M. (2008). Keeping and using reflective journals in the qualitative research process. The qualitative report, 13(4), 695-705. 
Orndorff Jr, E.B. (1998). The short-term study travel experience for adult professionals: A phenomenological study (Doctoral dissertation).

Özturgut, O. (2007). Study/teach abroad programs for higher education faculty. Essays in Education, 22, 42-49.

Patton, M.Q. (2002). Qualitative research and evaluation methods. California EU: Sage Publications Inc.

Pasquarelli, S.L. (2017). Defining an academically sound, culturally relevant study abroad curriculum. In Pasquarelli, S.L., Cole, R. A., \& Tyson, M.J.(Eds). Passport to Change: Designing academically sound, culturally relevant, shortterm, faculty-led study abroad programs. Sterling, Virginia: Stylus.

Paus, E., \& Robinson, M. (2008). Increasing Study Abroad Participation: The Faculty Makes the Difference. Frontiers: The Interdisciplinary Journal of Study Abroad, $17,33-49$.

Perry, L., Stoner, L., \& Tarrant, M. (2012). More than a vacation: Short-term study abroad as a critically reflective, transformative learning experience. Creative Education, 3(5), 679-683.

Perozzi, B., Seifert, T., \& Al-Sharif, M.A.B. (2016). Staffing for success. Enhancing Student Learning and Development in Cross-Border Higher Education: New Directions for Higher Education, Number 175, (175), 93.

Picard, E., Bernardino, F., \& Ehigiator, K. (2009). Global citizenship for all: Low minority student participation in study abroad-Seeking strategies for success. In R. Lewin (Ed.), The handbook of practice and research in study abroad: Higher education and the quest for global citizenship (pp. 321-345). New York, NY: Routledge.

Pond, U. (2018). Toward transformative learning during short-term international study tours: implications for instructional design (Doctoral dissertation, University of Glasgow).

Pope, J.A., Sánchez, C.M., Lehnert, K., \& Schmid, A.S. (2014). Why do gen Y students study abroad? Individual growth and the intent to study abroad. Journal of Teaching in International Business, 25(2), 97-118.

Prosser, J. \& Schwartz, D. (1998). Photographs within the Sociological Research Process. In Prosser, J. (Ed.). Image-based research: A sourcebook for qualitative researchers. Psychology Press.

Relyea, C., Cocchiara, F.K., \& Studdard, N.L. (2008). The effect of perceived value in the decision to participate in study abroad programs. Journal of Teaching in International Business, 19(4), 346-361. DOI: 10.1080/08975930802427551 
Ribeiro, M. (2004). A qualitative analysis of adult learners' immersion experiences to South Africa: Implications for multicultural training. In VISTAS 2004, proceedings of American Counseling Association Annual Conference, 121-128.

Richardson, J.W., Imig, S., \& Flora, K. (2014). Evaluating school leadership development through an international experience. Journal of Leadership in Education, 17 (3), 353 -369.

https://doi.org/10.1080/13603124.2013.8176111

Ritz, A.A. (2011). The educational value of short-term study abroad programs as course components. Journal of Teaching in Travel \& Tourism, 11(2), 164-178. DOI:10.1080/15313220.2010.525968

Roberts, D.M. (2007) Preferred Methods of Professional Development in Student Affairs, NASPA Journal, 44:3, 561-577, DOI: 10.2202/1949-6605.1836

Roberson, D.N. (2003) Learning Experiences of Senior Travellers, Studies in Continuing Education, 25:1, 125-144, DOI: $\underline{10.1080 / 01580370309288}$

Rodriguez, K. (2014). The perceived impact of study abroad activities for graduate counseling students (Order No. AAI3626213). Available from PsycINFO. (1676371072; 2015-99080-379). Retrieved from http://ezproxy.fiu.edu/login?url=https://search-proquestcom.ezproxy.fiu.edu/docview/1676371072?accountid=10901

Rogers, J., Cawthon, T, \& O’Connell, S., (2016, April 26). Internationalizing the Student Affairs in Higher Education Program. Retrieved: https://miamioh.edu/ehs/news/2016/04/rogers-study-abroad-sahe.html

Root, E., \& Ngampornchai, A. (2013). "I Came Back as a New Human Being” Student Descriptions of Intercultural Competence Acquired Through Education Abroad Experiences. Journal of Studies in International Education, 17(5), 513-532.

Rubin, H.J., \& Rubin. I.S. (2012). Qualitative interviewing: The art of hearing data ( $^{\text {rd }}$ ed.). Thousand Oaks, CA: Sage

Rundstrom W.T. (2005). Exploring the impact of study abroad on students' intercultural communication skills: Adaptability and sensitivity. Journal of Studies in International Education, 9(4), 356-371. DOI: 10.1177/1028315305277681

Sachau, D., Brasher, N., \& Fee, S. (2010). Three models for short-term study abroad. Journal of Management Education, 34(5), 645-670.

Saldaña, J. (2014). Thinking qualitatively: Methods of mind. Sage Publications. 
Sánchez, C.M., Fornerino, M., \& Zhang, M. (2006). Motivations and the intent to study abroad among US, French, and Chinese students. Journal of Teaching in International Business, 18(1), 27-52.

Sandgren, D., Elig, N., Hovde, P., Krejci, M., \& Rice, M. (1999). How international experience affects teaching: Understanding the impact of faculty study abroad. Journal of Studies in International Education, 3(1), 33-56.

Savicki, V., \& Price, M.V. (2017). Components of Reflection: A Longitudinal Analysis of Study Abroad Student Blog Posts. Frontiers: The Interdisciplinary Journal of Study Abroad, 29(2), 51-62

Schulz, S.A., Lee, J. J., Cantwell, B.J., McClellan, G., \& Woodard, D. (2007). Moving toward a global community: An analysis of the internationalization of student affairs graduate preparation programs. NASPA Journal, 44(3), 610-632.

Seidman, I. (2006). Interviewing As Qualitative Research: A Guide for Researchers in Education and the Social Sciences. New York: Teachers College Press.

Sewchuk, D. (2005). Experiential learning: a theoretical framework for perioperative education. AORN Journal, XXI(3)

Shames, W. \& Alden, P. (2005). The impact of short-term study abroad on the identity development of college students with learning disabilities and/or AD/HD.

Frontiers: The Interdisciplinary Journal of Study Abroad, 22, 1-31.

Sherlock, J.J \& Morgan, G. (2005) Learning journals: An underutilized tool in leadership education. In Huber, N. S., \& Walker, M. C. (ED). Emergent models of global leadership. James McGregor Burns Academy of Leadership.

Stebleton, M.J., Soria, K.M., \& Cherney, B.T. (2013). The high impact of education abroad: College students' engagement in international experiences and the development of intercultural competencies. Frontiers: The Interdisciplinary Journal of Study Abroad, 22, 1-24.

Stroud, A.H. (2010). Who plans (not) to study abroad? An examination of U.S. student intent. Journal of Studies in International Education, 14(5), 491-507.

Sullivan, J. (2011). Global leadership in higher education administration: Perspectives on internationalization by university presidents, vice-presidents and deans. (Ph.D., University of South Florida). ProQuest Dissertations and Theses. (861477187).

Toncar, M.F., Reid, J.S., \& Anderson, C.E. (2006). Perceptions and preferences of study abroad: Do business students have different needs?. Journal of Teaching in International Business, 17(1/2), 61-80. DOI: 10.1300/J066v17n01_04 
Trooboff, S., Vande Berg, M., \& Rayman, J. (2007-2008). Employer attitudes toward study abroad. Frontiers: The Interdisciplinary Journal of Study Abroad, 15, 1733.

Tucker, M. \& Weaver, D. (2013). A Longitudinal study of student outcomes from participation in an International study tour: Some preliminary findings. Journal of University Teaching \& Learning Practice. 10(2)

Wallace, L. (2015). Reflexive photography, attitudes, behavior, and CALL: ITAs improving spoken English intelligibility. calico journal, 32(3), 449.

Warner, N. (2004). University of Cape Town: Policy framework on internationalization. In D. K. Some \& B. M. Khaemba (Eds.) (pp. 85- 90). Eldoret, Kenya: Moi University Press.

Weaver, D., \& Tucker, M. (2010). An international business study tour: A student perspective. In HERDSA conference, Melbourne (Australia).[Online] Available: http://www. herdsa. org. au/newsite/wp.

Wiers-Jenssen, J. (2003). Norwegian students abroad: Experiences of students from a linguistically and geographically peripheral European country. Studies in Higher Education, 28(4), 391-411.

Williams, R.T. (2005). Exploring the impact of study abroad on students' intercultural communication skills: Adaptability and sensitivity. Journal of Studies in International Education, 9(4), 356-371. DOI: 10.1177/1028315305277681

Williams, T.R. (2009). The Reflective Model of Intercultural Competency: A Multidimensional, Qualitative Approach to Study Abroad Assessment. Frontiers: The Interdisciplinary Journal of Study Abroad, 18, 289-306.

Wilson, M.F. (2014). Life after study abroad: A narrative inquiry of graduate student study abroad returnees (Order No. 3624013). Available from ProQuest Dissertations \& Theses A\&I; ProQuest Dissertations \& Theses Global; Social Science Premium Collection. (1551759498). Retrieved from http://ezproxy.fiu.edu/login?url=https://search-proquestcom.ezproxy.fiu.edu/docview/1551759498?accountid=10901

Witkowsky, P., Mendez, S.L., \& Arminio, J. (2018). Influence of a Short-Term Study Abroad Experience on Professional Competencies and Career Aspirations of Graduate Students in Student Affairs. Journal of College Student Development, 59(6), 769-775.

Yakaboski, T., \& Perozzi, B. (2018). Internationalizing US Student Affairs Practice: An Intercultural and Inclusive Framework. Routledge. 
Young, R.Y.K. (2010). International study tours and the development of sociocultural consciousness in $\mathrm{K}-12$ teachers.

Younes, M.N., \& Asay, S.M. (2003). The world as a classroom: The impact of international study experiences on college students. College Teaching, 51(4), 141147, DOI:10.1080/87567550309556429 


\section{APPENDICES}

\section{Interview Questions}

1. Why did you decide to attend a study tour/s and how did you determine which tour/s?

2. What were the highlights of your study tour experience?

3. How did these trips influence you professionally and personally?

4. Were you aware of the impact the tour you attended had on your work and if so, when?

5. How has your study tour experience changed the ways in which you view student affairs?

6. How has your study tour experience changed the ways in which you interact with friends and others you work with?

7. Has your study tour experience changed your attitude and/or values?

8. Has your study tour experience changed your perception about your current position?

9. Has your study tour experience changed the way you go about learning new things?

10. Why should student affairs professionals attend study tours? 


\section{Follow Up Questions}

1. Is there anything in you have been reflecting on since our last interview that you would like to revisit?

2. Have you reviewed any notes, journals, materials from your international study tour since our last interview? If you have would you mind sharing what materials and your thoughts?

3. Do you consider your international study tour experience professional development? If so how and what portions of your experience?

4. In what ways has the international study tour experience influenced your global perspective?

5. What personal qualities do you posses as a result of your international study tour experience?

6. What professional qualities do you possess as a result of international study tour experience? 
VITA

\section{MICHELLE M. CASTRO}

1997-2001

2001-2001

2002-2004

2002-2004

2004-2006

2006-2011

2011-2019

2019- Present
Bachelor of Arts, International Relations

Florida International University

Miami, Florida

Leadership Consultant

Phi Sigma Sigma

Master of Arts, College Student Personnel

Bowling Green State University

Bowling Green, Ohio

Graduate Assistant

Fraternity and Sorority Affairs

Bowling Green State University

Bowling Green, Ohio

Greek Life Area Coordinator

Student Activities Office

University of New Mexico

Albuquerque, New Mexico

Assistant Dean of Students and Coordinator for Greek Life

Dean of Students Office

University of Miami

Coral Gables, Florida

Assistant Director

Campus Life

Florida International University

Miami, Florida

Associate Director

Student Government Association

Florida International University

Miami, Florida 